Marcus Vinícius Hirama

Estimativas da variação de produtividade superficial na porção central da Bacia de Santos desde o último período glacial com base na associação de cocolitoforídeos

Dissertação apresentada ao Instituto Oceanográfico da Universidade de São Paulo, como parte dos requisitos para obtenção do título de Mestre em Ciências, Programa de Oceanografia, área de Oceanografia Geológica.

Orientador: Prof. Dr. Felipe Antonio de Lima Toledo

São Paulo 
Universidade de São Paulo

Instituto Oceanográfico

\section{Estimativas da variação de produtividade superficial na porção central da Bacia de Santos desde o último período glacial com base na associação de cocolitoforídeos}

Marcus Vinícius Hirama

Dissertação apresentada ao Instituto Oceanográfico da Universidade de São Paulo, como parte dos requisitos para obtenção do título de Mestre em Ciências, área de Oceanografia Geológica.

Julgada em

$\operatorname{Prof(a).~Dr(a).~}$

Conceito

$\operatorname{Prof(a).~Dr(a).~}$

Conceito

$\operatorname{Prof(a).~Dr(a).~}$

Conceito 


\section{Sumário}

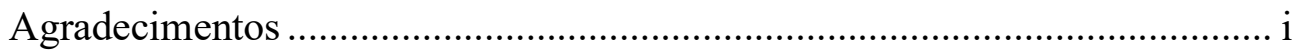

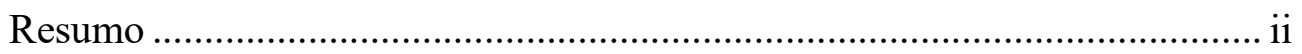

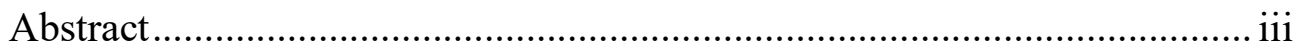

Lista de Siglas e Abreviaturas .............................................................. iv

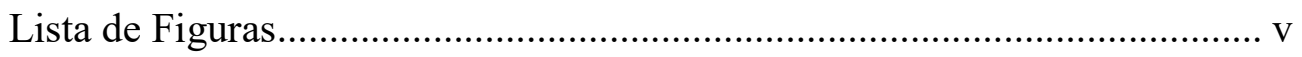

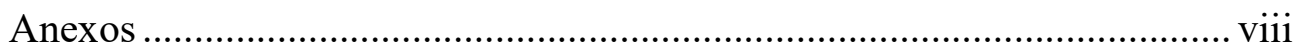

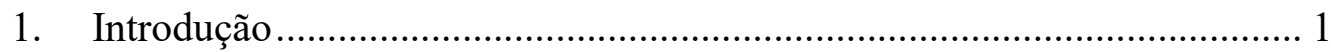

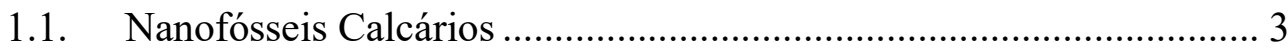

1.1.1. Classificação Taxonômica ........................................................... 6

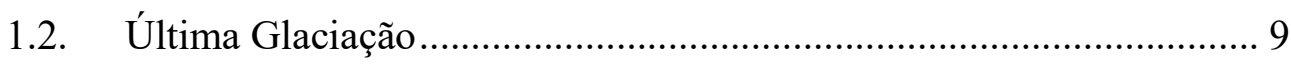

1.2.1. Ultimo Máximo Glacial (UMG) ............................................... 9

1. 2. 2. Eventos Heinrich ................................................................ 10

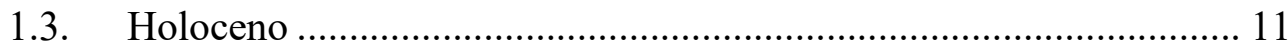

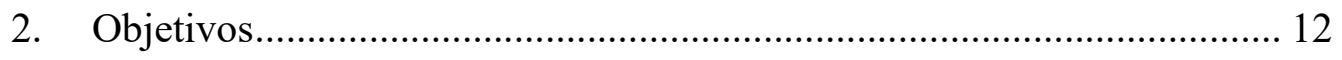

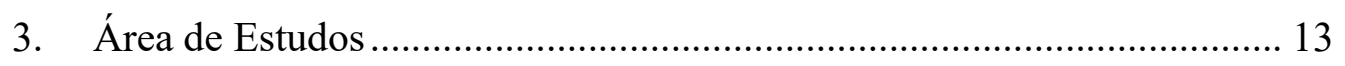

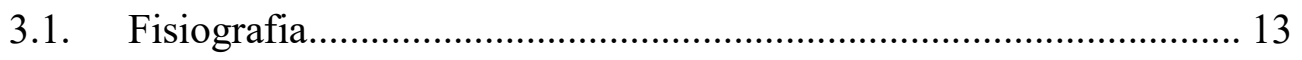

3.2. Topografia, Clima e Vegetação........................................................ 14

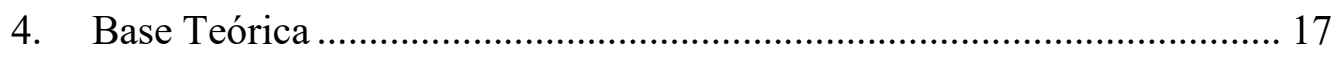

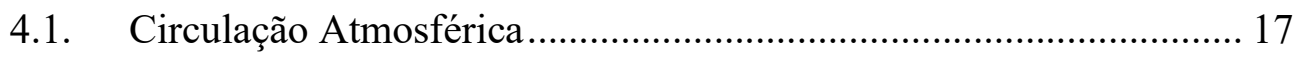

4. 1. 1. Zona de Convergência Intertropical (ZCIT) .......................... 17

4. 1. 2. Monção de Verão da América do Sul ...................................... 18

4. 1. 3. Zona de Convergência Intertropical (ZCIT) no Último Período Glacial $\quad 19$

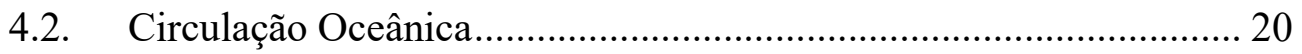

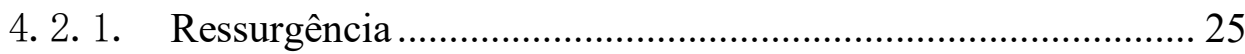


4. 2. 2. Circulação Oceânica no Último Período Glacial...................... 26

5. Produtividade Primária ............................................................................ 29

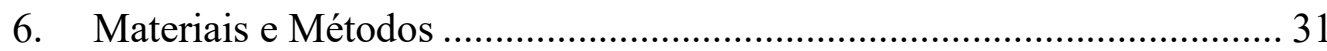

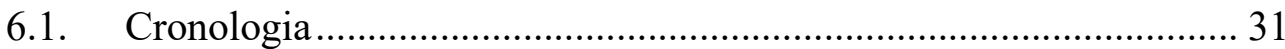

6.2. Análise de Elementos Maiores por Fluorescência de Raio-X (XRF) 32

6.3. Teor de Carbonato .............................................................................. 32

6.4. Isótopos Estáveis de Oxigênio ........................................................ 33

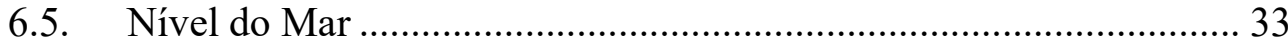

6.6. Preparação das Amostras para Análise Quantitativa de Nanofóssil Calcário $\quad 34$

6.7. Análise Qualitativa de Nanofóssil Calcário ...................................... 35

6.8. Análise Quantitativa de Nanofóssil Calcário .................................... 35

6.9. Análise Estatística Multivariada..................................................... 37

6.9.1 Análise Fatorial...................................................................... 37

6.9.2 Análise de Agrupamento .......................................................... 38

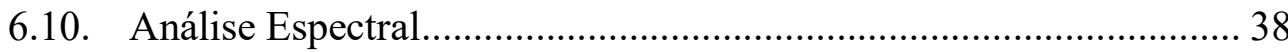

6.11. Índices Paleoceanográficos ......................................................... 38

6. 11. 1. Razão Nutriclina ................................................................ 38

6. 11.2. Equação Produtividade Primária ou Paleoprodutividade Primária(PP) 39

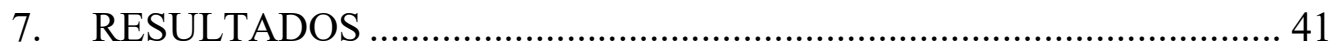

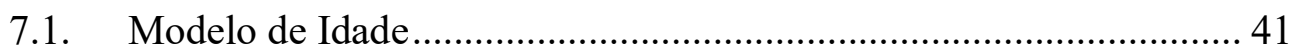

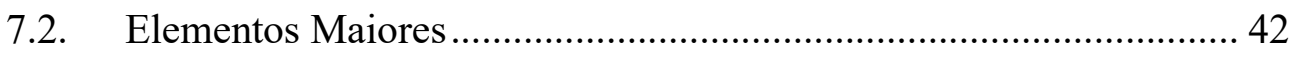

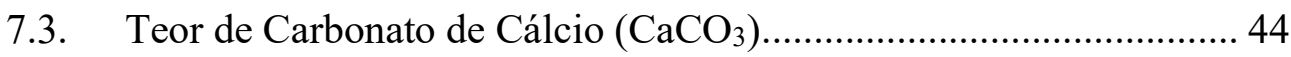

7.4. Isótopos Estáveis de Oxigênio ......................................................... 44

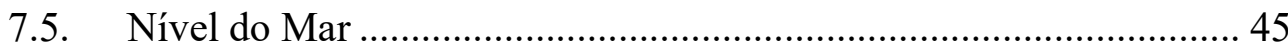

7.6. Nanofósseis Calcários ......................................................................... 46 


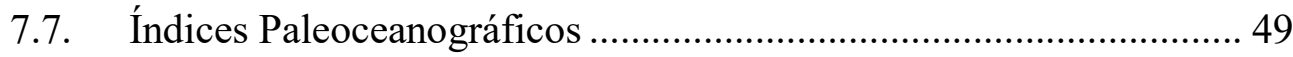

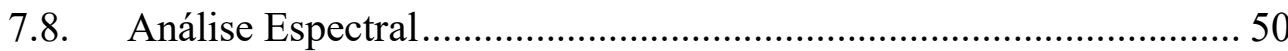

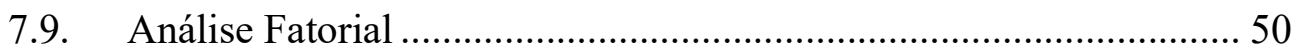

7.10. Análise de Agrupamento........................................................... 54

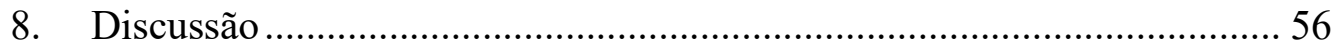

8.1. A Paleoprodutividade Primária .................................................... 56

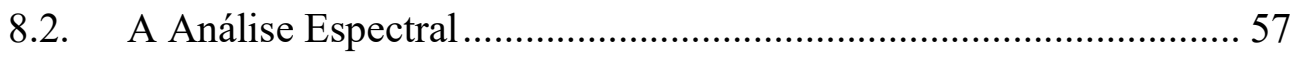

8.3. A Pluviosidade sobre o Centro/ Sul do Brasil................................. 58

8.4. O Nível Relativo do Mar ..................................................................... 59

8.5. As razões logarítmicas Elementares, $\mathrm{o} \mathrm{CaCO}_{3}$ e Paleoprodutividade Primária $\quad 60$

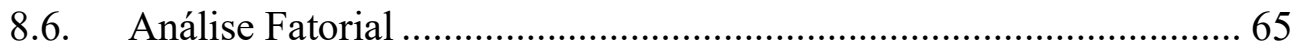

8.7. As associações das espécies de cocolitoforídeos ............................... 66

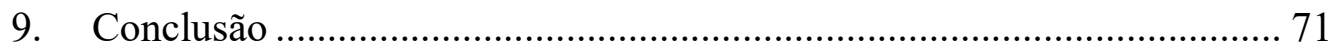

9.1. A Paleoprodutividade Primária (PP) e os elementos maiores........... 71

9.2. As associações de cocolitoforídeos ............................................ 72

9.3. As associações de cocolitoforídeos e os eventos Younger Dryas e

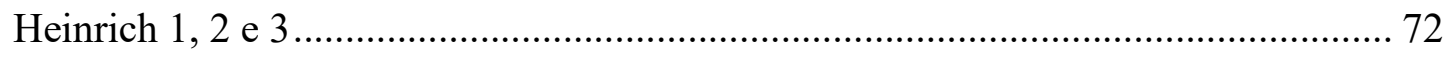

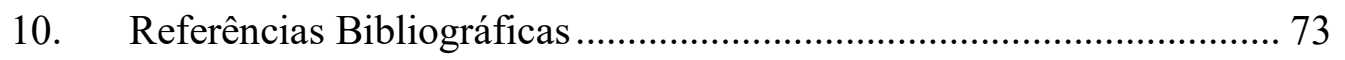

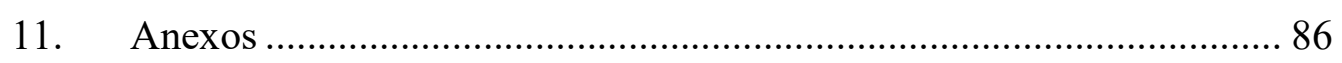




\section{Agradecimentos}

Eu dedico esta dissertação aos meus queridos orientadores Prof. Dr. Felipe Antonio de Lima Toledo e Profa. Dra. Karen Badaraco Costa que desde a graduação ofereceram oportunidade de um crescimento intelectual, acadêmico e profissional, e muito mais que isso, que já não é pouca coisa, ofereceram suas amizades. A vocês meus sinceros agradecimentos.

Agradeço também, a todos os meus amigos e colegas de laboratório, em especial a Heliane B. Ferrarese, que me ajudou com suas opiniões, seus conhecimentos e sua paciência, a Fabiane Sayuri Iuwai e Juliana Pereira de Quadros pelas suas revisões e opiniões, a Eloy Cabarcos Barro, Beatriz Bidoli Battaglin, Ana Cláudia A. Santarosa, Janaína Campos, Guilherme Pedrão e Mariana Tomazella.

Agradeço a todos os amigos do meio acadêmico que me incentivaram na realização deste trabalho e aqueles que de alguma forma me ajudaram em especial: Cintia Yamashita, Renata Hanae Nagai, Michael Martins do Santos, Guilherme Fluckiger e Nathalye E. A. M. Fluckiger.

Fora do âmbito acadêmico, agradeço o incentivo de toda hora de Geraldo Iajuc do Amaral, dos meus amigos que tornam a vida mais leve: João Henrique Cesar Ramos, Sheila Abreu Baravalle, Fabiano Mendes Oliveira, Luciana Placido Barbosa, Bruno Lopes Lima, João Paulo Moraes, Renata Nemeth, Paula Soraia Rogério Rodrigues, Lazaro Bueno, Pedro Burnier, Franco Dani Campos Pereira e Marcos Michelin.

Agradeço aos meus amigos irmãos: Adriana Marques Hirama, Jonathan Roberto Hirama, Osvaldo Luiz Hirama, Carina Souza Rodrigues Hirama, Maiko Ricardo Hirama e aos meus sobrinhos.

Aos meus queridos avós Benedito de Souza Filho (in memoriam), Bertha Marche de Souza, Kiichi Hirama (in memoriam) e Taki Hirama (in memoriam) que ao decorrer de suas vidas foram exemplo e me ajudaram a crescer em estatura e entendimento.

Agradeço a inestimável ajuda, a todo carinho, a dedicação, a paciência, as noites sem dormir...são tantos agradecimentos que não posso nem listar. A vocês amados pais Osvaldo Yoshiharu Hirama e Niobe Marques Hirama meus mais sinceros agradecimentos. 


\section{Resumo}

Neste trabalho, a partir de um testemunho coletado na Bacia de Santos, foi realizada a análise quantitativa de espécies de cocolitoforídeos com o intuito de estimar a variação da paleoprodutividade primaria superficial marinha e relacioná-la com a variação elementos maiores (Ti, Fe, $\mathrm{Ca}, \mathrm{Al}$ e K) para os últimos 35 mil anos. A paleoprodutividade apresentou relação com elementos maiores em períodos de nível do mar baixo com altas e baixas pluviosidade e pareceu não apresentar relação a partir da última transgressão marinha. Adicionalmente buscou-se identificar as associações de cocolitoforídeos para os estágios isotópicos marinhos 1, 2 e 3. Foram observadas duas associações de espécies: uma com maiores abundâncias relativas durante o Glacial e outra no Interglacial. Por último procurou-se relacionar as variações das espécies de cocolitoforídeos aos eventos climáticos Younger Dryas e Heinrich 1, 2 e 3, porém os táxons não apresentaram padrão de variação em suas abundâncias durante estes eventos.

Palavras-chave: Cocolitoforídeos, Paleoprodutividade Primária, Elementos Maiores, Nanofósseis, Glacial, Interglacial, Bacia de Santos. 


\begin{abstract}
In this work, a quantitative analysis of cocolithophores species was carried out from a piston core collected in the Santos Basin in order to estimate primary paleoproductivity variation at the sea surface and to relate it with the fluctuation of major elements $(\mathrm{Ti}, \mathrm{Fe}$, $\mathrm{Ca}, \mathrm{Al}$ and $\mathrm{K}$ ) in the interval for the last 35 thousand years and the present. The paleoproductivity was related to major elements in periods of low sea level with high and low rainfall and did not present a relation since the last marine transgression. It was also sought to identify associations of cocolithophores for the marine isotopes stages 1, 2 and 3. Two most abundant species associations were observed: one during the Glacial and another one in the Interglacial. Finally, we sought to relate the cocolithophores species with the climatic events of Younger Dryas and Heinrich 1, 2 and 3, however, the species showed no pattern of variation in their abundance during these events.
\end{abstract}

Key words: Cocolithophores, Primary Paleoproductivity, Major Elements, Nanofossils, Glacial, Interglacial, Santos Basin. 


\section{Lista de Siglas e Abreviaturas}
AAF
Água Antártica de Fundo
AMOC Atlantic Meridional Overturning Circulation
AMS
Accelerator Mass Spectrometry
AP
Antes do Presente
APAN
Água Profunda do Atlântico Norte
ASAS
Anticiclone Subtropical do Atlântico Sul
BP
Before the Present
CB
Corrente do Brasil
CCB
Corrente Costeira do Brasil
cps
contagem por segundo
CRMA Circulação (célula) de Revolvimento Meridional do Atlântico
DMS Dimetilsulfeto
HS Heinrich Stadial
IRD Ice-Rafted Detritus
MIS Marine Isotope Stage
PP Paleoprodutividade Primária
RN Razão Nutriclina
TSM Temperatura da Superfície do Mar
UMG Último Máximo Glacial
XRF Fluorescência de Raio-X
ZCAS Zona de Convergência do Atlântico Sul
ZCIT Zona de Convergência Intertropical 


\section{Lista de Figuras}

Figura 1: Localização do testemunho GL1109 (coordenadas $25^{\circ} 11,0^{\prime} \mathrm{S}$ e $44^{\circ}$ 43,3’ W) dentro do Embaiamento São Paulo, na Bacia de Santos. 13

Figura 2: Representação esquemática das células de Hadley, Ferrel e Polar (setas pretas). As linhas vermelhas representam a tropopausa e os círculos verde em degrade representam correntes de jatos. FONTE: Modificado de http://www.srh.noaa.gov/jetstream//global/images/jetstream3.jpg (19/04/2018 08:23). 17

Figura 3: Representação da posição da ZCIT em julho (área em vermelho) e janeiro (área em azul). Imagem de Mats Halldin FONTE: https://pt.wikipedia.org/wiki/Zona_de_converg\%C3\%AAncia_intertropical\#/media/File :ITCZ_january-july.png (19/04/2018 09:10)..... 18

Figura 4: Representação esquemática da circulação termoalina (modificado de Rahmstorf, 2002). A faixa vermelha representa os fluxos de superfície, a azul os fluxos profundos e a vinho os fluxos de fundo. As áreas delimitadas em verde representam áreas do oceano com salinidade maiores que $36 \%$ e as em azul claro áreas com salinidade menores que 34\%o. Os círculos em amarelo representam as regiões de formação de águas profundas e de fundo. 21

Figura 5: Esquema da circulação superficial no Atlântico Sul (modificado de Peterson e Stramma, 1991). 23

Figura 6: Ilustração esquemática em corte vertical das massas e da Corrente do Brasil que atuam ao largo da costa Sul/Sudeste do Brasil (modificado de Matsura, 1986)

Figura 7: Esquema com os três diferentes modos de funcionamento da CRMA: quente, frio e Heinrich (desligado). As setas vinho representam a formação da APAN e as em azul a circulação da AAF (Böhm et al., 2015).

Figura 8: Principais fenômenos da costa Sul-Sudeste (Braga e Niencheski, 2006). Em hachurado estão representadas as áreas de ocorrência de ressurgência e as linhas paralelo/radiais áreas de aporte de sedimento terrígenos 30

Figura 9: Modelo de idade e taxa de sedimentação para o testemunho KF-19. A curva vermelha representa a taxa de sedimentação $(\mathrm{cm} / \mathrm{kano})$ e a curva preta o modelo de idade (kano antes do presente) com barras de erro com incerteza de 2 sigma para cada datação. 
Figura 10: Gráfico das razões logarítmicas de $\mathrm{Fe} / \mathrm{Ca}$ e Ti/Ca do testemunho KF19 com as faixas de estágios isotópicos marinho 1, 2 e 3 .

Figura 11: Gráfico da razão logarítmica de Al/Si do testemunho KF-19 com as faixas de estágios isotópicos marinho 1,2 e 3 .

Figura 12: Gráfico das razões logarítmicas de Fe/K do testemunho KF-19 com as faixas de estágios isotópicos marinho 1,2 e 3 . 44

Figura 13: Gráfico da percentagem de carbonato de cálcio do testemunho KF-19 com as faixas de estágios isotópicos marinho 1,2 e 3 . 44

Figura 14: Gráfico da razão isotópica de oxigênio em foraminíferos bentônicos (\%, VPDB). Estão representados os intervalos isotópicos marinhos 1, 2 e 3 e os eventos Younger Dryas (faixa cinza) e Heinrich 1, 2 e 3 (faixas azuis) (Salgueiro et al.,2014). 45

Figura 15: Gráfico do nível do mar (m) do testemunho KF-19. Estão representados os intervalos isotópicos marinhos 1, 2 e 3 e os eventos Younger Dryas (faixa cinza) e Heinrich 1, 2 e 3 (faixas azuis) (Salgueiro et al.,2014). 45

Figura 16: Gráfico com a variação relativa (\%) e de Gephyrocapsa spp., F. profunda e E. huxleyi (a, b, c respectivamente) ao longo do testemunho KF-19 com as faixas de estágios isotópicos marinho 1, 2 e 3 .....

Figura 17: Gráfico com a variação relativa de Syracosphaera spp., Umbelosphaera spp., Umbilicosphaera spp. e Espículas de Ascídias (a, b, c, d respectivamente) ao longo do testemunho KF-19 com as faixas de estágios isotópicos marinho 1,2 e 3 . 48

Figura 18: Gráfico da Razão Nutriclína (a) e da Paleoprodutividade Primária (b) $\left(\mathrm{gC} \cdot \mathrm{m}^{2}\right.$.ano $\left.{ }^{-1}\right)$ do testemunho KF-19 com as faixas de estágios isotópicos marinho 1, 2 e 3 .

Figura 19: Periodograma da análise espectral (REDFIT method) da paleoprodutividade primária do testemunho KF-19. A faixa em laranja e azul representam respectivamente a banda espectral de obliquidade (41 mil anos) e precessão (19-23 mil anos). As linhas verde (90\%) e roxa (95\%) são linhas nível de significância. 50

Figura 20: Diagrama da Análise Agrupamento modo Q pelo método Ward e coeficiente de correlação de Person para o testemunho KF-19. A numeração de 1 a 34 representam amostras do MIS 1, de 35 a 123 do MIS 2 e de 123 a 130 do MIS 3. Para os eventos YD, HS 1, 2 e 3 os intervalos de numeração são respectivamente: 32 e 33; 38 a $51 ; 105$ a 113 e 124 a 126. 
Figura 21: Gráfico com curva de Hidrocarbonetos Alifáticos de cadeia curta (a) de Lourenço et al. (2016) e Paleoprodutividade Primária (b) do testemunho KF-19. As setas sob as curvas indicam amostras datadas por $\mathrm{C}^{14}$. Estão representados os intervalos isotópicos marinhos 1, 2 e 3 e os eventos Younger Dryas (faixa cinza) e Heinrich 1, 2 e 3 (faixas azuis) (Salgueiro et al.,2014). 57

Figura 22: Gráfico com curva de paleoprodutividade primária de cocolitoforídeos (linha verde)(KF-19), de precessão (linha cinza) e insolação de verão em $25^{\circ} \mathrm{S}$ (linha vermelha). Estão representados os intervalos isotópicos marinhos 1, 2 e 3 e os eventos Younger Dryas (faixa cinza) e Heinrich 1, 2 e 3 (faixas azuis) (Salgueiro et al.,2014). As curvas de precessão e insolação de verão foram obtidas por Laskar et al. (2004).

Figura 23: A curva lilás (a) representa o gráfico de $\delta^{18} \mathrm{O}$ (\%, VPDB) de Wang et al. (2007), a curva cinza (b) representa a razão logarítmica de Ti/Ca e a curva em azul claro (c) representa $\mathrm{CaCO}_{3}$. Estão representados os intervalos isotópicos marinhos $1,2 \mathrm{e}$ 3 e os eventos Younger Dryas (faixa cinza) e Heinrich 1, 2 e 3 (faixas azuis) (Salgueiro et al.,2014).

Figura 24: Gráfico de nível do mar (m) do testemunho KF-19 (em roxo) e a curva de nível do mar (m) proposta por Spratt e Lisiecki et al. (2016). Estão representados os intervalos isotópicos marinhos 1, 2 e 3 e os eventos Younger Dryas (faixa cinza) e Heinrich 1, 2 e 3 (faixas azuis) (Salgueiro et al.,2014). 60

Figura 25: Gráficos de teor de carbonato de cálcio (\%) (a), das razões logarítmicas de $\mathrm{Ti} / \mathrm{Ca}$ (b), $\mathrm{Fe} / \mathrm{K}$ (c), $\mathrm{Al} / \mathrm{Si}$ (d) e da paleoprodutividade primária ( $\mathrm{gC} / \mathrm{m}^{2} / \mathrm{ano}$ ) (e). Estão representados os intervalos isotópicos marinhos 1,2 e 3 e os eventos Younger Dryas (faixa cinza) e Heinrich 1, 2 e 3 (faixas azuis) (Salgueiro et al.,2014)

Figura 26: Gráficos das espécies de cocolitoforídeos que apresentaram maior abundância e ocorrência durante o período glacial. Ao topo da figura estão representados por barras os intervalos do MIS 1, 2 e 3 que são acompanhados pelas faixas amarelas e brancas. A faixa cinza representa o evento Younger Dryas e as azuis os eventos Heinrich 1, 2 e 3 (da esquerda para a direita) (Salgueiro et al.,2014). 68

Figura 27: Gráficos das espécies de cocolitoforídeos que apresentaram maior abundância e ocorrência durante o período glacial. Ao topo da figura estão representados por barras os intervalos do MIS 1, 2 e 3 que são acompanhados pelas faixas amarelas e 
brancas. A faixa cinza representa o evento Younger Dryas e as azuis os eventos Heinrich 1, 2 e 3 (da esquerda para a direita) (Salgueiro et al.,2014).

Figura 28: Gráficos das espécies de cocolitoforídeos que apresentaram maior abundância durante o MIS 1. Ao topo da figura estão representados por barras os intervalos do MIS 1, 2 e 3 que são acompanhados pelas faixas amarelas e brancas. A faixa cinza representa o evento Younger Dryas e as azuis os eventos Heinrich 1, 2 e 3 (da esquerda para a direita) (Salgueiro et al.,2014) 70

\section{Lista de Tabelas}

Tabela 1: Dados da datação de radiocarbono para o testemunho KF-19 com erro, calibração 2 sigma, a variedade de G. ruber (pink ou white). 42

Tabela 2: Fatores extraídos na Análise Fatorial modo Q com autovalores e percentagem de variância. Em cinza estão destacados os dois primeiros fatores utilizados na interpretação dos resultados. 51

Tabela 3: Fatores extraídos na Análise Fatorial modo R com autovalores e percentagem de variância. Em cinza estão destacados os dois primeiros fatores utilizados na interpretação dos resultados. 52

Tabela 4: Cargas Fatoriais (modo Q). Os valores sublinhados em azul e vermelho são aqueles de maior peso carga (maior ou igual a 0,7 ). 53

Tabela 5: Cargas Fatoriais (modo R). Os valores sublinhados em cinza são aqueles de maior peso positivo e negativo $(>0,6) . \mathrm{PMP}=$ placolito muito pequeno $(<2$ $\mu \mathrm{m})$ e CNI = cocólito não identificado.

Anexos

Anexo 1: Fotomicrografia de entidades taxonômicas observadas no testemunho KF-19

Anexo 2: Fotomicrografia de entidades taxonômicas observadas no testemunho KF-19 88

Anexo 3: Planilha com abundância percentual de cocolitoforídeos, placolitos muito pequenos (PMP), cocólitos não identificados (CNI) e espículas de ascídeas; razões logarítmicas de: $\mathrm{Fe} / \mathrm{K}, \mathrm{Fe} / \mathrm{Ca}, \mathrm{Ti} / \mathrm{Ca}$ e Al/Si; e Paleoprodutividade Primária (gC/m2/ano) utilizadas na análise fatorial. 89 
Anexo 4: Planilha de abundância percentual de nanofósseis calcários utilizada

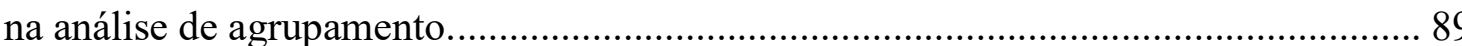




\section{Introdução}

Nos últimos anos a temática das variações climáticas tem sido exaustivamente noticiada pelos diversos meios de comunicação. Derretimento de geleiras, aridificação de regiões outrora úmidas e inundações, são alguns exemplos de eventos rapidamente associados, por estes veículos de informação, as variações climáticas como uma tentativa de comprová-las.

Embora este assunto tenha se popularizado recentemente, as variações climáticas vêm ocorrendo durante o tempo geológico desde os primórdios da origem do planeta e, a pelo menos 2,5 milhões de anos, ao início do Pleistoceno, o clima da Terra tem sido marcado por uma contínua sucessão de glaciações e períodos interglaciais (Uriarte, 2011).

Estudar estas oscilações entre períodos quentes e frios torna-se importante, pois além de contar uma parte da história do clima do planeta e elucidar os mecanismos pelos quais acontecem tais variações, é possível ter uma ideia dos possíveis cenários climáticos que poderão se estabelecer em nosso planeta.

Os oceanos e a sua interação com a atmosfera possuem papel fundamental no sistema climático, e a produção biológica marinha, por sua vez, constitui um parâmetro essencial no estudo da evolução paleoceanográfica de uma região. As alterações na concentração de $\mathrm{CO}_{2}$ ocasionadas pelas flutuações na produtividade também podem contribuir para a alterações na temperatura média global (Uriarte, 2011).

Os cocolitoforídeos são um dos maiores grupos de produtores primários dos oceanos e possuem grande importância no ciclo do $\mathrm{CO}_{2}$, uma vez que transporta carbono orgânico e carbonato para o sedimento (Thierstein \& Young, 2004; Baumann, 2005). Esta retirada de $\mathrm{CO}_{2}$ atmosférico, e posterior aprisionamento no fundo marinho promovida pelos cocolitoforídeos, influenciam diretamente o sistema climático terrestre. Além disso, estes organismos também afetam o clima do planeta, pois são emissores de dimetilsulfeto (DMS) para a atmosfera, componente essencial para a formação de nuvens, as quais permitem o aumento do albedo (devido a refletância) (Charlson et al., 1987).

Os cocolitoforídeos são algas unicelulares que fazem parte do fitoplâncton marinho e estão classificadas dentro do Filo Haptophyta, na Classe Prymnesiophyceae. Sua capacidade de produzir um envoltório calcário, possibilita que o mesmo fique preservada no sedimento oceânico, sendo muitas vezes o principal componente destes (Cabarcos, 2013). 
Os cocolitoforídeos possuem ampla distribuição oceânica, vivem na zona fótica e sua diversidade aumenta em regiões de baixas latitudes. Preferem águas quentes, estratificadas e oligotróficas. Seu padrão de distribuição também é influenciado pela maior ou menor disponibilidade de nutrientes principalmente nitrato e fosfato, porém a abundância de outros elementos, tais como Fe, Zn e Mn, também podem influenciar na sua distribuição (Bown \& Young, 1998).

O estudo das associações de cocolitoforídeos preservadas nos sedimentos, tornase uma ferramenta importante para a reconstrução das condições paleoceanográficas, pois refletem as condições ambientais da coluna de água em que viveram podendo responder a alterações na concentração de nutrientes, temperatura e salinidade (Winter et al., 1994).

Outros proxies utilizados em estudos sobre as variações climáticas são as concentrações dos elementos maiores ( $\mathrm{Ca}, \mathrm{Fe}, \mathrm{Al}, \mathrm{Si}, \mathrm{Ti}, \mathrm{K}$, entre outros), medidos em sedimentos da plataforma continental. Cada elemento pode ser usado para traçar o suprimento de material terrígeno para o oceano e o meio pelo qual foi transportado (fluvial ou eólico). Por exemplo, o aumento da intensidade de Fe e Ti pode ser interpretado como um aumento de suprimento de material siliciclástico de origem fluvial, porém a escolha e a interpretação de cada elemento podem variar de lugar para lugar. A forma mais usual de empregar os elementos maiores em estudos de reconstrução paleoclimática é a utilização de suas razões. As razões mais comuns são: $\mathrm{Fe} / \mathrm{Ca}$ e Ti/Ca (indicativo de variações no aporte de terrígenos e da produtividade marinha), Ti/Al (granulometria), Fe/K e Al/Si (grau de intemperismo químico) (Govin et al., 2012).

Atualmente, a margem continental sudeste brasileira entre $24^{\circ} \mathrm{S}$ e $27^{\circ} \mathrm{S}$ representa uma região de transição de dominância da Corrente do Brasil (CB) e a Corrente Costeira do Brasil (CCB). A primeira, alimenta a plataforma com minerais argilosos de regiões equatoriais, a última transporta os sedimentos finos derivados do Rio da Prata (Nagai et al., 2014). Ambas são fortemente associadas a sistemas de correntes conduzidas por ventos, a CCB em direção ao norte, que através da pluma do Rio da Prata deposita sedimentos sobre a plataforma interna e média e, a $\mathrm{CB}$, em direção ao sul que através de vórtices meandrantes deposita sedimentos em cima da plataforma externa, sendo a região entre 28 e $24^{\circ} \mathrm{S}$ uma zona transicional (Mahiques et al., 2008; Mahiques et al., 2017).

Considerando o que foi dito anteriormente, buscou-se neste trabalho observar a relação entre a entrada de elementos maiores no ambiente marinho com a variação da 
produtividade primária de cocolitoforídeos nos últimos 35 mil anos na região do Atlântico sudoeste. A seguir é feita uma breve introdução sobre os nanofósseis calcários, a última glaciação e o Holoceno.

\subsection{Nanofósseis Calcários}

Os nanofósseis calcários são, por definição, um conjunto de partículas carbonáticas $\left(\mathrm{CaCO}_{3}\right)$ de dimensões inferiores a $63 \mu \mathrm{m}$ que não incluem os fragmentos de organismos maiores e suas formas juvenis (Bown \& Young, 1998). Esta definiç̧ão é muito abrangente, porém o mais numeroso e amplamente estudado grupo são os cocolitoforídeos, os quais, junto às diatomáceas, formam a maior parte do fitoplâncton unicelular marinho. Assim, os nanofósseis calcários são predominantemente constituídos de microalgas calcárias, no entanto também é incluso espículas de ascídias e cistos de dinoflagelados calcários.

Grande parte dos nanofósseis calcários é formada por cocólitos, os quais, são pequenas placas calcíticas de 5 a $15 \mu \mathrm{m}$ de diâmetro médio (Seyve, 1990). Estas são provenientes da desagregação do envoltório carbonático das células dos cocolitoforídeos que são compostas em média por 20 ou mais cocólitos por célula. Ao conjunto de cocólitos não desagregados de uma célula se dá o nome de cocosfera.

Os cocolitoforídeos são exclusivamente marinhos e habitam principalmente a zona fótica dos oceanos entre 0 e 200 metros de profundidade aproximadamente (Antunes, 1997). Este grupo cosmopolita é abundante nos domínios temperados e quentes, mas apenas poucas espécies vivem em águas fria das regiões polares (Seyve, 1990).

Os cocolitoforídeos são geralmente organismos oligotróficos. Por este motivo, são mais diversos em regiões quentes, onde são observados em todas as estações do ano, e de baixa produtividade, o que os difere dos outros grupos fitoplanctônicos (Okada \&McIntyre, 1979 e Winter et al., 1994). Desta forma, sua distribuição é controlada pelas variações de temperatura e sofrem forte influência das características das águas superficiais (salinidade, nutrientes e disponibilidade de luz) e das mudanças climáticas (Mostajo, 1986).

Associações típicas em várias regiões do oceano são reconhecidas por estudos ecológicos e biogeográficos e estas podem ser classificadas latitudinalmente por zonas climáticas (McIntyre \& Bé, 1967; Okada \& Honjo, 1973). Através do tempo geológico, 
a distribuição biogeográfica das espécies individuais podem alterar-se significativamente resultante das mudanças ambientais ocorridas no planeta (Brand, 1994).

A espécie de cocolitoforídeo mais abundante, cosmopolita e de ampla distribuição nos oceanos é nomeada de Emiliania huxleyi (Roth, 1994). Esta é capaz de se desenvolver em regiões eutróficas e oligotróficas, tolerar variação de temperatura entre 1 e $30^{\circ} \mathrm{C}$, salinidade entre 11 e 44 ppt (Brand, 1994) e habita desde a superfície até aproximadamente $200 \mathrm{~m}$ de profundidade e, por este motivo, é a espécie mais estudada em cultivos de laboratório (Winter et al., 1994). Capaz de formar blooms reconhecidos em imagens de satélite, esta espécie é também uma considerável fonte de dimetilsulfeto (DMS) (Westbroek et al., 1993).

E. huxleyi é capaz de se desenvolver em condições de baixas concentrações de $\mathrm{Fe}, \mathrm{Zn}$ e Mn. Da mesma forma, Gephyrocapsa oceanica, Calcidiscus leptoporus e Umbilicosphaera sibogae também se desenvolvem em condições de concentrações baixas destes metais em comparação a outros cocolitoforídeos costeiros e outras espécies do fitoplâncton. (Brand, 1994).

$\mathrm{O}$ aumento de disponibilidade de nutrientes no oceano propicia o aumento das populações de E. huxleyi e G. oceanica (Brand, 1994). G. oceanica possui modestas frequências em mares pobres em nutrientes, aumentando sua frequência expressivamente com incremento destes (Brand, 1994). Esta espécie é utilizada como indicadora de produtividade.

Outras espécies como Helicosphaera carteri, Umbellosphaera irregularis e Rhabdosphaera clavigera não aumentam sua frequência com a maior disponibilidade de nutrientes não sendo observada o aumento substancial de suas abundâncias em regiões de ressurgência ou em regiões dos oceanos com elevado teor de nutrientes. Estas espécies não respondem ao acréscimo de nutrientes, porém se desenvolvem bem em condições muito baixas destes (Brand, 1994).

A maior parte das espécies de cocolitoforídeos possui preferência por determinadas intervalos de profundidade. Por exemplo, $R$. clavigera, G. oceanica e Ceratolithus spp. se desenvolvem na zona fótica superior $(0-80 \mathrm{~m})$, enquanto Umbellosphaera tenuis na zona fótica intermediária (80-120m) e Florisphaera profunda e Gladiolithus flabellathus são espécies características da zona fótica inferior (100 a 200m) (Brand, 1994). 
A espécie $F$. profunda apresenta maior abundância relativa com o aumento da profundidade e com maior distância da costa (Okada, 1983). Esta espécie reflete a variação da profundidade da nutriclina/termoclina e da produtividade de águas superficiais. Em regiões oceânicas, uma nutriclina mais profunda implica em uma zona fótica superior pobre em nutrientes e, por consequência, uma maior frequência de $F$. profunda em detrimento de outras espécies de cocolitoforídeos (Molfino e McIntyre, 1990). Por outro lado, baixa percentagem desta espécie pode ou não ser associada diretamente a nutriclina superficial, uma vez que seu decréscimo pode estar relacionado a menor transparência das águas, pois também necessita de luz para se desenvolver.

De acordo com Cachão e Moita (2000), Coccolithus pelagicus é uma espécie que pode ser encontrada em ambientes com disponibilidade de nutrientes e com moderada turbulência. A espécie ocupa ambientes de frentes de diversas origens, incluindo térmicas (regiões de ressurgência), salinas (plumas de rios) e confluência de corpos de águas distintos.

As espécies $U$. tenuis e U. irregularis e Discophaera tubifera, são características de massas de águas dos giros centrais oligotróficos, relativamente quentes $\left(20^{\circ}\right.$ a $\left.30^{\circ} \mathrm{C}\right) \mathrm{e}$ salinas (Brand, 1994; Baumann, 2005). Syracosphaera pulchra apresenta preferência por águas quentes, salinas, oligotróficas e estáveis, enquanto $H$. carteri apresenta-se distribuída em ambientes neríticos, águas quentes e de alta produtividade (Okada, 1992; Baumann, 2005). A espécie tropical U. sibogae tem preferência por águas quentes, salinas e oligotróficas e com baixas concentrações de Fe, Zn e Mn (Brand, 1994). Sua distribuição é mais abundante nos sedimentos de latitudes tropicais e subtropicais (Boeckel et al., 2006).

As ascídias são animais pertencentes aos tunicados exclusivamente marinhos, bentônicos, na maioria sésseis, vivendo fixados aos substratos. As ascídias didemnideas possuem corpo mole, exceto por suas espículas calcárias encontradas juntos com os demais nanofósseis calcários. São abundantes em regiões costeiras, mas estão distribuídas amplamente, desde águas rasas até grandes profundidades, incrustadas em diferentes tipos de substratos consolidados, como rochas, esqueletos de corais, substratos artificiais, ou simplesmente apoiadas sobre o fundo, principalmente em substratos lodosos (Rodrigues et al. 1999). Segundo Okada (1992) pode ser indicador de sedimentos retrabalhados. 
Os cistos calcários de dinoflagelados do gênero Thoracosphaera apresentam maior taxa de acumulação em águas oligotróficas e coluna d'água estratificadas (Karwath et al., 2000).

\subsubsection{Classificação Taxonômica}

A classificação taxonômica adotada neste estudo seguiu a classificação adotada por Young et al. (2003), e está apresentada a seguir.

Reino CHROMISTA Cavalier-Smith, 1981

Divisão HAPTOPHYTA Hibberd ex Cavalier-Smith, 1986

Classe PRYMNESIOPHYCEAE Hibberd, 1976

Subclasse PRYMNESIOPHYCIDAE Cavalier-Smith, 1986

Ordem ISOCHRYSIDALES Pascher 1910

Família NOELAERHABDACEAE Jerkovic 1970 emend. Young \& Bown 1997

Gênero/ Espécie Emiliania huxleyi (Lohmann 1902) Hay \& Mohler, in Hay et al.1967

Gephyrocapsa spp. Kamptner 1943

Gephyrocapsa oceanica Kamptner 1943

Gephyrocapas muellerae Bréhéret 1978

Gephyrocapsa ericsonii McIntyre \& Bé 1967

Reticulofenestra sp. Hay, Mohler \& Wade 1966

Ordem COCCOSPHAERALES Haeckel 1894 emend. Young \& Bown 1997

Família COCCOLITHACEAE Poche 1913 emend. Young \& Bown 1997

Gênero/ Espécie Coccolithus pelagicus (Wallich1877) Schiller 1930

\section{Família CALCIDISCACEAE}

Gênero/ Espécie Calcidiscus leptoporus (Murray \& Blackman 1898)

Loeblich \& Tappan 1978

Gênero/ Espécie Oolithotus fragilis (Lohmann 1912) 
Gênero/ Espécie Umbilicosphaera sibogae (Weber-van Bosse 1901)

Gaarder 1970

Umbilicosphaera foliosa (Kampter 1963)

Umbilicosphaera huburtiana (Gaarder 1970)

Umbilicosphaera jafari Muller 1974

Ordem ZIGODISCALES (Young \& Bown 1997)

Família HELICOSPHAERACEAE Black 1971

Gênero/ Espécie Helicosphaera sp. Kamptner 1954

Helicosphaera carteri (Wallich 1877) Kamptner 1954

Helicosphaera hyalina Gaarder 1970

Helicosphaera wallichii (Lohmann 1902) Okada \&

McIntyre 1977

Helicosphaera pavimentum Okada \& McIntyre 1977

Família PONTOSPHAERACEAE Lemmerman 1908

Gênero/ Espécie Pontosphaera sp. Schiller 1925

Pontosphaera discopora Schiller 1925

Pontosphaera japonica (Takayama 1967) Nishida 1971

Pontosphaera multipora (Kamptner 1948) Roth 1970

Pontosphaera syracusana Lohmann 1902

Gênero/ Espécie Schyphosphaera apsteinii Lohmann 1902

Ordem SYRACOSPHAERALES Hay 1977 emend.

Família SYRACOSPHAERACEAE (Lohmann 1902) Lemmerman 1903

Gênero/ Espécie Syracosphaera sp. Lohmann 1902

Syracosphaera pulchra Lohmann, 1902

Syracosphaera histrica Kamptner, 1941

Syracosphaera lamina Lecal-Schlauder 1951

Gênero/ Espécie Coronosphaera Gaarder in Gaarder \& Heimdal 1977 
Coronosphaera mediterranea (Lohmann 1902) Gaarder, in

Gaarder \& Heimdal 1977

Coronosphaera binodata (Kamptner 1927) Gaarder in Gaarder

\& Heimdal 1977

Família CALCIOSOLENIACEAE Kamptner 1927

Gênero/ Espécie Calciosolenia murrayi Gran 1912

Calciosolenia brasiliensis (Lohmann 1919)

Família RABDOSPHAERACEAE Haeckel 1984

Gênero/ Espécie Rhabdosphaera clavigera Murray \& Blackman 1898

Rhabdosphaera clavigera var. stylifera (Lohmann, 1902)

Kleijne and Jordan, 1990

Gênero/ Espécie Discosphaera tubifera (Murray \& Blackman 1989)

Gênero/ Espécie Acanthoica sp. Lohmann 1903

Família UMBELLOSPHAERACEAE

Gênero/ Espécie Umbellosphaera sp. Paasche in Markali \& Paasche 1955

Umbellosphaera irregularis Paasche in Markali \& Paasche 1955

Umbellosphaera tenuis (Kamptner 1937) Paasche in Markali \&

Paasche 1955

Family BRAARUDOSPHAERACEAE Deflandre 1947

Gênero/ Espécie Braarudosphaera bigelowii (Gran \& Braarud 1935) Deflandre 1947

Família CERATOLITHACEAE Norris 1965

Gênero/ Espécie Ceratolithus cristatus Kamptner 1950

Nanolito incertae sedis

Gênero/ Espécie Florisphaera profunda Okada \& Honjo 1973

Algumas entidades taxonômicas foram fotomicrografádas e estão apresentadas no Anexo 1 e 2. 


\section{2. Última Glaciação}

Segundo Uriarte (2011), depois de permanecer em um longo período de estabilidade climática no Plioceno, a Terra começou a arrefecer devido ao resfriamento dos oceanos e, há aproximadamente 2,5 milhões de anos, início do Quaternário, o frio era suficiente para ocasionar abundantes precipitações de neves, em altas latitudes, capaz de acumular espessos mantos de gelo sobre o norte da América e da Europa. Desde então, a Terra começou a experimentar períodos sucessivos de esfriamento e aquecimento.

O Quaternário, período que abarca o Pleistoceno e o Holoceno, é portanto um momento de instabilidade climática e de bruscas e importantes mudanças ambientais que afetaram com maior ou menor intensidade a todas as latitudes.

Neste panorama é que se estabeleceu a última glaciação, há aproximadamente 115 mil anos. Após um período interglacial quente, os gelos acumulados durante nevascas sobre o norte do Canadá começaram a resistir ao derretimento durante o verão, em razão de condições de insolação favoráveis. Devido a excentricidade da órbita terrestre maior e menor eixo de inclinação (ciclos de Milancovitch), as altas latitudes do hemisfério norte passaram por uma rápida transição de insolação de verão forte para outra bem mais fraca. Soma-se a isto o fato de que o periélio da órbita anual da Terra em torno do Sol ocorria no inverno do hemisfério norte, isto ocasionava um menor contraste estacional com insolações maiores no inverno e menores no verão. Estes fatores todos reunidos possibilitaram o estabelecimento de um período glacial (Uriarte, 2011).

\subsubsection{Ultimo Máximo Glacial (UMG)}

O mais recente intervalo cuja a cobertura de gelo global atingiu seu volume máximo é definido como Ultimo Máximo Glacial (UMG) (Mix et al.,2001). Este intervalo de cerca de 4 mil anos se estendeu de 23.000 a 19.000 anos antes do presente (Clark et al., 2009) e é definido pelo ponto médio do estágio isotópico marinho 2 (Shackleton, 1977).

O acúmulo de gelo sobre os continentes gerou uma retirada de água dos oceanos o que ocasionou a descida do nível do mar para algo em torno de 120 e $135 \mathrm{~m}$ abaixo do atual (Yokoyama et al., 2000; Uriarte, 2011; Furtado, 2013; Correa et al., 2014). Por consequência, grandes regiões da plataforma continental, que atualmente se encontram submergidas, emergiram tornando possível que os cursos de muitos rios seguissem uma 
trajetória muito diferente além de desembocaduras muito mais afastadas de suas posições atuais (Uriarte, 2011; Furtado, 2013). Desta forma, canais foram formados e sedimentos terrígenos conseguiram ser depositados no talude superior (Furtado, 2013).

Durante o UMG, a temperatura média em regiões emersas tropicais foi cerca de $5^{\circ} \mathrm{C}$ abaixo da atual e mudanças no regime hidrológico e paisagístico também foram consideráveis, com grandes extensões de selva sendo substituídas por savana, devido à queda da precipitação (Uriarte,2011). Contudo, Wang et al., 2007, observou que o resfriamento do Atlântico Norte teria ocasionado um aumento de precipitação no sul do Brasil.

\subsubsection{Eventos Heinrich}

Os eventos Heinrich foram nomeados depois da descoberta feita por Harmut Heinrich. Em 1988 ele observou, em seções de testemunhos de sedimento glaciais do Atlântico Noroeste, sucessivas camas de areia, as quais foram por ele atribuídas a uma sucessão de períodos de larga escala com sedimentação de ice-rafted detritus (IRD) provenientes do derretimento de aicebergues. Em 1992, Wally Broecker cunhou o termo e foi o primeiro a reconhecer as implicações da descoberta feita por Heinrich, incluindo a ligação provável entre o grande desprendimento de aicebergues, a entrada de gelo derretido no Atlântico Norte, a interrupção da circulação termoalina e o resfriamento de altas latitudes (Labeyrie et al., 2007).

Portanto, os eventos Heinrich apresentam aumento da sedimentação de IRD devido aos longos períodos de resfriamento do Atlântico Norte e consequente diminuição da temperatura da superfície do mar (TSM) (Strikis et al., 2015). Nesse cenário, a ação dos eventos Heinrich sobre as regiões tropicais e subtropicais do Atlântico Sul pode ser observada por mudanças na intensidade das Monções de Verão da América do Sul com a redução da TSM do Atlântico Norte. A diminuição do gradiente térmico no Atlântico Norte tropical ocasiona o deslocamento da Zona de Convergência Intertropical (ZCIT) mais a sul intensificando a Monção de Verão do Atlântico Sul (Cruz et al.,2005).

No período estudado neste trabalho, são destacados 3 eventos Heinrich Stadial: HS1 (18 - 15 mil anos AP), HS2 (26,1 - 23,2 mil anos AP) e HS3 (30,6 - 29,2 mil AP), bem como o Younger Dryas (12,9 - 11,8 mil anos AP) (Salgueiro et al.,2014) que é considerado as vezes como HS0 (Labeyrie et al., 2007). 


\subsection{Holoceno}

O término do último grande período glacial foi ocasionado por fatores de ordem orbital que permitiram dar início, entre 20 e 14 mil anos AP, a grandes retrocessos das geleiras em direção aos polos. Esse lento recuo das geleiras foi acompanhado do aquecimento de todo o planeta de tal modo que os climas glaciais da porção setentrional do Hemisfério Norte foram amenizados (Santa'Anna Neto e Nery, 2005).

É nesse panorama que se inicia o Holoceno, a época mais recente do período Quaternário, e que teve início com o final da última glaciação, há cerca de 11,7 mil anos AP (Walker et al., 2012).

Por volta de 10 a 9 mil anos AP, a América do Norte recebe chuvas mais torrenciais o que tornou o clima continental mais ameno e úmido. As zonas intertropicais, por sua vez, tornaram-se mais secas e com a presença de fortes ventos. Os verões eram mais quentes e os invernos mais rigoroso do que na atualidade (Santa'Anna Neto e Nery, 2005).

O intervalo de 5,6 e 2,5 mil a.C. (7,6 e 4,5 mil anos AP) é reconhecido como o período mais quente do interglacial atual e é conhecido como o "ótimo climático", quando a Terra estava, em média, 2 a $3^{\circ} \mathrm{C}$ mais quentes que na atualidade (Santa'Anna Neto e Nery, 2005).

No período compreendido entre 4,5 e 4 mil anos AP, ocorreu a época mais fria do Holoceno. Um retorno a clima mais frio no norte da Europa e clima mais ameno e muito chuvoso no norte da África e na Ásia Menor.

Entre 1,8 e 1 mil anos AP ocorre um novo "ótimo climático" que torna as condições climáticas ao norte Hemisfério Norte mais favoráveis, ao passo que o aumento de temperatura provocou grande deficiência hídrica no Mediterrâneo.

Novos períodos de resfriamentos foram observados entre os séculos XI e XV e entre o século XVI e XIX. Estima-se que a temperatura era cerca de 2 a $3^{\circ} \mathrm{C}$ mais baixas que hoje e as precipitações de neve muito mais constante. Desde então, o globo passa por uma subida rápida de temperatura, que pode ter ou não uma forte colaboração da ação do homem (Santa'Anna Neto e Nery, 2005). 


\section{Objetivos}

Este estudo tem por objetivo geral estimar a produtividade primária através da análise quantitativa de cocolitoforídeos em amostras de testemunho da Bacia de Santos desde 34 mil anos AP, buscando responder a seguinte questão:

É possível relacionar a paleoprodutividade primária, obtida através da contagem de cocolitoforídeos, com as razões de elementos maiores (Ti/Ca, $\mathrm{Fe} / \mathrm{Ca}, \mathrm{Fe} / \mathrm{K}$ e $\mathrm{Al} / \mathrm{Si}$ )?

Adicionalmente, como objetivos específicos, este estudo visou responder as questões que seguem:

- As associações de cocolitoforídeos do testemunho em estudo variaram durante os estágios isotópicos marinhos (MIS, do inglês Marine Isotope Stage) 1, 2 e 3 ?

- É possível associar as variações de nanofósseis calcários aos eventos climáticos do hemisfério norte Younger Dryas e Heinrich 1, 2 e 3 ? 


\section{3. Área de Estudos}

O testemunho GL1109, utilizado no presente estudo, foi coletado na Bacia de Santos sob as coordenadas $25^{\circ} 11,0^{\prime} \mathrm{S}$ e $44^{\circ} 43,3^{\prime} \mathrm{W}$ (Figura 1). O ponto de coleta está a $848 \mathrm{~m}$ de profundidade no talude continental ao sul da margem continental brasileira.

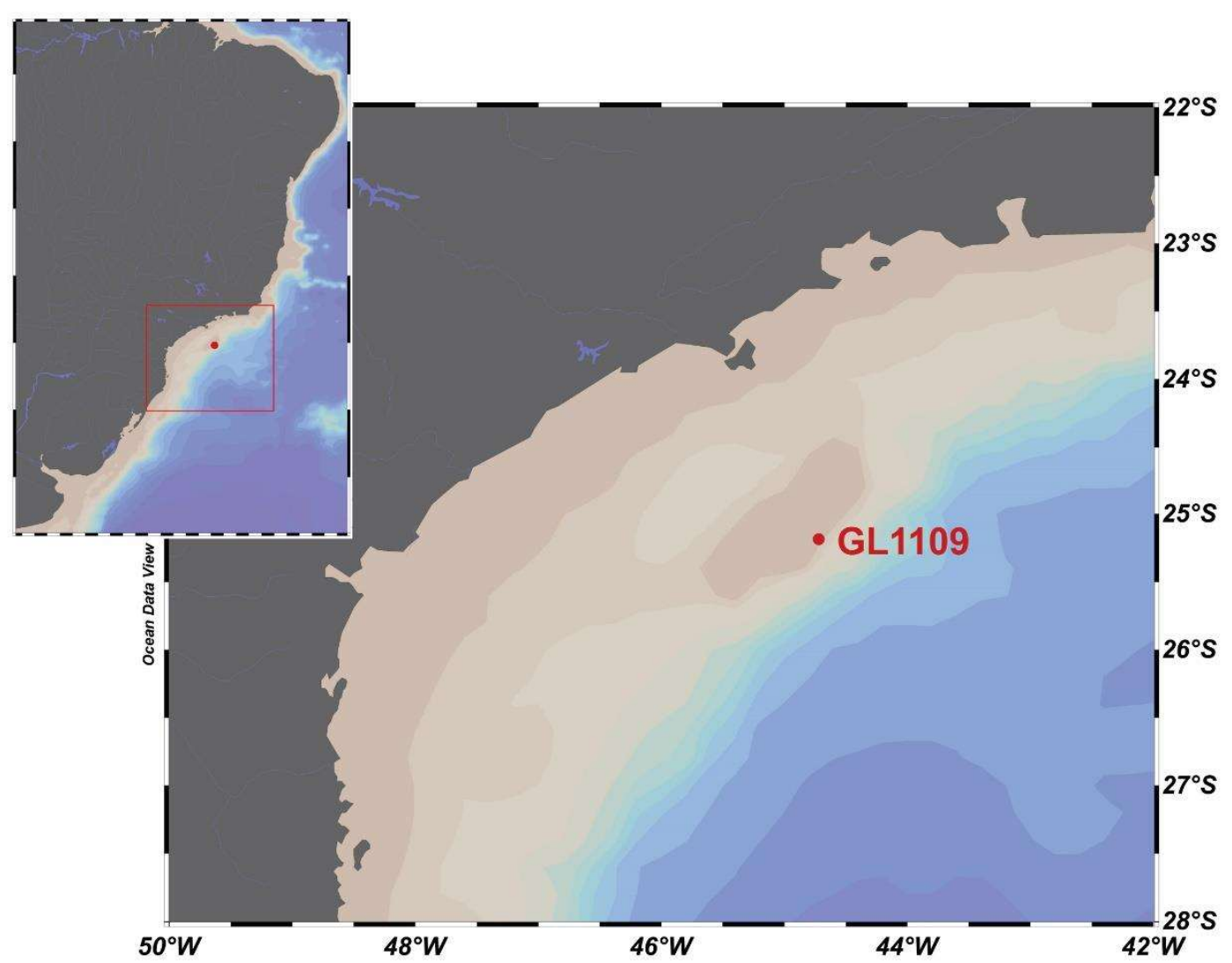

Figura 1: Localização do testemunho GL1 109 (coordenadas $25^{\circ} 11,0^{\prime} \mathrm{S}$ e $44^{\circ} 43,3^{\prime} \mathrm{W}$ ) dentro do Embaiamento São Paulo, na Bacia de Santos.

O testemunho GL1109, cedido pelo Projeto ASPECTO para este estudo, foi renomeado com a nomenclatura específica do LaPAS - Laboratório de Paleoceanografia do Atlântico Sul - para KF-19 e doravante será utilizada esta nomenclatura.

\subsection{Fisiografia}

A região de estudo do presente trabalho está situada na Margem Continental Sul brasileira. Esta margem caracteriza-se por ser do tipo passiva e estende-se desde a área ao sul do Embaiamento de Tubarão e Cadeia de Vitoria-Trindade ( $19^{\circ}$ sul e $26^{\circ}$ oeste) até além da fronteira do Uruguai $\left(38^{\circ} \mathrm{S}\right.$ e $\left.59^{\circ} \mathrm{O}\right)$.

De acordo com a descrição proposta por Zembruscki (1979), a margem é caracterizada por províncias geralmente amplas, de gradientes aproximadamente suaves. 
A largura máxima da plataforma continental, com $230 \mathrm{~km}$ de extensão, localiza-se no Embaiamento de São Paulo, pela altura de Santos. Por via de regra, a quebra da plataforma não é notória, e a borda possui configuração geral arredondada ou com estreitos terraços de abrasão marinha, em especial na porção norte.

A quebra da plataforma é definida pelo limite superior do talude. Por sua origem progradacional é normalmente convexa e suave e pode ter sido modelada pela abrasão de ondas e correntes, particularmente durante os períodos finais das regressões e os iniciais das transgressões marinhas.

De acordo com Zembruscki (1979), o talude possui largura relativamente homogênea, com frequência principal entre 120 e $150 \mathrm{~km}$, exceto algumas restrições locais como a porção mediana do Embaiamento de São Paulo que atinge $70 \mathrm{~km}$. O limite inferior encontra-se na profundidade entre 2400 e $2900 \mathrm{~m}$, salvo nas áreas próximas ao Platô de São Paulo (cerca de 2000 m) e ao extremo norte da região Sul (1600 m).

Em tese, é possível distinguir duas seções de talude, a superior e a inferior. A primeira possui maior largura, entre 20 e $30 \mathrm{~km}$, base nas cotas batimétricas entre 700 e $800 \mathrm{~m}$ e declividade entre 2 e $3^{\circ}$. A segunda seção, ao largo de Santos, se estreita para cerca de $40 \mathrm{~km}$ ou pouco menos, guardando proporcionalidade com a largura geral do talude.

O talude continental inferior é mais amplo e irregular em forma e relevo do que o superior, e nitidamente gradacional entre este e o sopé continental.

A Bacia de Santos localiza-se na costa sudeste brasileira entre os paralelos 23 e $28^{\circ}$ sul, é limitada a norte pela Bacia de Campos no Alto de Cabo Frio, e a sul pela Bacia de Pelotas na Plataforma de Florianópolis, e ocupa uma área cerca de $275.000 \mathrm{~km}^{2}$ até a linha batimétrica de 2000 m (Pereira e Feijó, 1994).

\subsection{Topografia, Clima e Vegetação}

A área de estudo encontra-se na margem continental sul brasileira dentro do Embaiamento de São Paulo. Este por sua vez está situado entre terras emersas continentais das regiões sul e sudeste do Brasil. A topografia das regiões Sul e Sudeste do Brasil caracterizam-se pelas terras do sul do Rio Grande do Sul, com elevações menores que $500 \mathrm{~m}$ acima do nível do mar ao longo de uma ampla faixa de 100 a $200 \mathrm{~km}$ ao longo da costa Atlântica, e pelas terras altas do Sul e Sudeste (entre 500 e 1200 m 
acima do nível do mar). As maiores elevações (> 1.200m acima do nível do mar) do sul do Brasil são formadas pela Serra Geral, continuando em direção nordeste através da Serra do Mar. No sudeste encontra-se ainda a Serra da Mantiqueira, outra cadeia montanhosa mais ao interior do continente (Behling, 2002) com elevações de até 2798,4 m e a Serra do Caparaó com a maior altitude da região (2892 m) (IBGE).

De acordo com Nimer (1989), o sudeste do Brasil é uma região de transição entre os climas quentes das latitudes baixas e os climas mesotérmicos de tipo temperado das latitudes médias. A zona tropical é caracterizada por duas estações, a chuvosa e a seca. Já nas latitudes médias (zonas temperadas), quatro estações são mais ou menos definidas, porém o que mais define seu clima é a variação de temperatura durante o ano. Entretanto, o caráter de transição climática da região sudeste se inclina mais para os climas tropicais do que para os temperados, apresentando como característica mais importante a presença de uma estação muito chuvosa e outra seca.

O sudeste brasileiro possuí uma notável diversificação climática devido a sua topografia muito acidentada, vasto litoral soprado pelos ventos $\mathrm{E}$ e NE quase constantemente, localiza-se sob a trajetória de frentes polares, e principalmente pela grande variação latitudinal e longitudinal deste território. A orografia desta região origina uma série de variedades climáticas, que pode ser devido à temperatura ou pela precipitação, porém o que mais distingue a região é o clima sub quente (Nimer, 1989).

Entre as regiões do Brasil o sul é a região que possuí maior uniformidade e que tem maior grau de unidade climática com domínio exclusivo e quase absoluto do clima mesotérmico do tipo temperado, caracterizado por alta umidade, sem estação seca (Nimer, 1989).

Na maioria das vezes possui invernos frios e verões quentes, contudo o norte do Paraná e nos litorais do Paraná e de Santa Catarina apresentam inverno ameno, e às superfícies elevadas do planalto possuem verão brando. Seu relevo mais regular não cria grandes interferências àquelas características impostas pelos fatores dinâmicos. Possui regime de chuvas bem distribuído para a maior parte de seu território, não apresentando regiões onde a precipitação seja excessiva ou carente (Nimer, 1989).

Quanto à vegetação, a predominância de formações florestais concorda com o caráter úmido do clima regional, assim como as distinções de composição e estrutura verificadas nessas formações com a variação das condições térmicas ao longo do seu 
território. De forma resumida, as regiões Sul e Sudeste brasileiras apresentam, de sul para norte, cinco tipos de vegetação principais associadas ao clima regional: a vegetação de campos, a floresta de Araucária (floresta ombrófila mista), a floresta ombrófila densa, a floresta semidecídua e o cerrado (Nimer, 1989; Behling, 2002 e IBGE). 


\section{Base Teórica}

\subsection{Circulação Atmosférica}

Se analisarmos a atmosfera terrestre de maneira superficial, uma das primeiras características que notaremos é que regiões tropicais são muito mais quentes que regiões polares. Isto se deve ao fato que regiões de baixa latitude recebem mais energia solar do que são capazes de emitir de volta para o espaço, enquanto regiões de alta latitude são mais eficientes em emitir aquela que recebem. Este desequilíbrio gera um gradiente de temperatura e energia potencial. Parte da energia potencial se converte em energia cinética, manifestando-se na forma de ventos. Estes são defletidos sob a influência da rotação da Terra, criando um complexo padrão geral de circulação de fluxo (Reichler, 2009)

Estes movimentos horizontais e verticais são de grande escala e caracterizam a circulação atmosférica, composta por um sistema de 3 células que se replicam para ambos hemisférios: uma célula Polar (dos polos até $60^{\circ}$ ), uma em médias latitudes nomeadas de célula de Ferrel (de 60 a 30) e uma próxima ao equador chamada de célula de Hadley (de 30 a $0^{\circ}$ ) (Figura 2$)$.

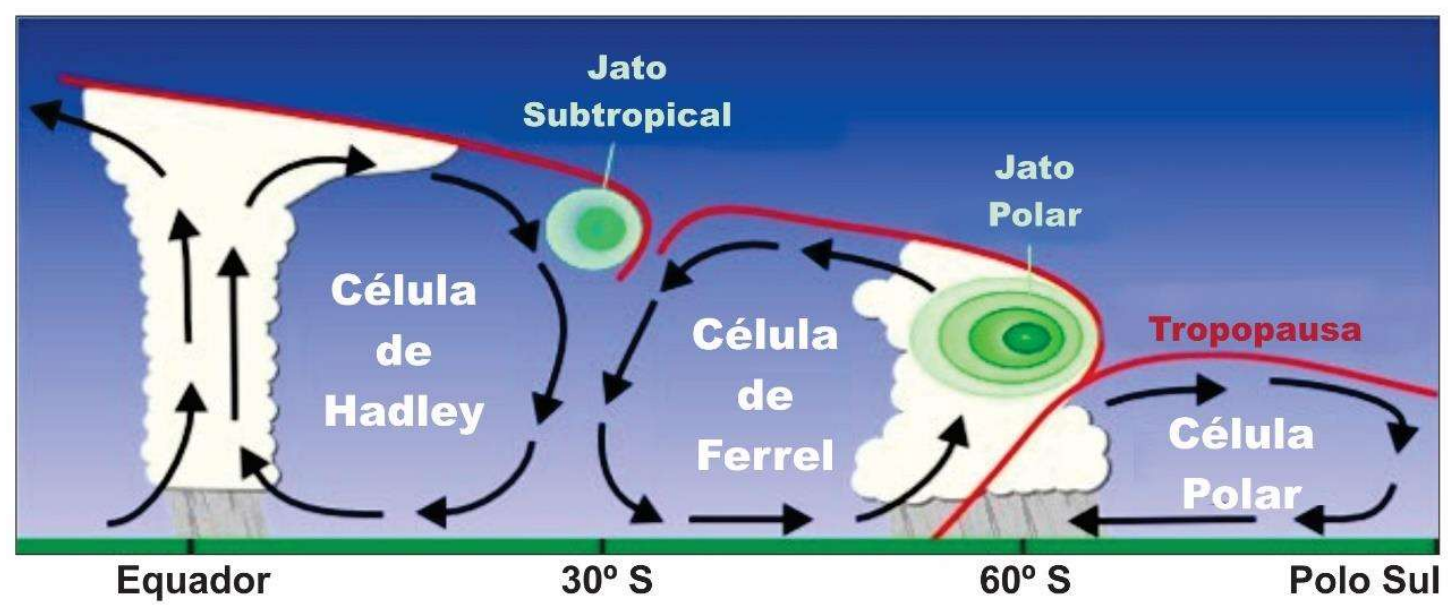

Figura 2: Representação esquemática das células de Hadley, Ferrel e Polar (setas pretas). As linhas vermelhas representam a tropopausa e os círculos verde em degrade representam correntes de jatos. FONTE: Modificado de http://www.srh.noaa.gov/jetstream//global/images/jetstream3.jpg (19/04/2018 08:23)

\section{1. 1. Zona de Convergência Intertropical (ZCIT)}

A ZCIT é o ramo ascendente da célula de Hadley e está relacionada com a baixa salinidade e a alta temperatura da superfície do mar (Waliser e Gautier, 1993 e 
Arbuszewski et al., 2013). É uma faixa permanente de baixa pressão onde os ventos alísios, associados a circulação meridional de Hadley, se convergem, carregando calor e umidade da evaporação superficial, gerando uma zona de intensa convecção, nebulosidade e pluviosidade (Waliser e Gautier, 1993; Grodsky e Carton, 2003 e Arbuszewski, 2013) (figura 3). Sobre o oceano Atlântico moderno sua posição média anual é de aproximadamente $5^{\circ} \mathrm{N}$ (Arbuszewski et al., 2013) alcançando sua posição máxima a norte em $10^{\circ} \mathrm{N}$ (agosto) e sua máxima a sul em aproximadamente $1^{\circ} \mathrm{S}$ (março) em $30^{\circ}$ de longitude oeste (Nobre e Shukla, 1996).

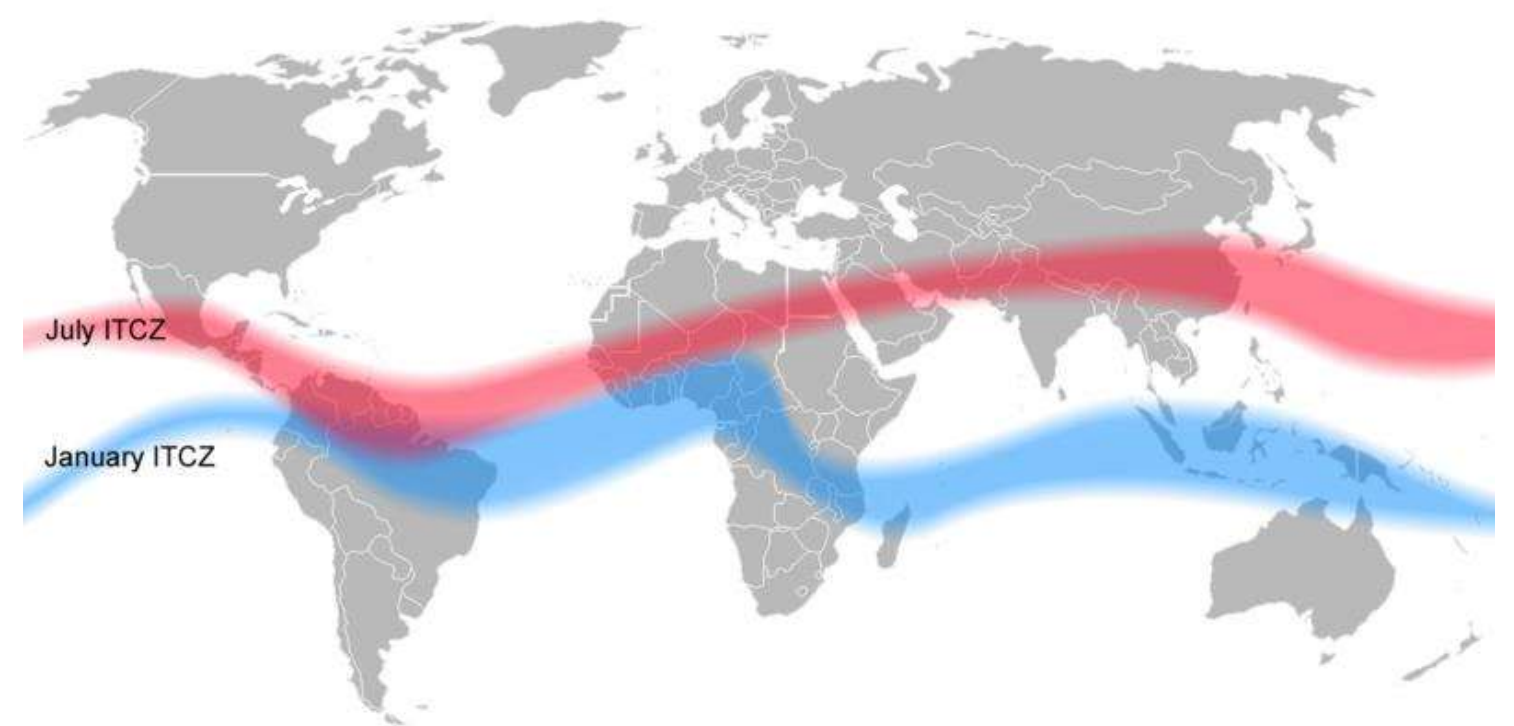

Figura 3: Representação da posição da ZCIT em julho (área em vermelho) e janeiro (área em azul). Imagem de Mats Halldin FONTE:

https://pt.wikipedia.org/wiki/Zona_de_converg\%C3\%AAncia_intertropical\#/media/File:ITCZ_january-july.png $(19 / 04 / 2018$ 09:10)

\section{1. 2. Monção de Verão da América do Sul}

Entre o fim de setembro e o começo de outubro, quando a posição da ZCIT já está se deslocando em direção a sul (Nobre e Shukla, 1996), dá-se início ao estabelecimento da Monção de Verão da América do Sul, primeiramente na Amazônia equatorial, espalhando-se rapidamente para leste e sudeste, seguida por abundantes chuvas.

O sistema monçonico se desenvolve sobre regiões continentais de baixa latitude e é uma resposta às mudanças sazonais no contraste termal entre o continente e as regiões 
oceânicas adjacentes, sendo o maior componente do regime chuvoso nas estações quentes sobre os continentes (Vera et al, 2006).

A Monção de Verão da América do Sul exibe uma circulação térmica direta, de larga escala, com ramo ascendente sobre o continente e descendente sobre oceano (Kousky e Molion, 1985 e Vera et al, 2006), interação terra-atmosfera associada com a elevação do terreno e com as condições superficiais do continente, baixa pressão superficial e um anticiclone em alto nível, intenso fluxo de umidade em baixo nível para o continente, e mudanças sazonais na precipitação (Vera et al, 2006).

Entre o fim de novembro e de fevereiro, a Monção de Verão da América do Sul está plenamente estabelecida. Neste período, uma profunda atividade convectiva está localizada sobre o centro do Brasil ligada a uma banda de nebulosidade e precipitação que se estende do sul da Amazônia ao sudeste do Brasil e ao entorno do Oceano Atlântico (Kodama, 1992). Esta banda de convecção é conhecida como Zona de Convergência do Atlântico Sul (ZCAS). Sobre a região do Chaco, em baixos níveis, é estabelecido um sistema de baixa pressão que força os ventos de leste, sobre a Bacia Amazônica, a virar para sul. Este fluxo, que possui uma estrutura de jatos de baixo nível, é então canalizado entre o sopé leste andino e o planalto brasileiro (Garreaud et al., 2008), sendo o mesmo, capaz de modular a ZCAS e a precipitação e convecção na região de saída dos jatos no sudeste da América do Sul (Marengo e Soares, 2004).

A Monção de Verão da América do Sul é influenciada principalmente por mudanças combinadas da precessão e insolação (Baker \& Fritz, 2015) e pela dinâmica da ZCIT, esta, por sua vez, é modulada pelos ventos alísios os quais também possuem uma componente precessional (Molfino \& McIntyre, 1990).

\section{1.3. Zona de Convergência Intertropical (ZCIT) no Último \\ Período Glacial}

No Oceano Atlântico, atualmente, a ZCIT varia sazonalmente e regionalmente, porém permanece a maior parte do ano sobre o Hemisfério Norte. A variabilidade interanual histórica da posição média marinha da ZCIT é da ordem de $\pm 2^{\circ}$ e está ligada a oscilações interanuais e multidecadais (Arbuszewski et al., 2013). 
Evidências paleontológicas mostram que no último período glacial e na deglaciação a posição da ZCIT no Atlântico variou significativamente, concomitante a mudanças climáticas no Atlântico Norte (Chiang et al., 2003). Os resultados do trabalho de Arbuszewski et al. (2013) mostraram que a ZCIT no Atlântico é fortemente sensível a forçantes climáticas em altas e baixas latitudes. Isto se manifesta durante a última glaciação com uma migração ao sul em resposta ao resfriamento em altas latitudes, a cobertura de gelo e ao enfraquecimento da circulação termoalina.

A temperatura no Hemisfério Norte é uma das principais forçantes climáticas responsáveis por abruptas mudanças na precipitação sobre a América do Sul tropical. A ligação entre a precipitação sobre a América do Sul tropical e a temperatura nas altas latitudes, é estabelecida, justamente, através das mudanças da posição da ZCIT, que responde às mudanças no balanço de energia entre os hemisférios (Novello et al., 2017). Assim, o deslocamento da ZCIT em direção ao sul é resposta ao resfriamento do Hemisfério Norte.

Novello et al. (2016), mostraram que seus registros de espeleotemas indicaram que o último período glacial foi mais húmido em comparação com o Holoceno inferior e médio.

\subsection{Circulação Oceânica}

O oceano é o maior reservatório de calor do sistema climático global sendo capaz de modular processos atmosféricos de escala temporal que variam de horas a milhares de anos (Chou e Nobre, 2014). Este controle exercido pelo oceano sobre o clima baseia-se fisicamente na absorção de grande parte da energia solar na região equatorial do planeta e sua redistribuição através do sistema de correntes oceânicas de superfície e profundas (Chou e Nobre, 2014).

As correntes oceânicas de escala global possuem uma estrutura tridimensional, com movimentos horizontais, cuja temperatura e os ventos exercem papel fundamental, e movimentos verticais, nos quais salinidade e temperatura são as forças impulsoras (Uriarte, 2011). Usualmente a circulação no oceano é dividida em dois tipos: uma circulação gerada por ventos que domina nas primeiras centenas de metros e uma circulação conduzida pela densidade (Toggweiler e Key, 2001). Esta última foi denominada de termoalina devido ao papel desempenhado pelo aquecimento, 
resfriamento, dessalinização e salinização em produzir diferenças regionais de densidade dentro do oceano.

A circulação termoalina é de larga escala e ocorre em "circuito fechado" no qual águas quentes (superficiais) fluem em direção aos polos, próximas a superfície, tornamse mais densas durante o percurso - devido ao resfriamento atmosférico e a expulsão do sal motivada pela formação de gelo sobre o mar - afundam, fluem (fluxos profundo e de fundo) em direção ao equador no interior do oceano e sofrem ressurgência pela atuação de ventos e marés (Toggweiler e Key, 2001 e Kuhlbrodt et al., 2007) (figura 4).

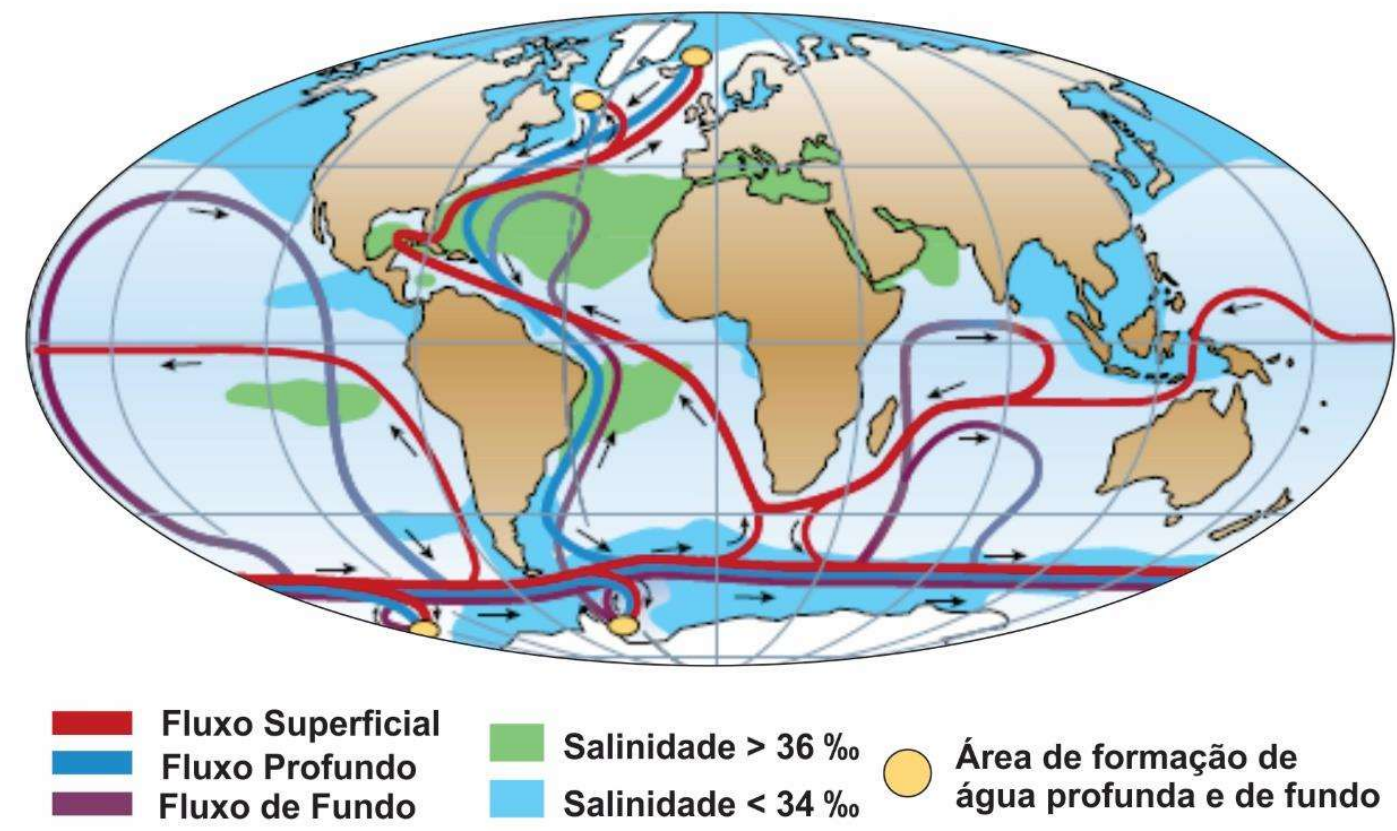

Figura 4: Representação esquemática da circulação termoalina (modificado de Rahmstorf, 2002). A faixa vermelha representa os fluxos de superfície, a azul os fluxos profundos e a vinho os fluxos de fundo. As áreas delimitadas em verde representam áreas do oceano com salinidade maiores que $36 \%$ e as em azul claro áreas com salinidade menores que 34\%. Os círculos em amarelo representam as regiões de formação de águas profundas e de fundo.

A seção atlântica da circulação termoalina é também conhecida como Circulação de Revolvimento Meridional do Atlântico (CRMA), do inglês, Atlantic Meridional Overturnig Circulation (AMOC). A CRMA possuí papel fundamental no controle do clima na região do Atlântico, através da sua alta capacidade relativa de reter calor e de transportar grande quantidade deste em direção aos polos (cerca de $\left.10^{15} \mathrm{~W}\right)($ Clark et al., 2002).

As forças propulsoras desta circulação, cujas salinidade e temperatura desempenham função crucial, são encontradas nos dois hemisférios: ao norte nos Mares Nórdicos (zona subpolar do Atlântico entre Groenlândia, Islândia e Noruega) e Mar de 
Labrador e ao sul no Mar de Wedell. Nestas regiões, as águas superficiais, provenientes de baixas latitudes, afundam devido ao aumento de densidade, causado pelo resfriamento e pela contração térmica, deixando espaço para chegada de outras águas provenientes daquelas latitudes (Uriarte, 2011). As águas formadas nestas regiões possuem assinaturas específicas (salinidade e temperatura dentre outros parâmetros) o que possibilitam sua identificação como massa d'água característica. A massa d'água formada nas duas regiões ao norte é chamada Água Profunda do Atlântico Norte (APAN) que flui em direção ao sul, e aquela formada no sul, Água Antártica de Fundo (AAF), escoa para o Norte (Toggweiler e Key, 2001).

A exportação de 15 a $20 \mathrm{~Sv}\left(1 \mathrm{~Sv}=1 \times 106 \mathrm{~m}^{3} / \mathrm{s}\right)$ de APAN através do Oceano Atlântico Sul para outras bacias oceânicas implica em uma compensação em outros níveis de um fluxo em direção ao norte no mesmo oceano (Piola et al., 2003). Para balancear esta equação, águas superficiais $(2,5 \mathrm{~Sv})$ e intermediarias $(1,6 \mathrm{~Sv})$ provenientes do Oceano Índico, trazidas pela Corrente das Agulhas, entram no Giro Subtropical do Atlântico Sul, bordejando a costa do sudoeste da África através da Corrente de Benguela, e são transportadas em direção ao equador pela Corrente Sul Equatorial (Peterson e Stramma, 1991). Além destas águas a CSE também é alimentada por águas originárias do Oceano Pacífico (6,5 Sv). Estas, passam pelo estreito de Drake e seguem em direção ao norte através da Corrente das Malvinas/Falkland sendo integradas ao Giro Subtropical do Atlântico Sul (GSAS) pela Confluência Brasil/Malvinas e a Corrente do Atlântico Sul (Piola et al., 2003) (figura 5). 


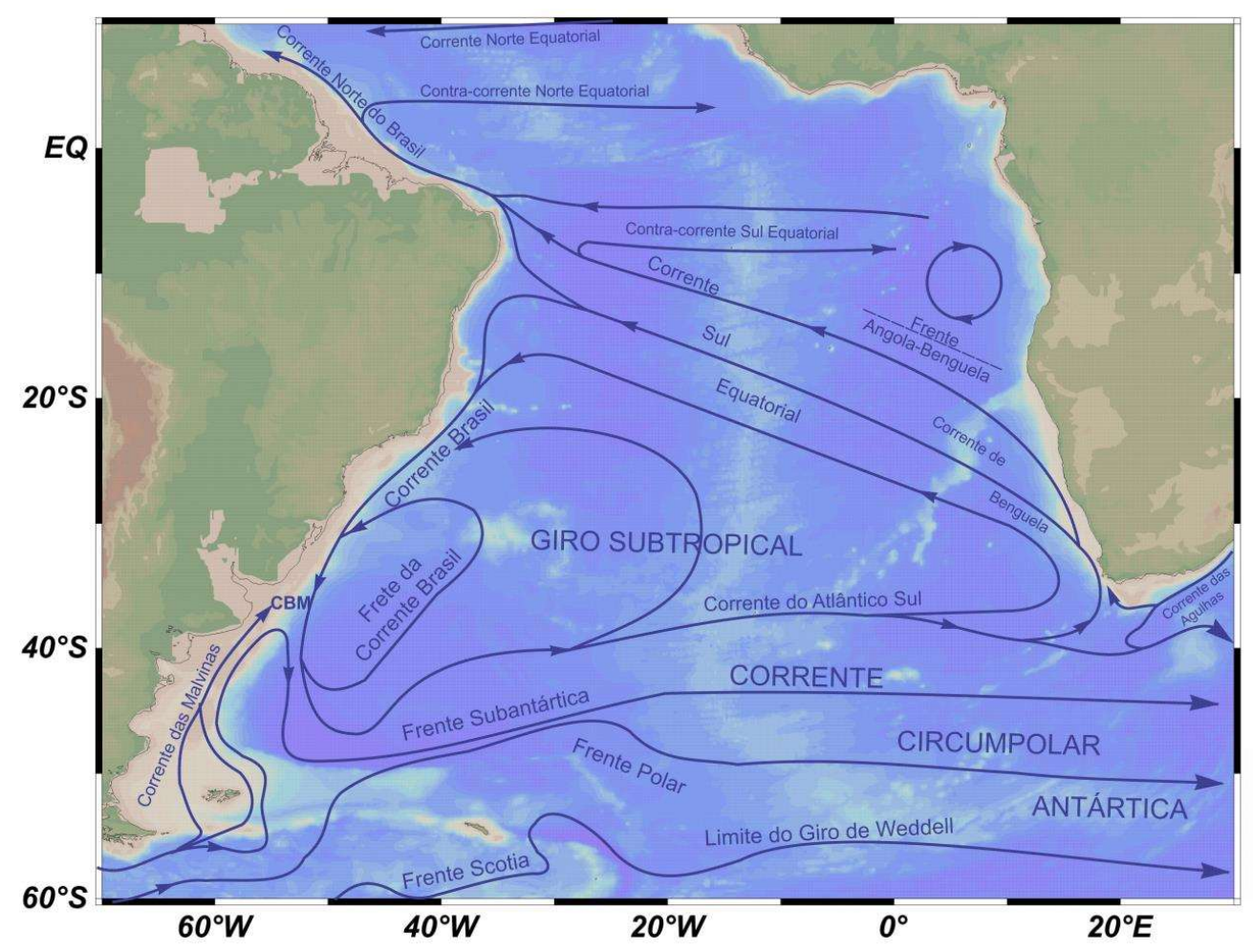

Figura 5: Esquema da circulação superficial no Atlântico Sul (modificado de Peterson e Stramma, 1991)

A Corrente Sul Equatorial flui para noroeste até um promontório no nordeste do Brasil $\left(15^{\circ} \mathrm{S}\right)$ onde se bifurca, originando a Corrente do Brasil e a Corrente Norte do Brasil (Peterson e Stramma, 1991 e Silveira et al., 2000). Ao longo do percurso há um acumulo de calor, devido à alta incidência solar, que é transportado em direção equatorial. O transporte de calor no Oceano Atlântico Sul é mais eficiente em direção ao equador do que para o polo, ao contrário do que se observa nos outros oceanos (Peterson e Stramma, 1991).

A maior parte da água transportada pela Corrente Sul Equatorial, cerca de $12 \mathrm{~Sv}$, se dirige para o noroeste formando a Corrente Norte do Brasil, e apenas 4 Sv seguirá em direção ao sul para alimentar a Corrente Brasil (Peterson \& Stramma, 1991).

A corrente preponderante na região de estudo é a Corrente do Brasil, que entre 19 e $25^{\circ} \mathrm{S}$ alcança $11 \mathrm{~Sv}$ (Miranda \& Castro Filho, 1982 e Peterson \& Stramma, 1991). A Corrente do Brasil é uma corrente de contorno oeste pertencente ao Giro Subtropical do Atlântico Sul, relativamente fraca e que transporta águas superficiais quentes para sul até encontrar o fluxo em direção ao norte da Corrente das Malvinas formando a Confluência Brasil/Malvinas na região da Convergência Subtropical (Silveira et al., 2000). 
A região na qual se insere a Corrente do Brasil é formada a partir do empilhamento de massas d'água encontradas do Atlântico Sul (figura 6). São elas: Água Tropical, Água Central do Atlântico Sul, Água Intermediária Antártica, Água Circumpolar Superior e Água Profunda do Atlântico Norte.

Na região de estudo, a cerca de $848 \mathrm{~m}$ de profundidade, atuam as três primeiras massas de água (Água Tropical, Água Central do Atlântico Sul e Água Intermediária Antártica). Estas serão apresentadas a seguir.

A massa de água mais superficial (até $100 \mathrm{~m}$ ) é a Água Tropical que é transportada para sul pela Corrente do Brasil. A Água Tropical é formada como consequência da intensa radiação e evaporação, além da mistura de águas costeiras mais frias e menos salinas, lhe conferindo temperatura maiores que $20^{\circ} \mathrm{C}$ e salinidade acima de 36 ups (Silveira et al., 2000).

De acordo com Silveira et al (2000), a Água Central do Atlântico Sul é uma massa de água que fica abaixo da Água Tropical (de 100 a 500 m) e é encontrada fluindo na região da picnoclina. Ela é formada por afundamento das águas na região da Convergência Subtropical, e subsequente espalhamento ao longo da superfície de densidade adequada a seu ajustamento hidrostático. A Água Central do Atlântico Sul entra como parte do Giro Subtropical do Atlântico Sul, circula com as Corrente do Atlântico Sul e Corrente de Beguela, e atinge a costa da América do Sul transportada pela Corrente Sul Equatorial. Como nas correntes em superfície, há bifurcação e parte da Água Central do Atlântico Sul flui rumo ao equador, enquanto outra porção toma a direção sul. Na região de estudo esta corrente flui para sul. A Água Central do Atlântico Sul possui temperatura entre 6 e $20^{\circ} \mathrm{C}$ e salinidade entre 34,6 e 36,2 ups. 
Por último, a Água Intermediária Antártica está logo abaixo da Água Central do Atlântico Sul (de 500 a 1200 m) e é uma massa de água intermediária relativamente fria, rica em oxigênio e pouco salina que possui um padrão de circulação associado à porção intermediária do GSAS e que na região de interesse flui para norte (Stramma \& England, 1999 e Silveira et al., 2000). Seus limites de temperatura e salinidade são: 3 a $6^{\circ} \mathrm{C}$ e 34,2 a 34,6 ups (Silveira et al., 2000).

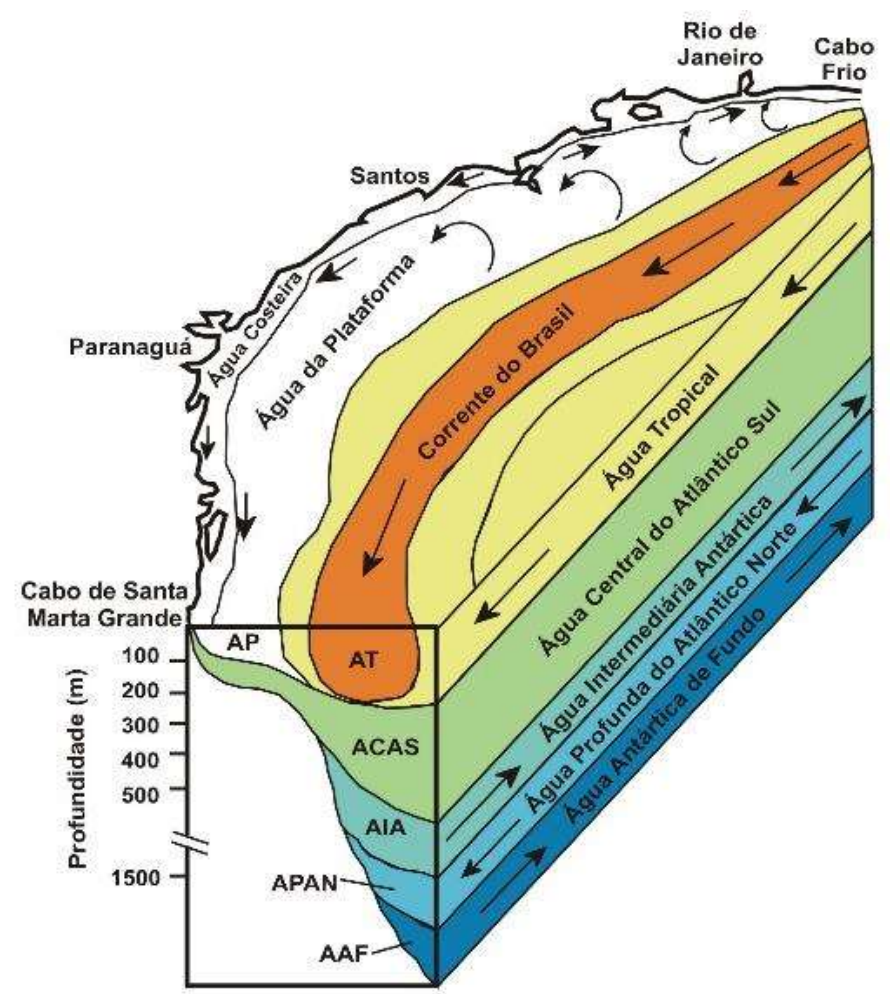

Figura 6: Ilustração esquemática em corte vertical das massas e da Corrente do Brasil que atuam ao largo da costa Sul/Sudeste do Brasil (modificado de Matsura, 1986)

\section{2. 1. Ressurgência}

A ressurgência é um processo oceanográfico através do qual águas de camadas mais profundas, frias e ricas em nutrientes são trazidas à superfície (Kampel et al., 1997). Este processo é mais intenso e comum no lado leste dos oceanos Atlântico e Pacífico (Valentin, 2001).

$\mathrm{Na}$ plataforma continental sudeste brasileira são observados eventos de ressurgência costeira ocasionada pela incidência de ventos especialmente no verão austral (Rodrigues \& Lorenzzetti, 2001) podendo ocorrer desde o Estado do Espírito Santo até o litoral Sul do Brasil (Kampel et al., 1997). No entanto, o domínio onde este evento ocorre com mais força se concentra próximo de Cabo Frio e então se espalha por uma grande 
área desde o sul da região de Campos-Abrolhos até ao norte da plataforma continental do sul do Brasil (Castro et al., 2006).

A região de Cabo Frio apresenta algumas características geomorfológicas, meteorológicas e oceanográficas que permitem a ocorrência da ressurgência. A região está sob influência do Anticiclone Subtropical do Atlântico Sul (ASAS), com predominância de ventos de leste e Nordeste. A partir de Cabo Frio ocorre a inflexão da orientação da linha de costa de Norte-Sul para Leste-Oeste. A conjunção destes dois fatores é favorável à ocorrência da ressurgência transversal à plataforma, uma vez que a camada d’água superior é transportado por Ekman ao largo e é compensada pela intrusão da ACAS em direção a costa (Valentin, 2001; Castro et al., 2006).

A presença destas águas ressurgidas na zona eufótica resulta em grande aumento de produtividade primária (Kampel et al., 1997).

\section{2. 2. Circulação Oceânica no Último Período Glacial}

O oceano é um dos principais constituintes do sistema climático e afeta o clima de múltiplas maneiras, uma vez que, por cobrir $71 \%$ da superfície terrestre, a maior parte da radiação solar recebida pela Terra vai para o oceano aquecendo sua superfície. Sua capacidade de reter calor e de circulação o torna habilitado a estocar e redistribuir calor liberando para atmosfera, principalmente na forma de vapor (calor latente) (Rahmstorf 2002). Assim, as mudanças na circulação oceânica possuem papel fundamental nas maiores mudanças climáticas pelo menos desde o último período glacial (Rahmstorf 2002; Böhm et al., 2015).

Como mencionado anteriormente, a Circulação de Revolvimento Meridional do Atlântico (CRMA) possuí papel fundamental no controle do clima (Clark et al., 2002) controlando o transporte de calor de baixas para altas latitudes e na estocagem de $\mathrm{CO}_{2}$ (Böhm et al., 2015). A CRMA, durante o Holoceno, opera em um modo vigoroso (quente) com formação de APAN nos mares nórdicos e no mar de Labrador. Esta massa de água ocupa grande fração do Atlântico em profundidades maiores que 5000 m (Rahmstorf 2002; Uriarte, 2011; Böhm et al., 2015).

Porém, no intervalo estudado pertencente ao último período glacial, a CRMA operou em dois modos: o modo "frio"e o modo "Heinrich" ou "desligado". No modo frio a formação da massa de água correspondente a atual APAN ou a então Água Glacial 
Intermediária do Atlântico Norte se dava em regiões ao sul da Islândia. Ela se aprofundava menos até profundidades próximas a $2000 \mathrm{~m}$. Como consequência, águas profundas provenientes do sul (água glacial correspondente a Água Antártica de Fundo) avançavam a maiores latitudes do Atlântico Norte. Por último, o modo "Heinrich" ocorria como resultado de pulsos catastróficos e momentâneos de descarga de água de degelo, que levava ao colapso da formação de águas profundas no Atlântico Norte durante eventos Heinrich intensos (durante o período estudado nos eventos Heinrich 1 e 2). Neste modo, águas profundas provenientes do sul preenchiam regiões da coluna de água de intermediária a profundas em altas latitudes do Atlânticos Norte (Rahmstorf, 2002; Böhm et al., 2015)(figura 7).
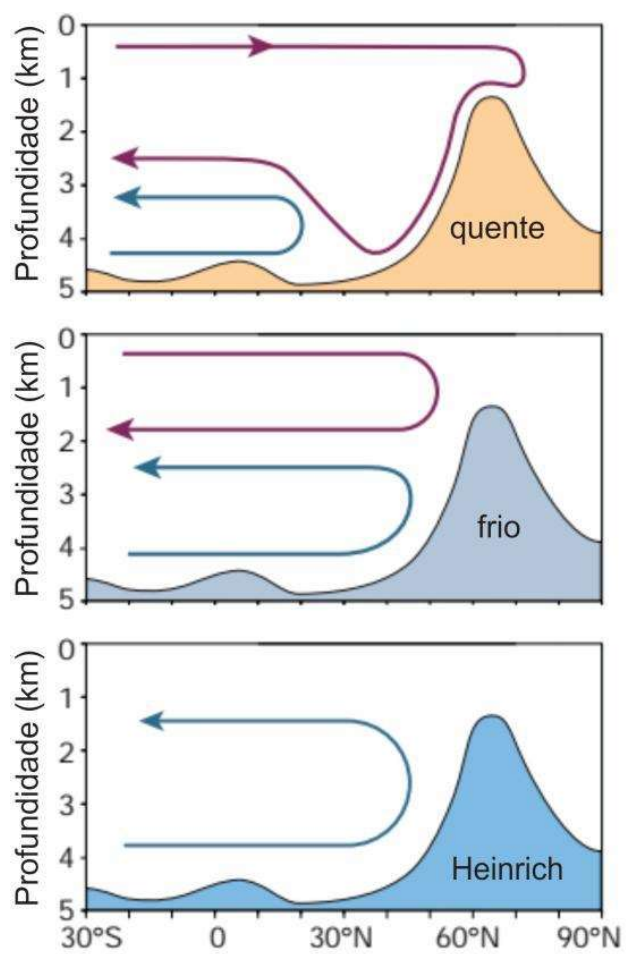

Figura 7: Esquema com os três diferentes modos de funcionamento da CRMA: quente, frio e Heinrich (desligado). As setas vinho representam a formação da APAN e as em azul a circulação da AAF (Böhm et al., 2015).

De acordo com Santos et al. (2017), o oeste do Atlântico Sul subtropical, em aproximadamente $24^{\circ} \mathrm{S}$, depois de ter experimentado temperaturas superficiais de aproximadamente $24^{\circ} \mathrm{C}$, fora de fase em relação as altas latitudes, entre $47 \mathrm{e} 45$ mil anos AP, sofreu um aumento repentino de $2^{\circ} \mathrm{C}$ depois de 45 mil anos AP e manteve-se relativamente estável até 32 mil anos AP, quando um novo e mais gradual aumento de temperatura deu início. Esta tendência de aquecimento permaneceu constante desde o final do MIS 3 até a última deglaciação, elevando a temperatura superficial do oceano em $1^{\circ} \mathrm{C}$. Na transição entre MIS 2 e 1 , há um novo aumento de $1{ }^{\circ} \mathrm{C}$ na temperatura superficial 
do oceano. Este contínuo aquecimento persistiu durante os modos "frio" e "Heinrich"(desligado) da CRMA do último período glacial no oeste do Atlântico Sul subtropical.

Com base em estudo de modelagem numérica, Clauzet et al. (2007) observaram um fortalecimento da Corrente do Brasil com intensificação e deslocamento (de 3 a $5^{\circ}$ para norte) do Giro Subtropical do Atlântico Sul durante o UMG. Os autores também notaram em seu modelo uma maior formação da correspondente glacial da Água de Fundo Antártica e consequente menor formação de águas intermediárias. Todos estes fatores ligados a uma CRMA reduzida e menos profunda, devido a menores profundidades da APAN glacial.

Mahiques et al., (2007), propôs que, em períodos de nível do mar baixo e de plataforma estreita, a CB teria se deslocado ao largo, permitindo a entrada de nutrientes e de material terrígeno. Entretanto, com o nível do mar do MIS 3 mais elevado, a CB tenderia a se aproximar da costa.

Durante períodos de CRMA reduzida, a intensificada CB teria estocado e redirecionado calor e sal do Atlântico Sul reduzindo a eficiência do transporte dos mesmos para o Atlântico Norte (Santos et al., 2017). O reservatório de águas quentes desenvolvidos no oeste do Atlântico Sul subtropical pode ter contribuído como fonte de umidade para o aumento das calotas polares na Antártica. 


\section{Produtividade Primária}

A produção primária consiste na fixação de carbono do ambiente através de atividade biológica. Quando o objetivo é medir a taxa de fixação de carbono da atividade biológica durante o tempo usa-se o termo produtividade primária. $\mathrm{O}$ que sustenta a produtividade nos oceanos é a fotossíntese realizada pelo fitoplâncton, ao passo que, todos os outros organismos, dependem, direta ou indiretamente, desta produção (Lourenço e Marques-Junior, 2002).

O fitoplâncton marinho, por meio da fotossíntese, é responsável por cerca de metade da produção primária líquida da biosfera, possuindo uma ligação vital entre a ciclagem dos estoques de carbono orgânico e inorgânico. Mais de cem milhões de toneladas de carbono na forma de $\mathrm{CO}_{2}$, por dia, são fixados em material orgânico por estas algas microscópicas na zona fótica dos oceanos e, a cada dia, uma quantidade similar de carbono é transferido para o ecossistema marinho via afundamento e pastagem (Behrenfeld et al., 2006).

O Atlântico Sudoeste é dominado pela Água Tropical na maior parte da zona eufótica das áreas oceânicas, possuindo boa disponibilidade de luz, porém é pobre em nutrientes, essencial para a proliferação do fitoplâncton. A principal fonte de nutrientes nesta região se encontra abaixo da termoclina, nos domínios da Água Central Atlântico Sul. Esta massa d'água é rica em nutrientes, entretanto, ocupa normalmente posição inferior na coluna d'água, onde a radiação solar é insuficiente para promover a produtividade primária. Caso movimentos ascendentes rompam a termoclina, a produtividade na zona eufótica aumenta.

A ressurgência é um processo capaz de enriquecer em nutrientes regenerados das camadas mais profundas para a zona fótica, podendo desta forma promover o aumento do potencial trófico local. Além da ressurgência costeira, núcleos com elevadas concentrações de nutrientes, provenientes da Água Central do Atlântico Sul, estão associados a formação de vórtices ciclônicos, os quais também são capazes de romper a estabilidade da termoclina. Em vários locais ao longo da região Sul-Sudeste (figura 8), estes processos ocorrem através da quebra da plataforma e possibilitam um aumento na produção fitoplanctônica e nos demais níveis da camada trófica (Braga e Niencheski, 2006 e Gaeta e Brandini, 2006). 
Muitas regiões próximas a costa apresentam uma maior disponibilidade de nutrientes provenientes do continente devido, por exemplo, a descarga de rios. A entrada de águas provenientes de drenagens continentais e de estuários nos sistemas costeiros contribui para a diminuição da salinidade e a alteração na composição química da água, promovendo alterações na constância das proporções entre os elementos maiores da água do mar e causando um enriquecimento em nutrientes, sobretudo silicato, que caracteriza esses aportes (Braga e Niencheski, 2006). Estes nutrientes favorecem a proliferação abundante do plâncton.

Os aportes continentais na plataforma continental sul-sudeste brasileiras são muito fortes na região da desembocadura da Lagoa dos Patos e também, de um modo geral, na porção sul do litoral do Estado do Rio Grande do Sul, devido à influência da descarga do Rio da Prata. Próximo à Baía de Paranaguá, ao sistema Cananéia-Iguape, os aportes continentais mostram sua influência sobretudo no período de verão, correspondente ao período de chuvas. A figura 8 simplifica os principais fenômenos da costa sul-sudeste (Braga e Niencheski, 2006).

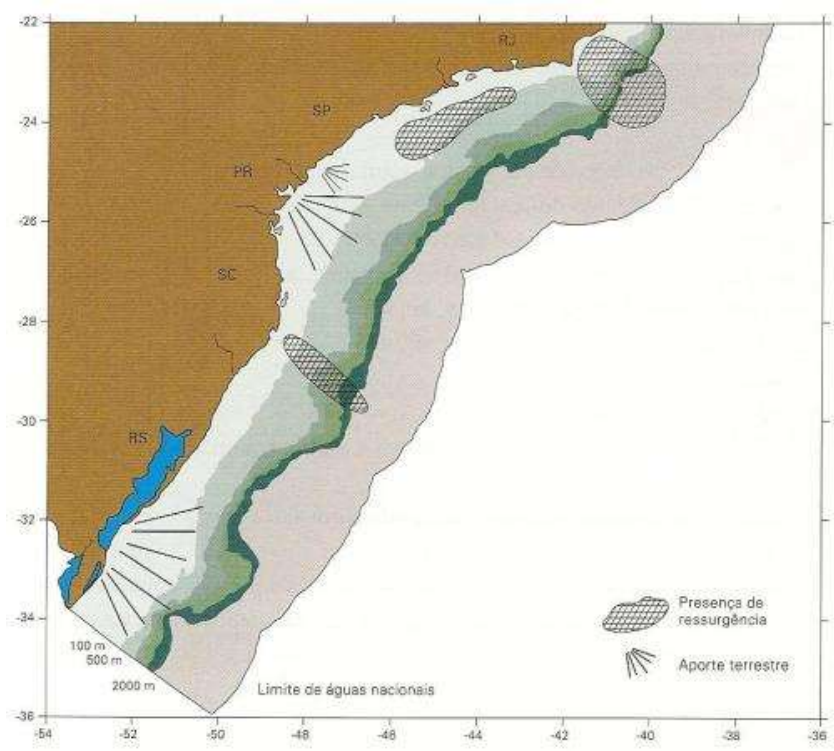

Figura 8: Principais fenômenos da costa Sul-Sudeste (Braga e Niencheski, 2006). Em hachurado estão representadas as áreas de ocorrência de ressurgência e as linhas paralelo/radiais áreas de aporte de sedimento terrígenos. 


\section{Materiais e Métodos}

O testemunho de sedimento marinho KF-19 foi coletado por um testemunhador a pistão (piston corer) na Bacia de Santos sob as coordenadas $25^{\circ} 11,0^{\prime} \mathrm{S}$ e $44^{\circ} 43,3^{\prime} \mathrm{W}$ a uma profundidade de $848 \mathrm{~m}$ no talude continental ao sul da margem continental brasileira. Foram recuperados $1367 \mathrm{~cm}$ de sedimento, com ausência de distúrbios, que permitiu uma abordagem com alta resolução temporal até aproximadamente 80.000 anos. No atual estudo, porém, foram utilizadas 130 amostras do intervalo compreendido entre o topo do testemunho e a profundidade de $847 \mathrm{~cm}$ o qual abrangem o Holoceno e parte do Último Período Glacial e estão dentro dos Estágios Isotópicos Marinhos 1, 2 e parte do 3. As amostragens foram realizadas a cada intervalo aproximado de $6,5 \mathrm{~cm}$ do referido testemunho.

Este testemunho faz parte de um projeto IODP/CAPES-BRASIL n ${ }^{0} 38 / 2014$, intitulado: "Projeto ASPECTO - Assimetria na Distribuição de Energia Entre as Correntes de Contorno Oeste do Atlântico Sul durante os Últimos 130ka e seu Impacto Sobre o Clima da América do Sul", uma parceria entre USP-UFF. Deste modo algumas análises (cronologia, elementos maiores, densidade gama, isótopos e teor de carbono) foram previamente efetuadas e os dados estão intercambiáveis entre os pesquisadores do projeto.

\subsection{Cronologia}

Como o testemunho KF-19 está inserido dentro de um outro projeto, como mencionado anteriormente, foi estabelecido uma cronologia para o intervalo de 1 a 967 $\mathrm{cm}$. Para este propósito foram realizadas datações radiocarbônicas MAS (Accelerator Mass Spectrometry) ${ }^{14} \mathrm{C}$ em testas de foraminíferos planctônicos no Laboratório BETA Analytic (Miami, EUA).

Foram selecionadas 19 amostras do testemunho KF-19 para produzir um detalhado modelo de idade. As amostras foram escolhidas de acordo com a disponibilidades de foraminífero planctônicos, pois em muitas amostras a quantidade de espécimes era muito pequena e não alcançavam a massa mínima de 10 mg necessária para a análise.

Através de lupa estereoscópica binocular foram separadas testas de Globigerinoides ruber (white e pink) da fração $>150 \mu \mathrm{m}$. Nas amostras cujo o número total de espécimes de Globigerinoides ruber (white e pink) não alcançaram a massa 
necessária, foram adicionados exemplares de Globigerinoides sacculifer até que atingissem o peso ideal. Se ainda assim o número de exemplares total das duas espécies não fossem suficiente, a espécie Globorotalia truncatulinoides foi adicionada a amostra até que esta estivesse completa.

Feitas as datações por AMS, as idades foram então calibradas fazendo-se uso da curva de calibração Marine13 (Reimer et al., 2013) e o software Calib7 (Stuiver e Reimer, 1993) e o modelo de idade resultou da interpolação linear destes resultados considerandose as taxas de sedimentação constante entre intervalos datados.

\subsection{Análise de Elementos Maiores por Fluorescência de Raio-X (XRF)}

A análise de Elementos Maiores foi realizada por XRF Core Scanner, um aparelho que realiza medidas rápidas e determina a composição química dos sedimentos de maneira não destrutiva, podendo ser realizada tanto a bordo de um navio bem como em laboratório. Foram identificados na composição do sedimento os seguintes elementos: Al, Si, Ca, Ti e Fe.

A análise foi realizada a cada $0,5 \mathrm{~cm}$ para todo o testemunho KF-19, entretanto foram utilizados apenas os resultados correspondentes às amostras das profundidades utilizadas neste estudo.

Os resultados obtidos a partir desta análise são parâmetros semi-quantitativos expressos em contagem por área por segundo (cps), diferentes do método utilizado por Govin et al. (2012) expresso em g/kg. A forma mais usual de empregar os elementos maiores em estudos de reconstrução paleoclimática é a utilização de suas razões, pois desta forma se minimiza o efeito de diluição (Govin et al., 2012). As razões mais comuns são: $\mathrm{Fe} / \mathrm{Ca}$ e Ti/Ca (indicativo de variações no aporte de terrígenos e da produtividade marinha), Al/Si (grau de intemperismo químico) (Govin et al., 2012) e Fe/K (proximidade da área fonte) (Mahiques et al., 2017).

\subsection{Teor de Carbonato}

Como nas análises anteriores, o resultado do teor de carbonato também foi obtido no âmbito do Projeto ASPECTO para o testemunho estudado. A análise foi realizada em todas as amostras coletadas e o espaçamento entre elas foi de aproximadamente $2 \mathrm{~cm}$. A análise de teor de carbonato foi realizada em amostra total com ataque de $\mathrm{HCl}$ diluído a 
10\%. A diferença entre os pesos secos do antes e depois do ataque ácido, equivalem a quantidade de $\mathrm{CaCO}_{3}$.

\subsection{Isótopos Estáveis de Oxigênio}

Foram realizadas análises de isótopos estáveis de oxigênio em foraminíferos bentônicos para todo o intervalo do período estudado do testemunho KF-19. Estes foram utilizados para o cálculo do nível do mar.

Para as medidas de isótopos estáveis de oxigênio em foraminíferos bentônicos o equipamento utilizado foi o espectrômetro de massa Finnigan MAT252 equipado com o sistema Kiel III do Laboratório de Micropaleontologia do Instituto Oceanográfico de Woods Hole. As análises foram realizadas em testas de Cibicidoides pachyderma e C. sp em 96 amostras do intervalo estudado.

\subsection{Nível do Mar}

As estimativas de variação do nível do mar são de grande importância em estudos paleoambientais (Waelbroeck et al., 2002), uma vez que mudanças de aproximadamente $130 \mathrm{~m}$, associado primariamente com o aumento e a diminuição das calotas de gelo sobre os continentes nos ciclos de 100 mil anos, são observados nos ciclos glacial e interglacial (Spratt e Lisiecki., 2016).

Para estimar a variação, em metros, do nível relativo do mar na área de estudo, foram utilizadas as equações propostas por Waelbroeck et al. (2002) para o Oceano Atlântico. Os autores sugerem que é possível estabelecer regressão robusta entre o nível do mar e as razões de isótopos de oxigênio em foraminíferos bentônicos através do último ciclo climático com erro resultante menor que $+/-13 \mathrm{~m}$.

Duas fórmulas foram propostas, uma para amostras do glacial e outra do deglacial :

Nível do Mar $(m)($ glacial $)=-21,18 \cdot x^{2}-23,24 \cdot x$

Nível do Mar $(\mathrm{m})($ deglacial $)=23,92 \cdot \mathrm{x}^{2}-108,63 \cdot \mathrm{x}$

Onde, 
$\mathrm{x}=\Delta \delta^{18} \mathrm{O}_{\mathrm{b}}-\Delta \delta^{18} \mathrm{O}_{\mathrm{b}(\text { atual })}$

$\Delta \delta^{18} \mathrm{O}_{\mathrm{b}}=$ razão de isótopos de oxigênio em foraminíferos bentônicos; e

$\Delta \delta^{18} \mathrm{O}_{\mathrm{b}(\text { atual })}=$ razão de isótopos de oxigênio em foraminíferos bentônicos na amostra mais atual. No caso do testemunho KF-19 o valor de $\Delta \delta^{18} \mathrm{O}_{\mathrm{b} \text { (atual) }}$ foi de $2,198 \%$ o (VPDB).

\subsection{Preparação das Amostras para Análise Quantitativa de Nanofóssil Calcário}

Para realizar a análise quantitativa de nanofóssil calcário foram preparadas, para cada uma das 130 amostras do intervalo de 1 a 847 cm do testemunho KF-19, lâminas para observação ao microscópio petrográfico.

Esta etapa do estudo é fundamental, pois a escolha da técnica de montagem de lâminas micropaleontológicas para observação de nanofóssil poderá influenciar no tempo gasto, na identificação e contagem das espécies, e nas informações que poderão ou não ser obtidas pela observação ao microscópio. Dito isto, para a confecção das lâminas foi utilizada a técnica de Decantação Aleatória desenvolvida por Flores e Sierro (1997). A proposta deste método é produzir lâminas cuja flora de nanofóssil calcário esteja distribuída homogeneamente sobre elas, permitir uma padronização e produção em série de lâminas de diversas amostras ao mesmo tempo. Este método fornece lâminas mais homogêneas o que resulta em menor tempo de contagem.

Inicialmente, foi subamostrado $0,100 \mathrm{~g}$ de sedimento total, previamente seco e pesado em balança analítica, de cada uma das 130 amostras. Estas alíquotas foram transferidas para tubos Falcon identificados e acrescidas de $5 \mathrm{ml}$ de água tamponada. A seguir cada conjunto tubo/suspensão foi energicamente agitado e posteriormente submetido a ultrassom por $20 \mathrm{~s}$ para que o sedimento desagregasse totalmente.

Com o auxílio de uma micropipeta, $0,2 \mathrm{ml}$ da solução da porção média do tubo foi transferida para uma placa de Petri (identificada) de área conhecida com uma lamínula de microscopia em seu interior e previamente preenchido de água tamponada. A solução dentro da placa sofreu então sucessivas sucções e reinjeções (fazendo-se uso da micropipeta) até que a mesma se tornasse homogênea. 
Após 24 horas de repouso, quando todo sedimento se depositou sobre o fundo da placa e da lamínula, a água restante é retirada por capilaridade através do uso de tiras de papel absorvente e o conjunto é então levado à estufa $\left(60^{\circ} \mathrm{C}\right)$ para evaporação total da mesma.

Passado o tempo necessário para total secagem, o conjunto placa/lamínula é levado à chapa aquecedora $\left(\sim 90^{\circ} \mathrm{C}\right)$. As lamínulas são retiradas das placas de Petri e são fixas sobre lâminas de microscopia, devidamente identificadas, com balsamo do Canadá. Por fim, a lâmina micropaleontológica é levada à estufa $\left(60^{\circ} \mathrm{C}\right)$ até secagem completa do balsamo, quando está pronta para ser utilizada junto ao microscópio petrográfico.

\subsection{Análise Qualitativa de Nanofóssil Calcário}

A preservação dos nanofósseis calcários é um aspecto muito importante em estudos paleoceanográficos que fazem uso deste grupo, pois fatores como dissolução e recristalização podem alterar o sinal destes microfósseis no sedimento. O critério utilizado neste estudo para este tipo de avaliação foi a escala qualitativa proposta por Roth \& Thierstein (1972) e Flores \& Marino (2002). Esta escala possui quatro categorias de preservação. A avaliação da amostra observada através do microscópio petrográfico confere a mesma uma das categorias de preservação, que são:

- (0) ESTÉRIL - não há registro de cocólitos;

- (1) POBRE - indica dissolução, fragmentação severa e/ou recristalização, que impossibilitam a identificação em nível de espécie;

- (2) MODERADA - Indica que houve alguma alteração morfológica, ocasionadas pelos fatores citados na categoria anterior, mas que não impossibilitam a identificação em nível de espécie; e

- (3) BOA - Indica que não houve modificação morfológica observável ao microscópio petrográfico.

\subsection{Análise Quantitativa de Nanofóssil Calcário}

Uma vez que as progressivas mudanças da composição da flora de cocolitoforídeos ao longo do tempo são resposta bióticas às mudanças ambientais (Matsuoka e Okada, 1989), a análise quantitativa da nanoflora calcária ganha importância como método útil em estudos paleoceanográficos e paleoclimáticos. 
A análise quantitativa permite observar as variações na abundância das espécies de nanofósseis calcários ao longo do tempo, bem como sua taxa de evolução. Através da análise dos dados quantitativos das espécies é possível reconhecer assembleias características que são determinadas pela variação percentual relativa entre as espécies de uma amostra (Toledo, 2000). Assim, o conhecimento da composição das assembleias de nanofóssil calcário é um importante instrumento nos estudos de reconstrução paleoclimáticas e paleoceanográficas, bem como na identificação de mudanças ecológicas que influenciam a distribuição de determinadas espécies (Buccianti \& Esposito, 2004). A importância das investigações quantitativas para o detalhamento bioestratigráfico e paleoceanográfico, e de como estes estudos podem auxiliar na identificação de diferentes ambientes, está muito bem descrito por Matsuoka e Okada (1989).

Para a identificação e a quantificação das espécies foi utilizado um Microscópio Petrográfico Zeiss modelo Imager.A2 com magnificação de 1600 vezes.

A estratégia de quantificação envolveu a contagem de no mínimo 300 cocólitos. Roth (1994) verificou que a contagem de 300 espécimes por amostra, são suficientes pois permitem detectar mesmo aqueles taxa cuja abundância relativa seja da ordem de apenas 1 a $2 \%$ da associação total, considerando um intervalo de confiança de 90 a $95 \%$.

A apuração do número de espécimes se deu por campos de observação aleatórios do aparelho de microscopia. Cada campo de observação foi contado até que se esgotassem os espécimes presentes. Além de cocólitos, espículas de ascídias e cistos de dinoflagelados carbonáticos também foram contados.

A espécie Florisphaera profunda foi contabilizada separadamente da contagem de 300 cocólitos nos campos de observação contabilizados, pois esta apresenta em regiões do oceano tropical abundâncias muito altas durante todo o Quaternário. Desta forma pretende-se fazer um estudo mais detalhado do significado paleoambiental das espécies menos expressivas, que poderiam ser disfarçadas pela presença numerosa de $F$. profunda (Okada, 1992; Tokutake, 2005).

Alguns táxons de um mesmo gênero foram contabilizados conjuntamente por três motivos: espécies de um mesmo gênero que apresentaram abundância muito reduzida; gêneros nos quais houveram dúvidas na identificação ao nível de espécie; gênero no qual uma das espécies apresentou abundância muito maior que as outras 
durante todo o intervalo estudado. A seguir seguem as espécies cuja as contagens foram unidas:

- Calciosolenia spp.: C. murrayi e C. brasiliensis

- Coccolithus spp.: C. pelagicus e C. pelagicus braarudii

- Coronosphaera spp.: C. binodata e C. mediterranea

- Gephyrocapsa spp.: G. oceanica, G. muellerae e G. ericsonii

- Helicosphaera spp.: H. carteri, H. hyalina, H. wallichii e H. pavimentum

- Pontosphaera spp.: P. syracusana, P. multipora P. messineaee P. japonica

- Rhabdosphaera spp.: R. clavigera e R. stylifera

- Syracosphaera spp.: S. hystrica, S. pulchra e S. lamina

- Thoracosphaera spp.: T. saxea e T. heimii

- Umbellosphaera spp.: U. irregulares e U. tenuis

- Umbilicosphaera spp.: U. sibogae, U. foliosa, U. jafari e U. hulburtiana

\subsection{Análise Estatística Multivariada}

Em muitos estudos de paleoecologia e paleoceanografia são utilizadas análises estatísticas multivariadas para ajudar interpretar uma grande massa de informações. Os procedimentos desenvolvidos por estas técnicas permitem a análise dos dados através da combinação das inúmeras variáveis (Brown, 1998).

\subsubsection{Análise Fatorial}

A Análise Fatorial (modo-Q com rotação Varimax) (Giraudeau, 1992; Toledo et al., 1999 e Toledo, 2000) é uma técnica estatística multivariada utilizada para analisar a relação entre um grande número de variáveis e explicá-las em termos de suas dimensões comuns, denominadas de fatores. A Análise Fatorial é um modo de condensar as informações contidas nas variáveis originais em um conjunto menor de dimensões com mínima perda de informação (Hirama et al., 2010).

Neste estudo as variáveis são as abundâncias relativas das espécies de nanofósseis calcários, a concentração de elementos maiores e os valores de produtividade primaria, os quais variam ao longo do tempo (amostras). A planilha com estas variáveis constitui um conjunto de dados multivariados a partir do qual, através de procedimentos estatísticos, é determinada matriz de correlação (ou covariância) que é a forma de dar entrada as técnicas de estatística multivariada (Kucera \& Malmgren, 1998). 
A Análise Fatorial foi realizada através do programa computacional StatSoft STATISTICA 8 e IBM SPSS Statistics 19 para Windows.

\subsubsection{Análise de Agrupamento}

A Análise de Agrupamento (método Ward com coeficiente de Pearson) (Parker e Arnold, 1999) é uma técnica estatística multivariada empregada na procura de semelhanças entre objetos (amostras) (modo Q) ou entre descritores (espécies) (modo R) (Valentin., 2000) definindo-as em grupos que considerem, respectivamente, todas as variáveis (espécies) observadas em cada amostra ou todas as amostras nas quais foram registradas as abundâncias específicas (Parker e Arnold., 1999).

A Análise de Agrupamento foi realizada através do programa computacional StatSoft STATISTICA 8 para Windows.

\subsection{Análise Espectral}

A análise espectral é uma importante ferramenta em pesquisas climáticas, pois ela possibilita separar as variações de uma serie temporal em contribuições associadas com diferentes escalas de tempo. Isto ajuda a compreender melhor os processos físicos que geraram a variabilidade registrada em uma serie temporal (Schulz e Mudelsee, 2002).

Para identificar frequências significantes no sinal da produtividade primária (obtida através da equação da paleoprodutividade primaria que será abordada a diante), foi realizada a análise espectral a partir do software Past 3.05 (Hammer et al., 2001). O periodograma foi calculado através do método "REDFIT" (Schulz e Mudelsee, 2002). Esta técnica remove tendências em dados espaçados desigualmente (Schulz e Mudelsee, 2002). As demais configurações seguiram aquelas utilizadas por Costa et al.(2016).

\subsection{1. Índices Paleoceanográficos}

\section{11. 1. Razão Nutriclina}

A Razão Nutriclina foi um índice proposto por Flores et al. (2000) e que é utilizado como indicador da profundidade da nutriclina/termoclina. Este índice se baseia na relação entre espécies de cocolitoforídeos que habitam a zona fótica superior $(E$. huxleyi e espécies do gênero Gephyrocapsa) e aquelas que ocupam a zona fótica inferior (F. profunda): 
$\mathrm{RN}=(\%$ E.huxleyi $+\%$ GephyrocapsaTotal $) /(\%$ E.huxleyi $+\%$ Gephyrocapsa Total $+\%$ F.profunda)

Onde, RN é a razão nutriclina, \%E.huxleyi é o percentual de E. huxleyi, \%GephyrocapsaTotal é o percentual correspondente às espécies do genêro Gephyrocapsa e $\% F$.profunda o percentual de $F$. profunda.

A razão nutriclina varia de 0 a 1 . Os valores próximos a 1, com maior proporção de espécies que habitam a zona fótica superior, são interpretados como indicação de alta produtividade relacionados a uma nutriclina mais rasa e intensificação dos processos de mistura. Valores próximos a 0, com maior abundância de espécies que ocupam a zona fótica inferior, sinalizam baixa produtividade superficial, relativos a uma nutriclina profunda e processos de misturas menos intensos.

\section{11.2. Equação Produtividade Primária ou Paleoprodutividade Primária(PP)}

Reconstruir a variação da produtividade primária é um requisito importante para estimar os efeitos da bomba biológica do oceano sobre a concentração de $\mathrm{CO}_{2}$ atmosférico através do tempo. A reconstrução da paleoprodutividade pode prover informações a respeito da dinâmica climática, uma vez que a produção primária em muitas áreas oceânicas está intimamente relacionada com o cisalhamento do vento (Beauford et al., 1997), bem como, regulada por processos físicos da circulação do oceano, da dinâmica da camada de mistura, ressurgência, da deposição de poeira atmosférica e pelo ciclo solar (Behrenfeld et al., 2006).

Desta forma, Beauford et al. (1997) propôs a equação da PP que se baseia na abundância relativa de $F$. profunda. Esta espécie é adaptada a viver preferencialmente nas maiores profundidades da zona fótica marinha onde há escassez de luminosidade e menores temperaturas, contudo em uma profundidade com grande disponibilidade de nutrientes, próximo à termoclina/nutriclina. Assim, uma termoclina/nutriclina profunda implica em maior abundância de $F$. profunda em relação aos demais cocolitoforídeos (Okada e McIntyre, 1979) ao passo que a situação inversa (uma termoclina/nutriclina mais rasa), que ocorre em eventos de instabilidade oceânica, promove o aumento da 
disponibilidade de nutrientes na zona fótica superior e consequentemente da abundância dos organismos característicos da mesma.

Vários autores propõem que a variação da abundância de $F$. profunda, bem como a variação das outras espécies de cocolitoforídeos ao longo do tempo possa ser um confiável registro da produtividade oceânica (Okada e McIntyre, 1979; Molfino e McIntyre, 1990; Baumann et al., 2005).

Em estudo realizado por Beaufort et al. (1997 e 1999) no oceano Índico, foi observado que a distribuição da abundância relativa de $F$. profunta se correlacionava muito bem com a produtividade primária de modo que os autores propuseram a equação a seguir:

$$
\mathrm{PP}\left(\mathrm{gC} / \mathrm{m}^{2} / \mathrm{ano}\right)=617-\left[279 \times \log _{10}(\% \text { F. profunda }+3)\right]
$$

Henriksson (2000) testou a aplicabilidade da equação no Oceano Atlântico Equatorial comparando valores conhecidos de produtividade primária e os resultados obtidos através da abundância relativa de $F$. profunda. O autor encontrou boa correlação entre os valores e sugeriu que a equação de Beaufort et al. (1997) possa ser usada em estudo de paleoprodutividade em baixas latitudes do Oceano Atlântico.

Do mesmo modo, Quadros et al. (2007), em estudo realizado no Nordeste do Brasil, testou a correlação entre os valores obtidos através da equação da PP e o índice de nutrientes proposto por Herrle (2003) e Herrle et al. (2003) e encontrou uma ótima correlação entre estes indicadores.

Assim, no presente estudo a paleoprodutividade foi calculada a partir da equação da PP. 


\section{RESULTADOS}

\subsection{Modelo de Idade}

O modelo de idade do testemunho KF-19 foi estabelecido a partir de 19 datações radiocarbônicas AMS ${ }^{14} \mathrm{C}$ (Tabela 1) que cobrem cerca de 45 mil anos. A figura 9 mostra o modelo de idade e a taxa de sedimentação do testemunho estudado.

As amostras utilizadas neste estudo compreenderam os estágios isotópicos marinhos (MIS, do inglês Marine Isotopic Stage) 1, 2 e 3 até a idade de aproximadamente 34,6 mil anos AP.

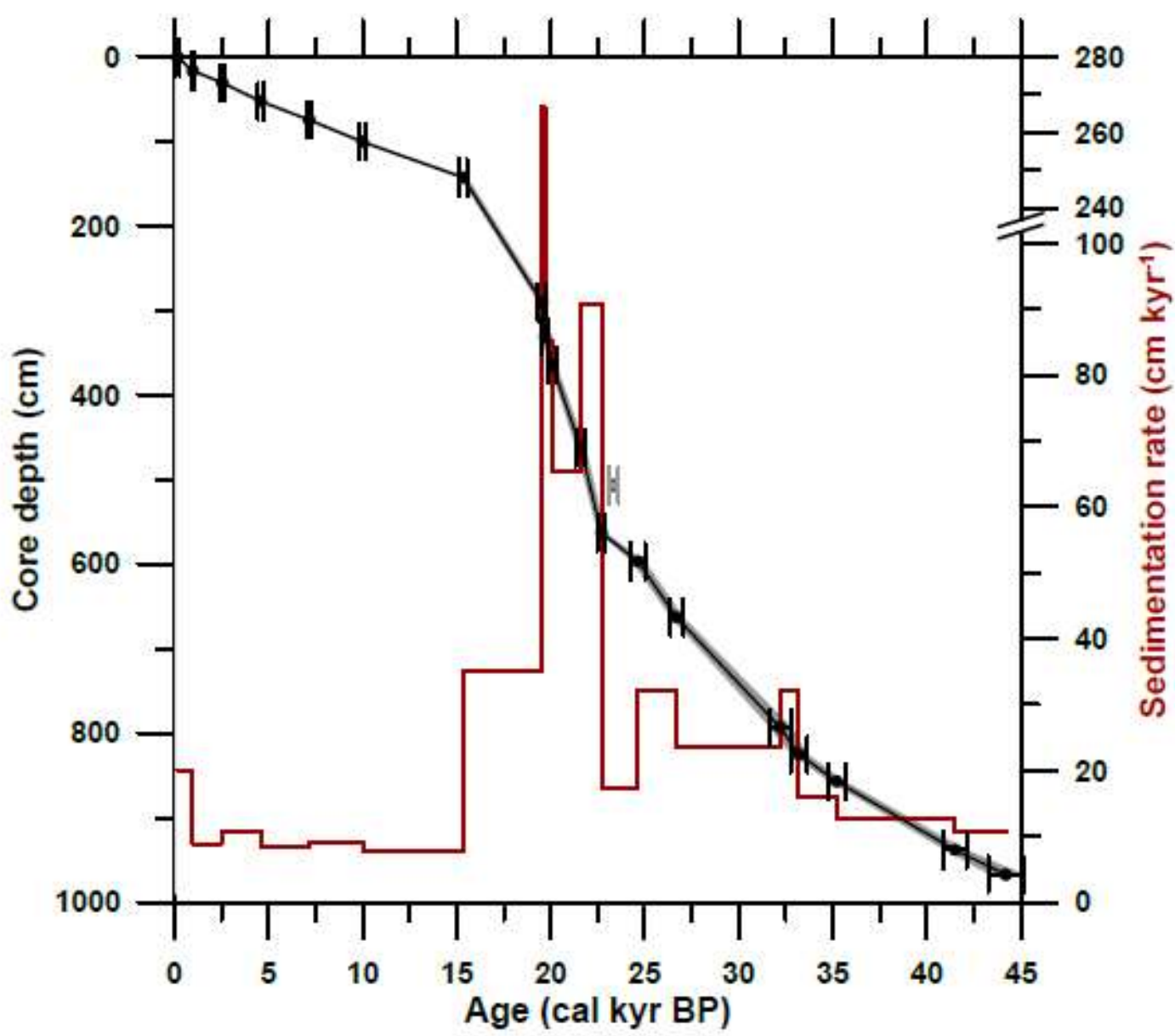

Figura 9: Modelo de idade e taxa de sedimentação para o testemunho KF-19. A curva vermelha representa a taxa de sedimentação (cm/ kano) e a curva preta o modelo de idade (kano antes do presente) com barras de erro com incerteza de 2 sigma para cada datação.

A maior taxa de sedimentação $(\sim 266 \mathrm{~cm} / \mathrm{kano})$ do testemunho aconteceu no intervalo entre 19,5 a 19,7 mil anos, porém o intervalo entre 15 e 22,7 mil anos possuíram uma taxa de sedimentação muito elevada. Mahiques et al. (2007) e Lourenço et al. (2016), em testemunho coletado próximo a região de coleta do testemunho KF-19, também encontraram taxas de sedimentação elevadas dentro do mesmo intervalo. 
Tabela 1: Dados da datação de radiocarbono para o testemunho KF-19 com erro, calibração 2 sigma, a variedade de $G$. ruber (pink ou white).

\begin{tabular}{|c|c|c|c|c|c|}
\hline $\begin{array}{c}\text { Amostra } \\
(\mathrm{cm})\end{array}$ & $\begin{array}{c}\text { Idade }{ }^{14} \mathrm{C} \\
\text { (anos) }\end{array}$ & $\begin{array}{c}\text { Erro } \\
\text { (anos) }\end{array}$ & Calibração 2 sigma & Espécies & Observações \\
\hline 1 & 120 & 30 & Cal BP 260 to 85 & G. ruber (w) & \\
\hline 17 & 970 & 30 & Cal BP 1010 to 905 & G. ruber (w) & \\
\hline 31 & 2360 & 30 & Cal BP 2670 to 2425 & G. ruber $(w)$ & \\
\hline 53 & 3980 & 30 & Cal BP 4685 to 4505 & G. ruber (w) & \\
\hline 75 & 6200 & 30 & Cal BP 7230 to 7125 & G. ruber (w) & \\
\hline 101 & 8790 & 30 & Cal BP 10130 to 9895 & G. ruber (w) & \\
\hline 143 & 12840 & 50 & Cal BP 15445 to 15180 & $*$ & \\
\hline 291 & 16170 & 60 & Cal BP 19655 to 19430 & $*$ & \\
\hline 331 & 16310 & 60 & Cal BP 19835 to 19540 & $*$ & \\
\hline 365 & 16690 & 50 & Cal BP 20225 to 20010 & G. ruber $(w+p)$ & \\
\hline 463 & 17810 & 80 & Cal BP 21810 to 21365 & $*$ & \\
\hline 507 & 19420 & 70 & Cal BP 23570 to 23205 & $*$ & Reversão de idade \\
\hline 563 & 18820 & 60 & Cal BP 22830 to 22520 & $*$ & \\
\hline 597 & 20470 & 80 & Cal BP 24920 to 24395 & $*$ & \\
\hline 663 & 22350 & 80 & Cal BP 26940 to 26450 & $*$ & \\
\hline 793 & 28300 & 140 & Cal BP 32720 to 31670 & G. ruber $(w+p)$ & \\
\hline 825 & 28970 & 150 & Cal BP 33560 to 32820 & G. ruber $(w)$ & \\
\hline 857 & 31280 & 190 & Cal BP 35575 to 34800 & G. ruber $(w)$ & \\
\hline 938 & 36950 & 330 & Cal BP 41990 to 40980 & G. ruber (w) & \\
\hline 967 & 40730 & 500 & Cal BP 45135 to 43325 & G. ruber (w) & \\
\hline
\end{tabular}

* G. ruber $(w+p), G$. saculifer e G. bulloides

\subsection{Elementos Maiores}

Nos estudos de reconstrução de paleoclima os elementos maiores são utilizados por meio de razões, pois desta forma evitam-se os efeitos de diluição (Weltje e Tjallingii, 2008).

A razão logarítmica de $\mathrm{Fe} / \mathrm{Ca}$ e Ti/Ca (figura 10) seguem uma tendência muito parecida no testemunho KF-19. De 34,575 a 21,864 mil anos AP se observa uma pequena tendência de aumento seguida de um período de estabilidade até 15,633 mil anos AP. Uma leve queda é notada entre 15,633 e 11,274 mil anos AP, período a partir do qual é sucedido por uma acentuada queda até 8 mil anos AP. Deste ponto até o topo do testemunho, uma nova tendência de aumento é registrada. 


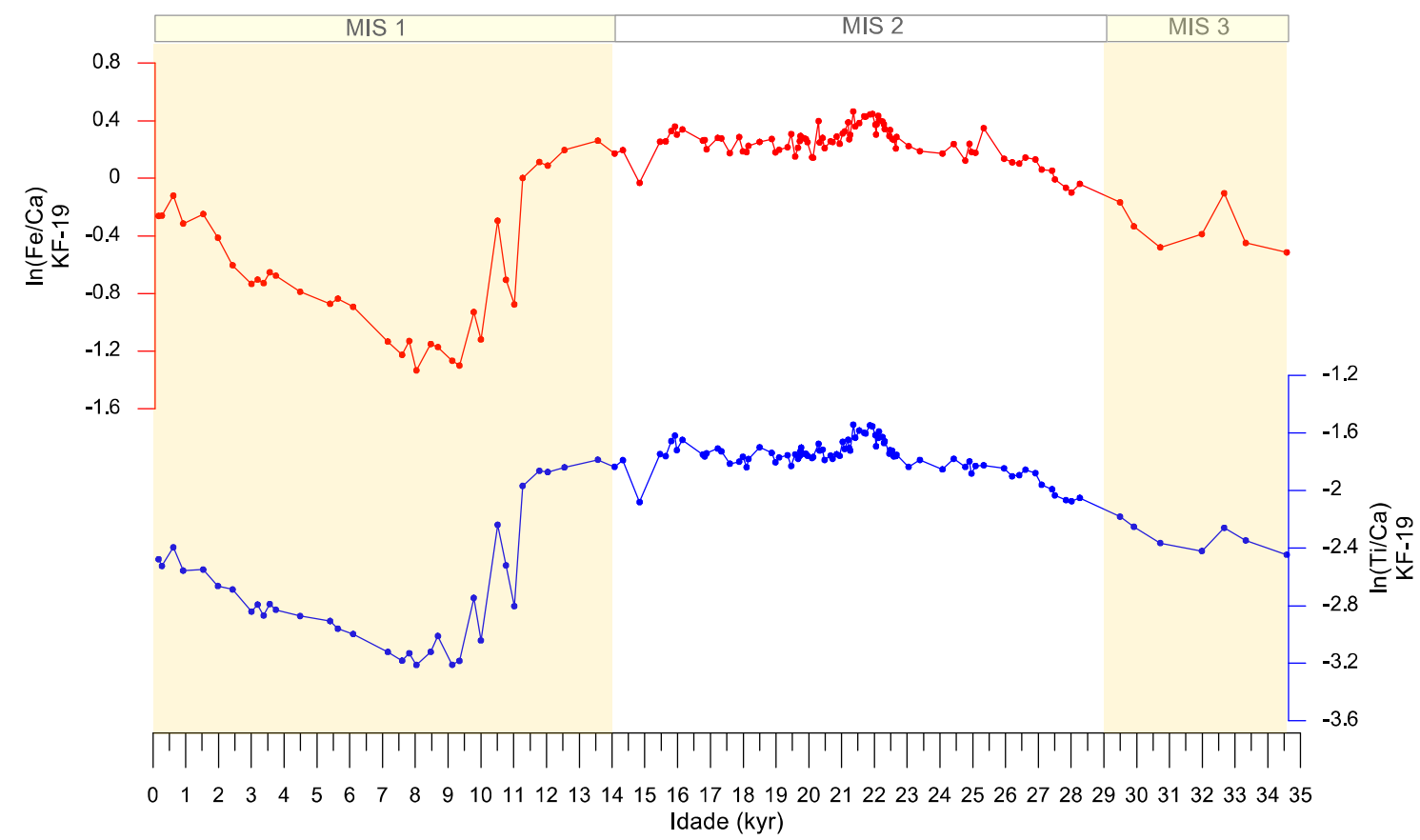

Figura 10: Gráfico das razões logarítmicas de Fe/Ca e Ti/Ca do testemunho KF-19 com as faixas de estágios isotópicos marinho 1,2 e 3 .

A razão logarítmica $\mathrm{Al} / \mathrm{Si}$ (figura 11) apresentou uma tendência a queda durante o MIS 3 e 2. O intervalo compreendido entre 14 e 11 mil anos é caracterizado por uma acentuada queda para $\mathrm{Al} / \mathrm{Si}$. Em seguida, ocorre uma proeminente tendência de aumento até o topo do testemunho.

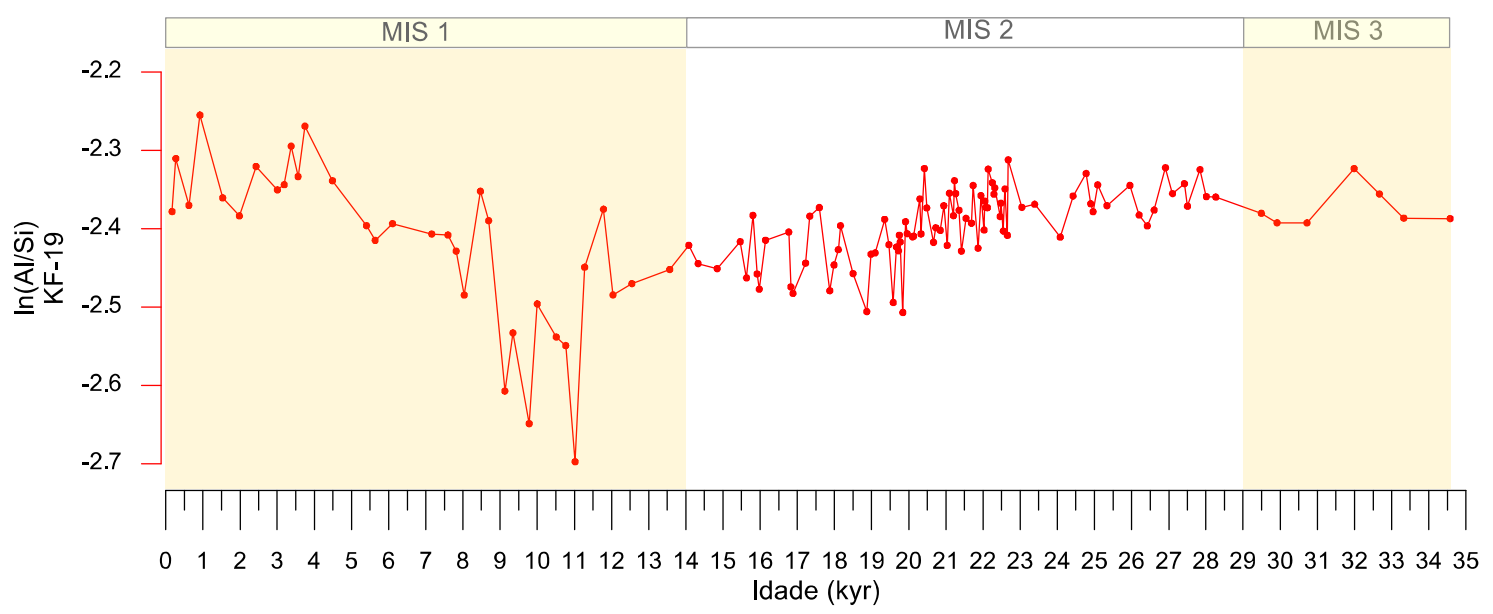

Figura 11: Gráfico da razão logarítmica de Al/Si do testemunho KF-19 com as faixas de estágios isotópicos marinho 1,2 e 3 .

A razão logarítmica Fe/K (figura 12) apresentou aumento da base do testemunho até a idade de 32,668 mil anos seguido por queda abrupta até 30,719 mil anos e por novo aumento até 29,492 mil anos. Um longo período de estabilidade é observado até 11,273 mil anos o qual é sucedido por uma acentuada caída até 9,344 mil anos, sendo precedido por um aumento gradual até o topo do testemunho. 


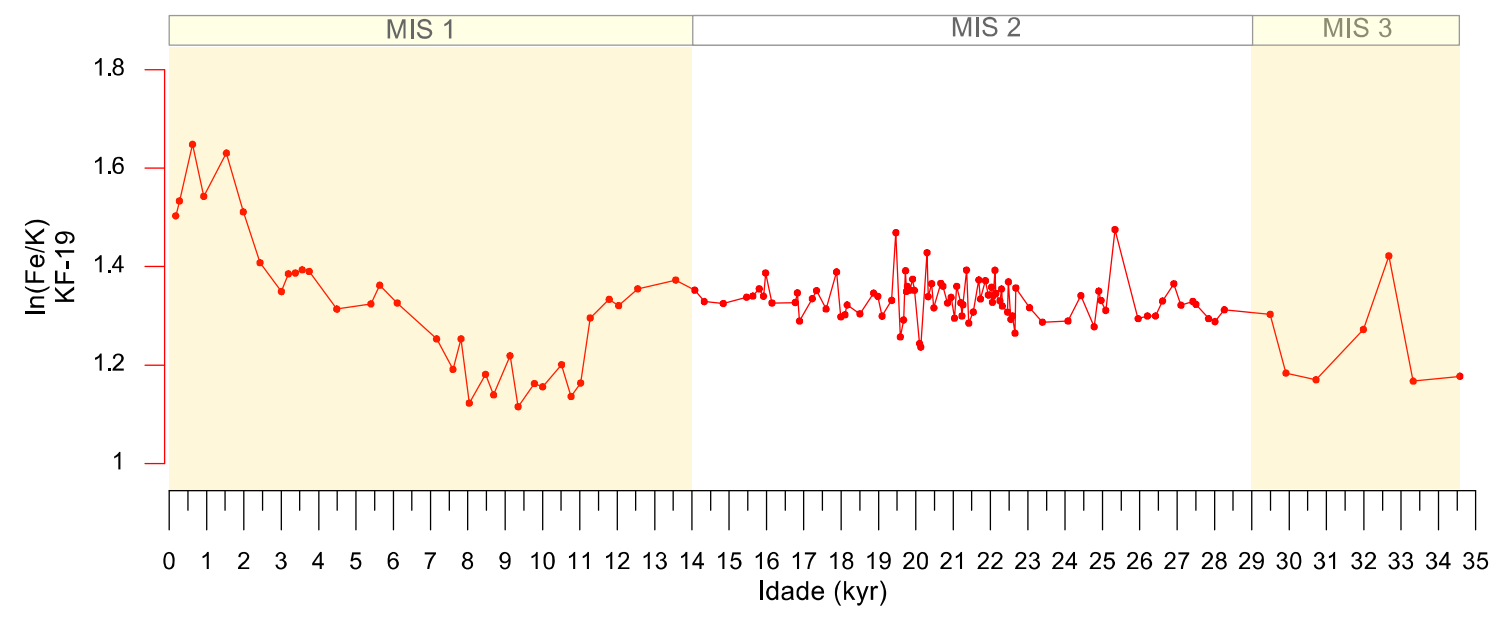

Figura 12: Gráfico das razões logarítmicas de Fe/K do testemunho KF-19 com as faixas de estágios isotópicos marinho 1,2 e 3.

\subsection{Teor de Carbonato de Cálcio ( $\left.\mathrm{CaCO}_{3}\right)$}

O teor de $\mathrm{CaCO}_{3}$ (figura 13), nas amostras do testemunho KF-19, variou aproximadamente entre 8 e 18,6\% na porção correspondente ao período glacial com uma tendência de queda da base do testemunho até o fim do último período glacial, quando foi observado um forte aumento na percentagem que variaram de 9,17 a $24,77 \%$ no Holoceno.

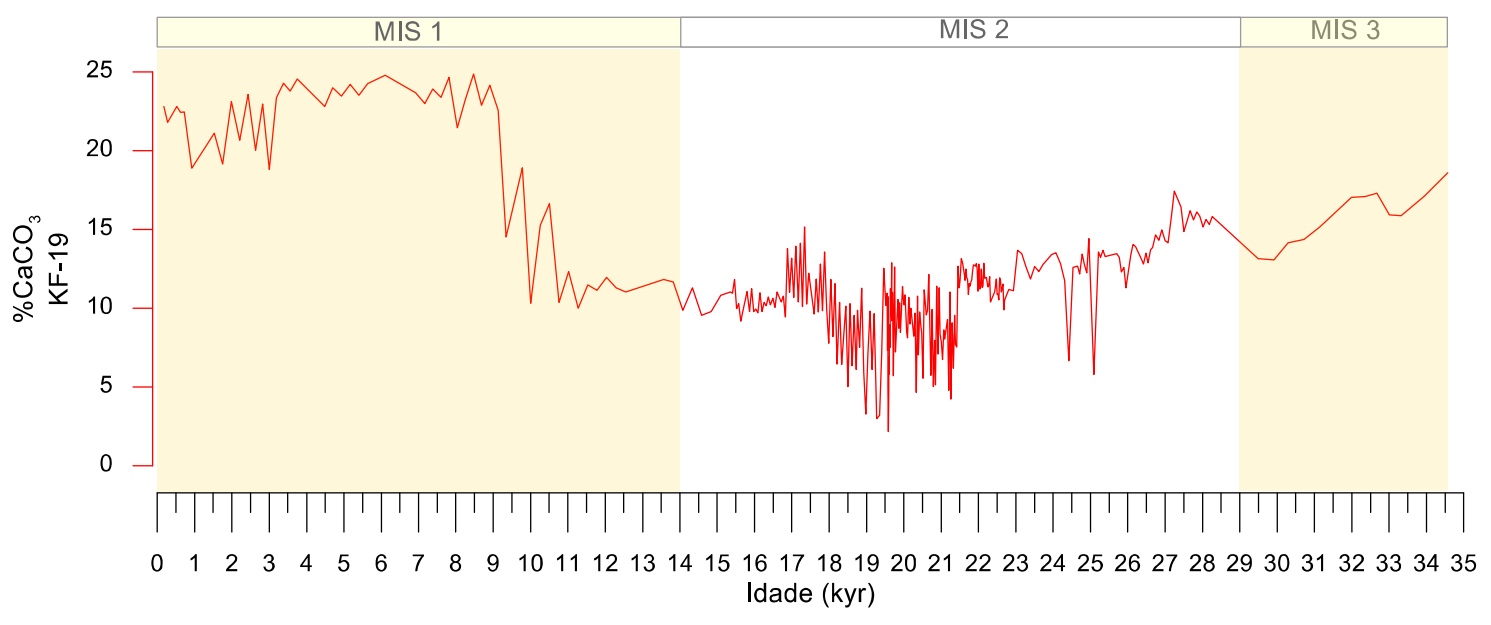

Figura 13: Gráfico da percentagem de carbonato de cálcio do testemunho KF-19 com as faixas de estágios isotópicos marinho 1,2 e 3.

\subsection{Isótopos Estáveis de Oxigênio}

O resultado das 96 medições de isótopos de oxigênio em foraminíferos bentônicos são apresentados na figura 14. Os maiores valores são observados nas amostras correspondentes aos estágios isotópicos marinhos 2 e 3 e variarão entre 4,07 e 3,04\% (VPDB). No estágio isotópico marinho 1 os valores oscilaram entre 3,52 e 2,07\%o (VPDB). 


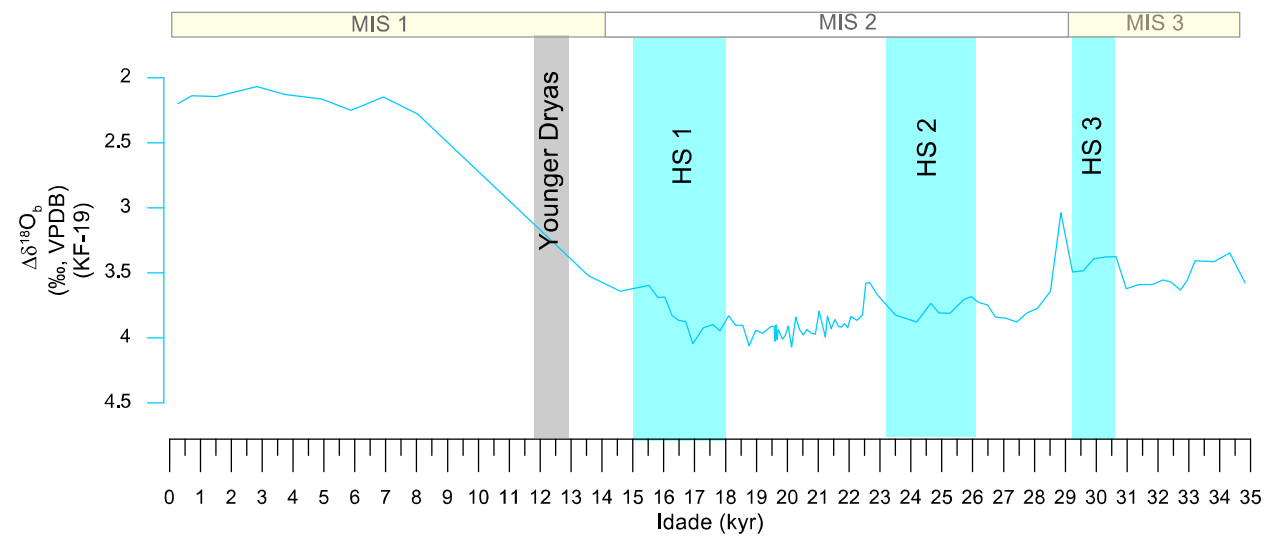

Figura 14: Gráfico da razão isotópica de oxigênio em foraminíferos bentônicos (\%o, VPDB). Estão representados os intervalos isotópicos marinhos 1, 2 e 3 e os eventos Younger Dryas (faixa cinza) e Heinrich 1, 2 e 3 (faixas azuis) (Salgueiro et al.,2014).

\subsection{Nível do Mar}

A estimativa da curva do nível relativo do mar obtida através das fórmulas propostas por Waelbroeck et al., (2002) está representada na figura 15. Os valores sugerem que o menor nível do mar foi alcançado em aproximadamente 20 mil anos AP com uma profundidade de $\sim 118 \mathrm{~m}$ abaixo da atual e o maior em $\sim 3$ mil anos AP atingindo $\sim 15 \mathrm{~m}$ acima do atual.

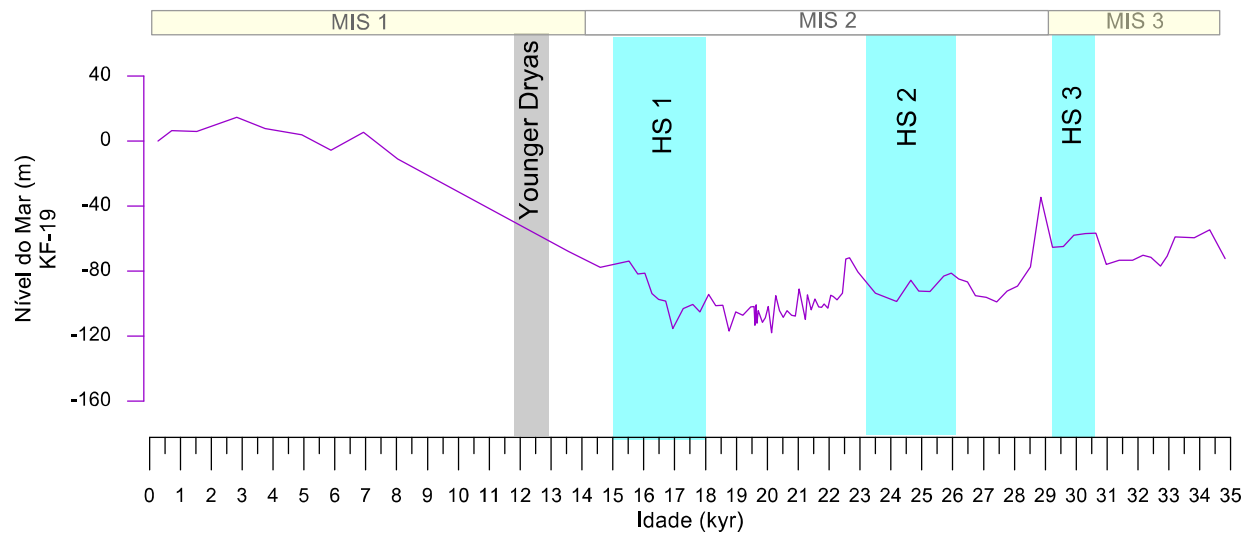

Figura 15: Gráfico do nível do mar (m) do testemunho KF-19. Estão representados os intervalos isotópicos marinhos 1, 2 e 3 e os eventos Younger Dryas (faixa cinza) e Heinrich 1, 2 e 3 (faixas azuis) (Salgueiro et al.,2014). 


\subsection{Nanofósseis Calcários}

A análise qualitativa de nanofósseis calcários realizada nas amostras do testemunho KF-19, mostrou que as mesmas apresentaram categorias de preservação entre 2 (Moderada) e 3 (boa). Entre as 130 amostras analisadas, apenas 5 foram classificadas como MODERADA e as 125 restantes BOA, condição que possibilitou a realização confiável da análise quantitativa em todo período estudado.

A análise quantitativa no testemunho KF-19 mostrou a dominância de três entidades taxonômicas, sendo elas: Emiliania huxleyi, Florisphaera profunda $e$ Gephyrocapsa spp.. A somatória de suas abundancias relativas variou entre 85 e $97 \%$ em todas as amostras. Umbellosphaera spp., Umbilicosphaera spp., Syracosphaera spp. e espículas de ascidias alcançaram abundancia relativa máximas entre 3 e 7\%. Os outros táxons não atingiram, individualmente, $3 \%$ de abundância relativa máxima, sendo frequentemente menores que $1 \%$.

Os resultados das variações relativas das entidades taxonômicas mais relevantes estão descritos a seguir. A figura 16 apresenta a variação relativa dos táxons dominantes (Gephyrocapsa spp., F. profunda e E. huxleyi). 


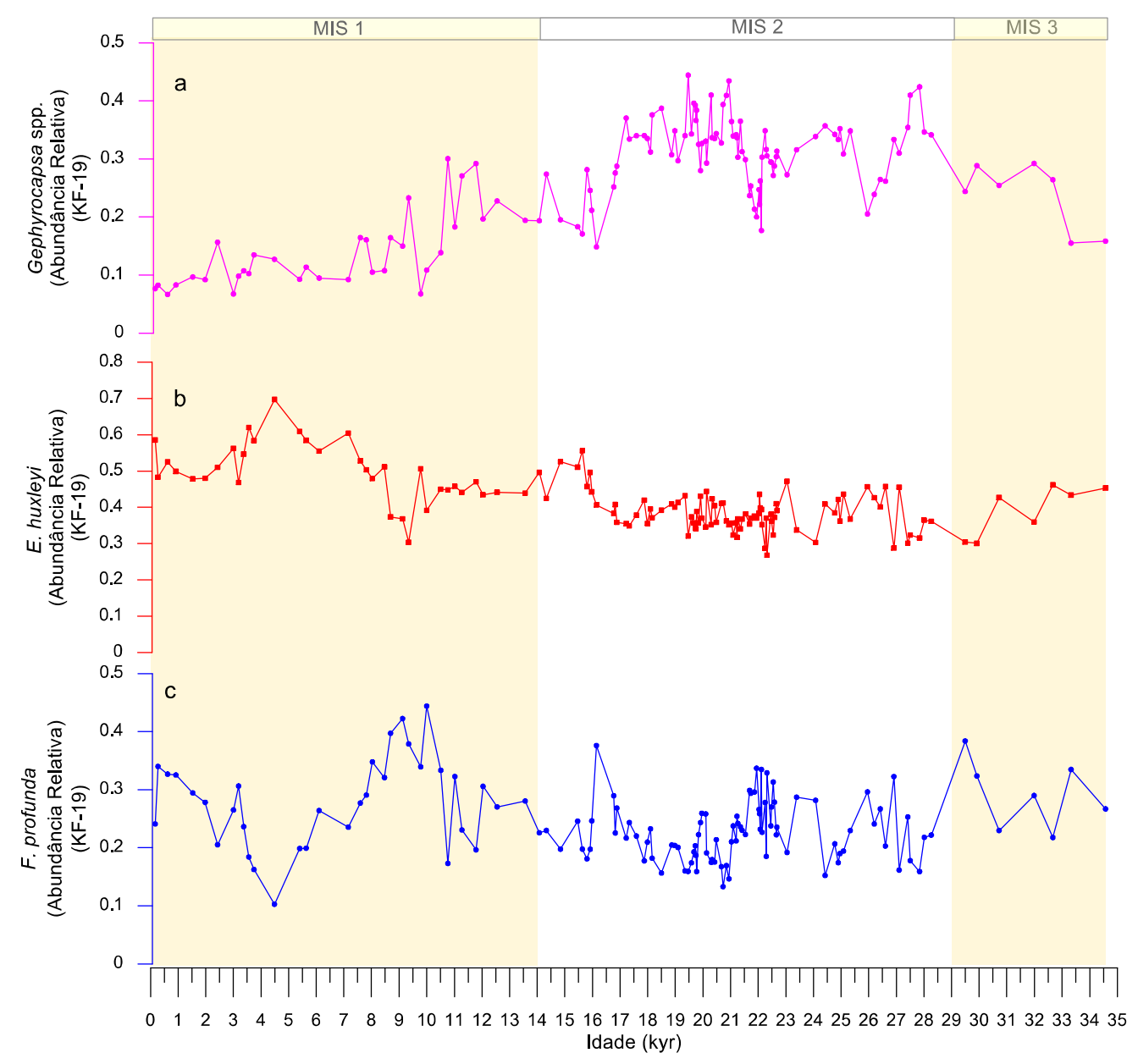

Figura 16: Gráfico com a variação relativa (\%) e de Gephyrocapsa spp., F. profunda e E. huxleyi (a, b, c respectivamente) ao longo do testemunho KF-19 com as faixas de estágios isotópicos marinho 1,2 e 3 .

A abundância relativa de Gephyrocapsa spp. variou entre 6,6 e 44,4\% (0,62 e 19,46 mil anos AP respectivamente) da assembleia total. E. huxleyi variou entre 26,8 e 69,7\% (22,31 e 4,48 mil anos AP) da assembleia total. Em 10 mil anos AP, F. profunda alcançou sua maior abundância relativa $(44,4 \%)$ e menor $(10,2 \%)$ em 4,48 mil anos AP.

A variação das abundancias dos táxons que alcançaram de 3 a 7\% da assembleia total de cocolitoforídeos é apresentada na figura 17. 


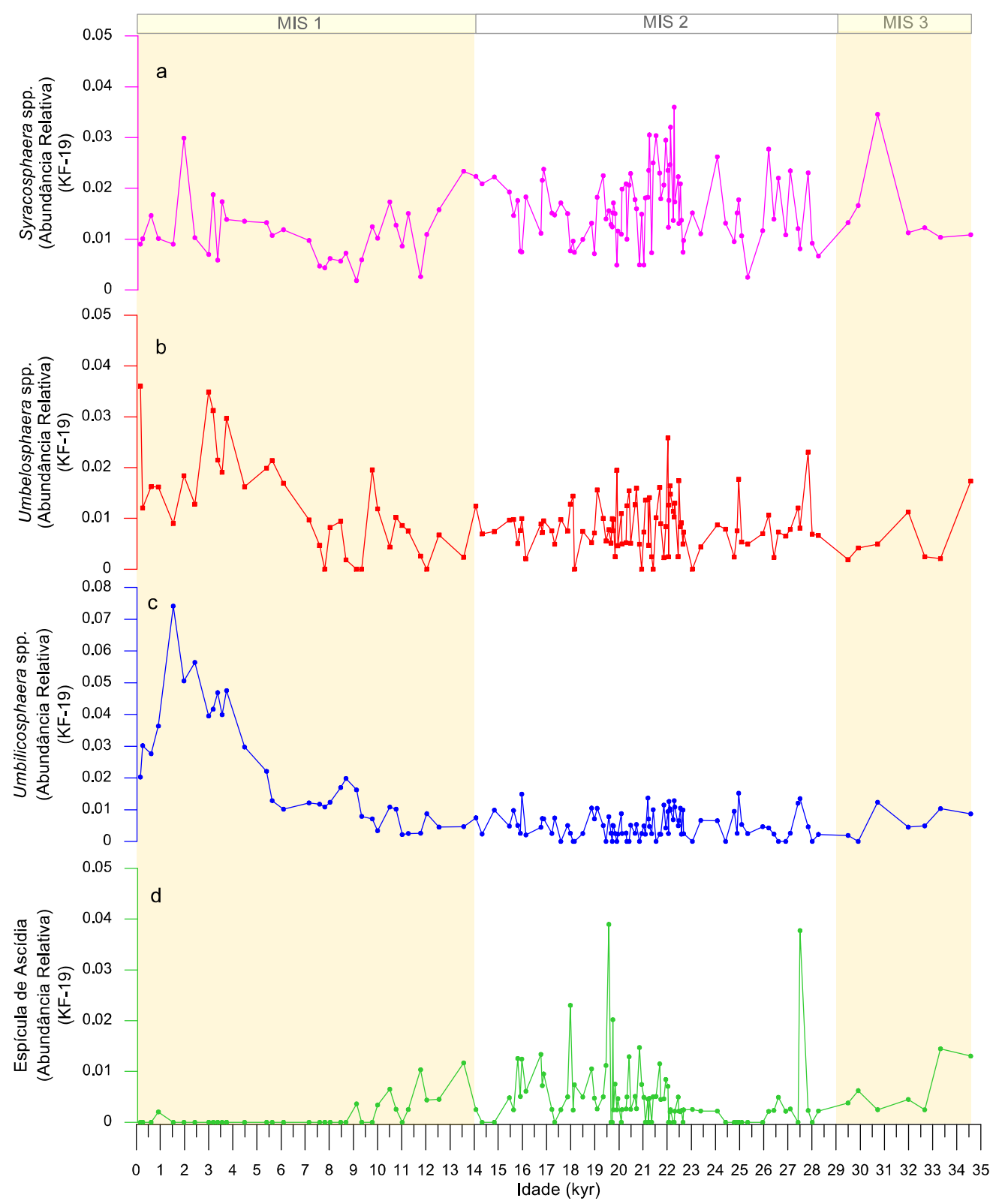

Figura 17: Gráfico com a variação relativa de Syracosphaera spp., Umbelosphaera spp., Umbilicosphaera spp. e Espículas de Ascídias (a, b, c, d respectivamente) ao longo do testemunho KF-19 com as faixas de estágios isotópicos marinho 1,2 e 3.

Syracosphaera spp. apresentou variação percentual entre 0,24 a 3,59\% (25,3 e 22,2 mil anos AP) do total de cocolitoforídeos contabilizados. A flutuação da abundância relativa máxima $(3,6 \%)$ de Umbellosphaera spp. aconteceu em 170 anos $\mathrm{AP}$, sendo a mínima igual a zero em diversas amostras do testemunho. Umbilicosphaera spp. atingiu sua maior ocorrência percentual (5,64\%) em 2,42 mil anos AP. Por último, espícula de ascídias alcançou 3,89\% de abundância relativa em 19,58 mil anos AP. 


\section{7. Índices Paleoceanográficos}

$\mathrm{Na}$ figura 18 são apresentadas as curvas de razão nutriclina e de paleoprodutividade primária.

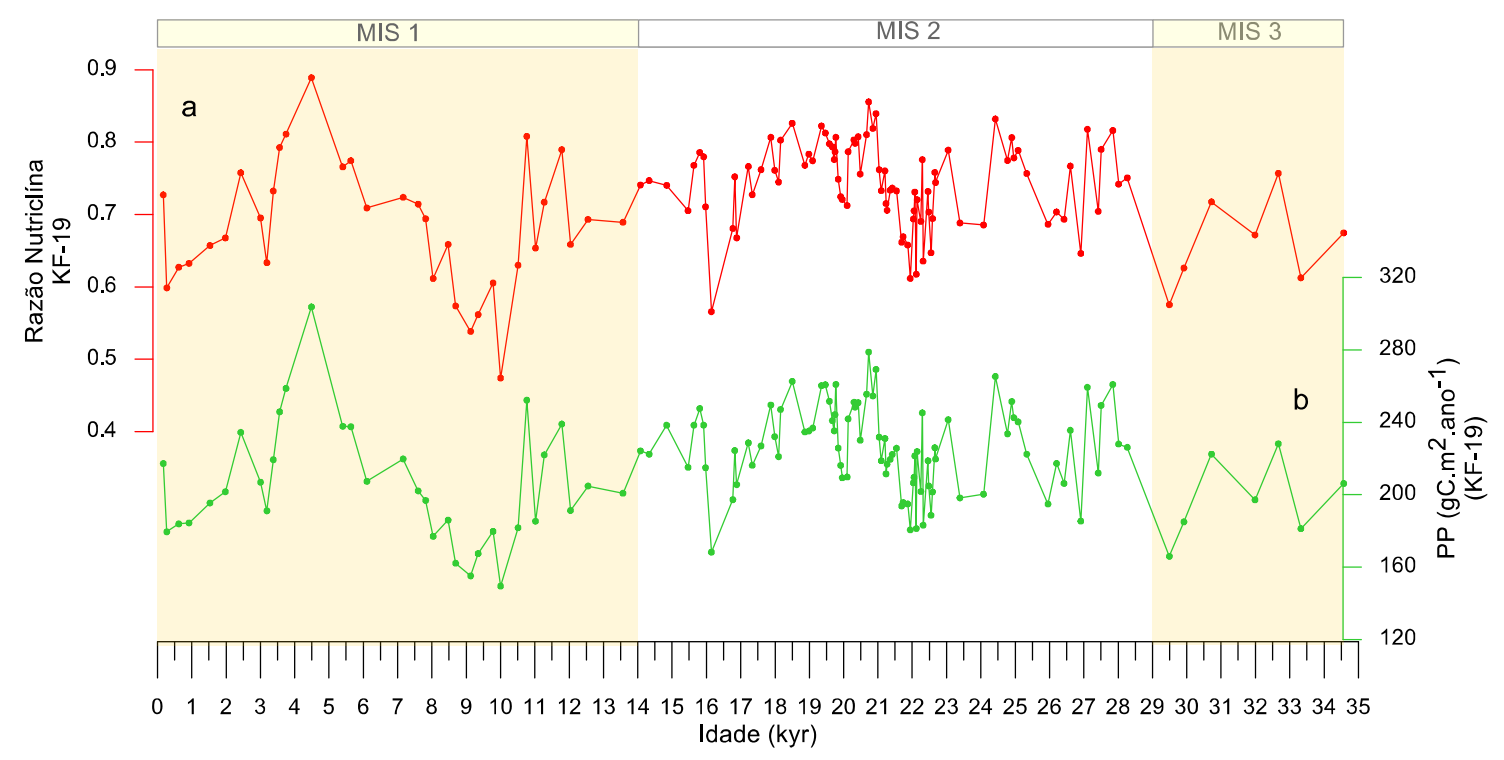

Figura 18: Gráfico da Razão Nutriclína (a) e da Paleoprodutividade Primária (b)(gC.m².ano-1 $)$ do testemunho KF-19 com as faixas de estágios isotópicos marinho 1,2 e 3.

Estes índices foram calculados a partir de espécies de cocolitoforídeos relacionadas à produtividade e, conforme esperado, as duas curvas seguiram padrão muito semelhante.

O índice razão nutriclina $(\mathrm{RN})$ indica uma posição mais rasa ou mais profunda da nutriclina ao passo que o índice paleoprodutividade primária (PP) quantifica a produtividade primária em conteúdo de carbono (g de $\mathrm{C} / \mathrm{m}^{2} / \mathrm{ano}$ ).

No testemunho KF-19 a curva da RN e da PP apresentaram variações de máximos e mínimos menos acentuados durante o último período glacial, sendo máximas de 0,85 para $\mathrm{RN}$ e $278,8 \mathrm{gC} / \mathrm{m}^{2} /$ ano para PP e mínimas de 0,57 e $165,9 \mathrm{gC} / \mathrm{m}^{2} /$ ano respectivamente.

Durante o Holoceno as variações foram mais acentuadas, com máximas de 0,89 para $\mathrm{RN}$ e $303,7 \mathrm{gC} / \mathrm{m}^{2} /$ ano para PP e mínimas de 0,47 e $149,4 \mathrm{gC} / \mathrm{m}^{2} / \mathrm{ano}$, seguindo a mesma ordem.

Como o comportamento das curvas de RN e PP são muito similares, as discussões serão referidas apenas à curva de PP. 


\subsection{Análise Espectral}

A análise espectral nos dados de paleoprodutividade primária identificou um pico espectral de frequência entre 0,02 e 0,06. Este pico excede o nível de significância de $90 \%$.

O pico espectral da paleoprodutividade primária está intimamente relacionado com a banda espectral de 19-23 mil anos (precessão) e de 41 mil anos (obliquidade) (figura 19).

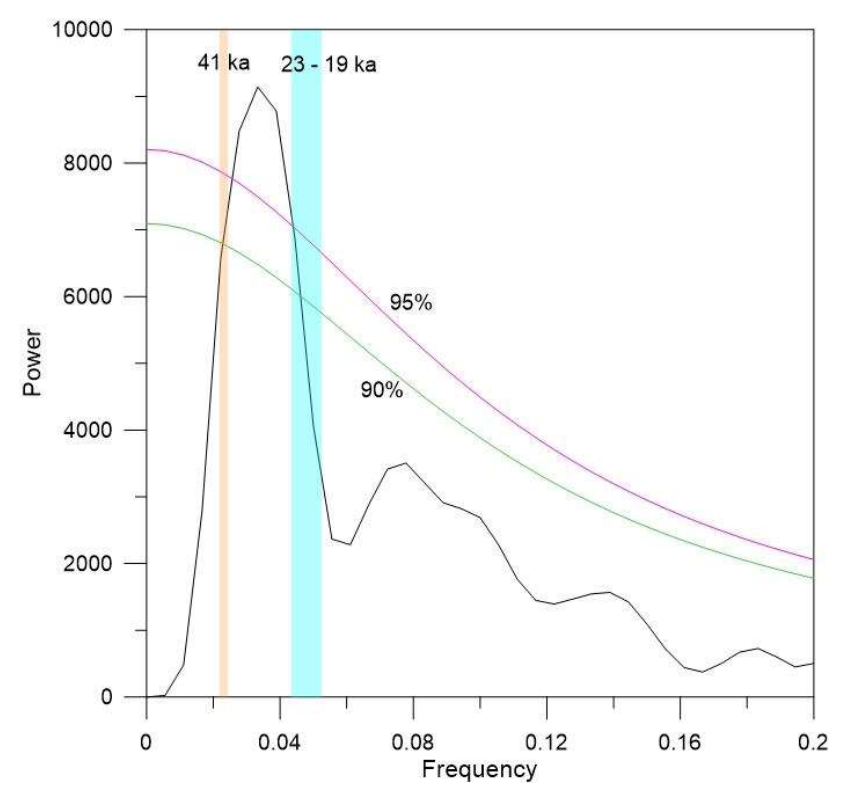

Figura 19: Periodograma da análise espectral (REDFIT method) da paleoprodutividade primária do testemunho KF19. A faixa em laranja e azul representam respectivamente a banda espectral de obliquidade (41 mil anos) e precessão (19-23 mil anos). As linhas verde (90\%) e roxa (95\%) são linhas nível de significância.

\subsection{Análise Fatorial}

A análise fatorial foi aplicada sobre a planilha de dados (anexo 3) do testemunho KF-19 nos modos Q e R.

A extração de fatores foi realizada pelo método de componentes principais e com rotação normalizada de fatores Varimax. Foram extraídos 29 fatores, tanto para o modo Q quanto para o R (Tabelas 2 e 3). 
Tabela 2: Fatores extraídos na Análise Fatorial modo Q com autovalores e percentagem de variância. Em cinza estão destacados os dois primeiros fatores utilizados na interpretação dos resultados.

\begin{tabular}{|c|c|c|}
\hline Fatores & Autovalor & $\%$ de variância \\
\hline \hline 1 & 129,278 & 99,445 \\
\hline 2 & 0,502 & 0,386 \\
\hline 3 & 0,202 & 0,155 \\
\hline 4 & 0,009 & 0,007 \\
\hline 5 & 0,003 & 0,002 \\
\hline 6 & 0,002 & 0,001 \\
\hline 7 & 0,001 & 0,001 \\
\hline 8 & 0,001 & 0,001 \\
\hline 9 & 0,001 & 0,001 \\
\hline 10 & 0,001 & 0,000 \\
\hline 11 & 0,000 & 0,000 \\
\hline 12 & 0,000 & 0,000 \\
\hline 13 & 0,000 & 0,000 \\
\hline 14 & 0,000 & 0,000 \\
\hline 15 & 0,000 & 0,000 \\
\hline 16 & 0,000 & 0,000 \\
\hline 17 & 0,000 & 0,000 \\
\hline 18 & 0,000 & 0,000 \\
\hline 19 & 0,000 & 0,000 \\
\hline 20 & 0,000 & 0,000 \\
\hline 21 & 0,000 & 0,000 \\
\hline 22 & 0,000 & 0,000 \\
\hline 23 & 0,000 & 0,000 \\
\hline 24 & 0,000 & 0,000 \\
\hline 25 & 0,000 & 0,000 \\
\hline 26 & 0,000 & 0,000 \\
\hline 27 & 0,000 & 0,000 \\
\hline 28 & 0,000 & 0,000 \\
\hline 29 & 0,000 & 0,000 \\
\hline & & \\
\hline
\end{tabular}


Tabela 3: Fatores extraídos na Análise Fatorial modo R com autovalores e percentagem de variância. Em cinza estão destacados os dois primeiros fatores utilizados na interpretação dos resultados.

\begin{tabular}{|c|c|c|}
\hline Fatores & Autovalor & \% de variância \\
\hline 1 & 4,771 & 15,905 \\
\hline 2 & 2,918 & 9,726 \\
\hline 3 & 1,988 & 6,628 \\
\hline 4 & 1,706 & 5,687 \\
\hline 5 & 1,470 & 4,900 \\
\hline 6 & 1,377 & 4,590 \\
\hline 7 & 1,341 & 4,471 \\
\hline 8 & 1,299 & 4,329 \\
\hline 9 & 1,194 & 3,982 \\
\hline 10 & 1,140 & 3,799 \\
\hline 11 & 1,121 & 3,737 \\
\hline 12 & 1,037 & 3,455 \\
\hline 13 & 0,936 & 3,121 \\
\hline 14 & 0,861 & 2,870 \\
\hline 15 & 0,841 & 2,805 \\
\hline 16 & 0,752 & 2,505 \\
\hline 17 & 0,725 & 2,415 \\
\hline 18 & 0,652 & 2,175 \\
\hline 19 & 0,607 & 2,024 \\
\hline 20 & 0,570 & 1,899 \\
\hline 21 & 0,534 & 1,779 \\
\hline 22 & 0,528 & 1,759 \\
\hline 23 & 0,494 & 1,646 \\
\hline 24 & 0,429 & 1,432 \\
\hline 25 & 0,337 & 1,123 \\
\hline 26 & 0,208 & 0,693 \\
\hline 27 & 0,156 & 0,520 \\
\hline 28 & 0,006 & 0,021 \\
\hline 29 & 0,001 & 0,005 \\
\hline
\end{tabular}

Os dados de cargas fatoriais modo Q e modo R são apresentados nas tabelas 4 e 5 respectivamente. Estes valores alternam entre 1 a -1 e indicam quanto um fator influência ou não uma variável. 
Tabela 4: Cargas Fatoriais (modo Q). Os valores sublinhados em azul e vermelho são aqueles de maior peso carga (maior ou igual a 0,7 ).

\begin{tabular}{|c|c|c|c|c|c|c|c|c|}
\hline Amostra/ldade & Fator 1 & Fator 2 & Amostra/ldade & Fator 1 & Fator 2 & Amostra/ldade & Fator 1 & Fator 2 \\
\hline 0,17 & 0,64 & 0,76 & 16,83 & 0,73 & 0,68 & 21,94 & 0,69 & 0,72 \\
\hline 0,27 & 0,63 & 0,78 & 16,88 & 0,73 & 0,68 & 22,03 & 0,72 & 0,69 \\
\hline 0,62 & 0,62 & 0,79 & 17,22 & 0,76 & 0,65 & 22,05 & 0,70 & 0,71 \\
\hline 0,92 & 0,63 & 0,78 & 17,34 & 0,75 & 0,66 & 22,07 & 0,73 & 0,69 \\
\hline 1,53 & 0,65 & 0,76 & 17,59 & 0,75 & 0,66 & 22,12 & 0,68 & 0,73 \\
\hline 1,98 & 0,65 & 0,75 & 17,88 & 0,75 & 0,66 & 22,14 & 0,75 & 0,66 \\
\hline 2,43 & 0,69 & 0,72 & 17,99 & 0,76 & 0,65 & 22,25 & 0,76 & 0,65 \\
\hline 3,00 & 0,63 & 0,77 & 18,10 & 0,74 & 0,67 & 22,29 & 0,75 & 0,66 \\
\hline 3,19 & 0,65 & 0,76 & 18,16 & 0,77 & 0,64 & 22,32 & 0,74 & 0,67 \\
\hline 3,37 & 0,66 & 0,75 & 18,50 & 0,77 & 0,64 & 22,46 & 0,74 & 0,68 \\
\hline 3,56 & 0,66 & 0,74 & 18,87 & 0,74 & 0,67 & 22,48 & 0,73 & 0,68 \\
\hline 3,75 & 0,68 & 0,72 & 18,98 & 0,75 & 0,66 & 22,55 & 0,72 & 0,69 \\
\hline 4,49 & 0,68 & 0,72 & 19,10 & 0,74 & 0,67 & 22,59 & 0,73 & 0,69 \\
\hline 5,40 & 0,66 & 0,75 & 19,35 & 0,75 & 0,66 & 22,66 & 0,74 & 0,68 \\
\hline 5,64 & 0,67 & 0,74 & 19,46 & 0,79 & 0,61 & 22,68 & 0,74 & 0,67 \\
\hline 6,10 & 0,64 & 0,76 & 19,58 & 0,76 & 0,65 & 23,04 & 0,73 & 0,69 \\
\hline 7,16 & 0,64 & 0,76 & 19,67 & 0,77 & 0,64 & 23,39 & 0,74 & 0,67 \\
\hline 7,60 & 0,66 & 0,75 & 19,72 & 0,77 & 0,64 & 24,08 & 0,75 & 0,66 \\
\hline 7,82 & 0,66 & 0,75 & 19,75 & 0,77 & 0,64 & 24,42 & 0,76 & 0,65 \\
\hline 8,03 & 0,63 & 0,78 & 19,77 & 0,77 & 0,64 & 24,77 & 0,75 & 0,66 \\
\hline 8,47 & 0,63 & 0,77 & 19,84 & 0,75 & 0,66 & 24,90 & 0,75 & 0,66 \\
\hline 8,69 & 0,65 & 0,75 & 19,91 & 0,72 & 0,69 & 24,96 & 0,76 & 0,65 \\
\hline 9,13 & 0,64 & 0,76 & 19,96 & 0,74 & 0,67 & 25,08 & 0,74 & 0,67 \\
\hline 9,34 & 0,70 & 0,71 & 20,10 & 0,75 & 0,66 & 25,33 & 0,75 & 0,66 \\
\hline 9,78 & 0,62 & 0,79 & 20,13 & 0,74 & 0,68 & 25,95 & 0,68 & 0,73 \\
\hline 10,00 & 0,61 & 0,79 & 20,30 & 0,78 & 0,63 & 26,20 & 0,72 & 0,70 \\
\hline 10,51 & 0,65 & 0,76 & 20,33 & 0,75 & 0,66 & 26,42 & 0,72 & 0,69 \\
\hline 10,76 & 0,74 & 0,67 & 20,42 & 0,75 & 0,66 & 26,61 & 0,72 & 0,69 \\
\hline 11,02 & 0,67 & 0,74 & 20,48 & 0,76 & 0,65 & 26,91 & 0,74 & 0,66 \\
\hline 11,27 & 0,72 & 0,69 & 20,67 & 0,75 & 0,66 & 27,10 & 0,74 & 0,67 \\
\hline 11,78 & 0,73 & 0,68 & 20,73 & 0,77 & 0,64 & 27,42 & 0,76 & 0,65 \\
\hline 12,04 & 0,68 & 0,73 & 20,85 & 0,78 & 0,63 & 27,50 & 0,78 & 0,62 \\
\hline 12,55 & 0,70 & 0,71 & 20,94 & 0,78 & 0,62 & 27,84 & 0,79 & 0,62 \\
\hline 13,57 & 0,69 & 0,72 & 21,03 & 0,76 & 0,65 & 28,01 & 0,76 & 0,66 \\
\hline 14,08 & 0,70 & 0,72 & 21,09 & 0,76 & 0,65 & 28,27 & 0,75 & 0,66 \\
\hline 14,33 & 0,73 & 0,69 & 21,20 & 0,76 & 0,65 & 29,49 & 0,70 & 0,71 \\
\hline 14,84 & 0,70 & 0,71 & 21,23 & 0,75 & 0,65 & 29,92 & 0,73 & 0,68 \\
\hline 15,46 & 0,68 & 0,73 & 21,26 & 0,74 & 0,67 & 30,72 & 0,72 & 0,69 \\
\hline 15,63 & 0,69 & 0,72 & 21,36 & 0,76 & 0,65 & 31,99 & 0,73 & 0,68 \\
\hline 15,80 & 0,73 & 0,68 & 21,42 & 0,75 & 0,67 & 32,67 & 0,72 & 0,69 \\
\hline 15,92 & 0,71 & 0,70 & 21,54 & 0,74 & 0,67 & 33,33 & 0,66 & 0,75 \\
\hline 15,97 & 0,70 & 0,71 & 21,69 & 0,71 & 0,70 & 34,58 & 0,68 & 0,73 \\
\hline 16,14 & 0,65 & 0,76 & 21,73 & 0,72 & 0,70 & & & \\
\hline 16,77 & 0,71 & 0,70 & 21,86 & 0,70 & 0,71 & & & \\
\hline
\end{tabular}


Tabela 5: Cargas Fatoriais (modo R). Os valores sublinhados em cinza são aqueles de maior peso positivo e negativo $(>0,6) . \mathrm{PMP}=$ placolito muito pequeno $(<2 \mu \mathrm{m})$ e $\mathrm{CNI}=$ cocólito não identificado.

\begin{tabular}{|c|c|c|}
\hline Variável & Fator 1 & Fator 2 \\
\hline \hline Acanthoica spp. & 0,12 & 0,14 \\
\hline B. bigelowii & 0,02 & 0,12 \\
\hline Ceratolithus TOTAL & 0,04 & 0,15 \\
\hline Calcidiscus TOTAL & $-0,40$ & $-0,05$ \\
\hline Calciosolenia TOTAL & $-0,09$ & $-0,28$ \\
\hline Coccolithus TOTAL & $-0,02$ & 0,32 \\
\hline Coronosphaera TOTAL & 0,20 & $-0,15$ \\
\hline D. tubifera & 0,31 & 0,00 \\
\hline E. huxleyi TOTAL & $-0,41$ & $-0,69$ \\
\hline F. profunda & $-0,70$ & 0,32 \\
\hline Gephyrocapsa TOTAL & 0,77 & 0,43 \\
\hline Helicosphaera TOTAL & $-0,02$ & $-0,15$ \\
\hline Oolithotus spp & $-0,13$ & 0,31 \\
\hline Pontosphaera TOTAL & 0,06 & 0,02 \\
\hline Reticulofenestra TOTAL & 0,02 & $-0,17$ \\
\hline Rhabdosphaera TOTAL & 0,24 & $-0,01$ \\
\hline S. apsteinii & 0,07 & 0,21 \\
\hline Syracosphaera TOTAL & 0,41 & $-0,08$ \\
\hline T. quadrilaminata & 0,11 & 0,02 \\
\hline Thoracosphaera TOTAL & $-0,01$ & 0,03 \\
\hline Umbellosphaera TOTAL & $-0,11$ & $-0,66$ \\
\hline Umbilicosphaera TOTAL & $-0,42$ & $-0,70$ \\
\hline PMP & 0,38 & 0,16 \\
\hline CNI & 0,04 & 0,51 \\
\hline Espiculas & 0,27 & 0,26 \\
\hline In(Fe/K) & 0,35 & $-0,60$ \\
\hline In(Fe/Ca) & 0,88 & 0,16 \\
\hline In(Ti/Ca) & 0,87 & 0,27 \\
\hline In(A/Si) & 0,28 & $-0,42$ \\
\hline PP (gC/m^2/ano) & 0,67 & $-0,32$ \\
\hline
\end{tabular}

\subsection{Análise de Agrupamento}

O objetivo do uso da Análise de Agrupamento foi encontrar padrões de associações de espécies e de amostras.

A análise foi realizada a partir da planilha de dados de abundância relativa de cocolitoforídeos (anexo 4) em modo Q. Utilizou-se o coeficiente de correlação de Pearson e como método de agrupamento o Ward, pois, como sugerido por Parker e Arnold (1999), o diagrama gerado define melhor os agrupamentos devido a sua natureza não-linear.

A figura 20 ilustra o diagrama resultado da análise de agrupamento em modo Q. 


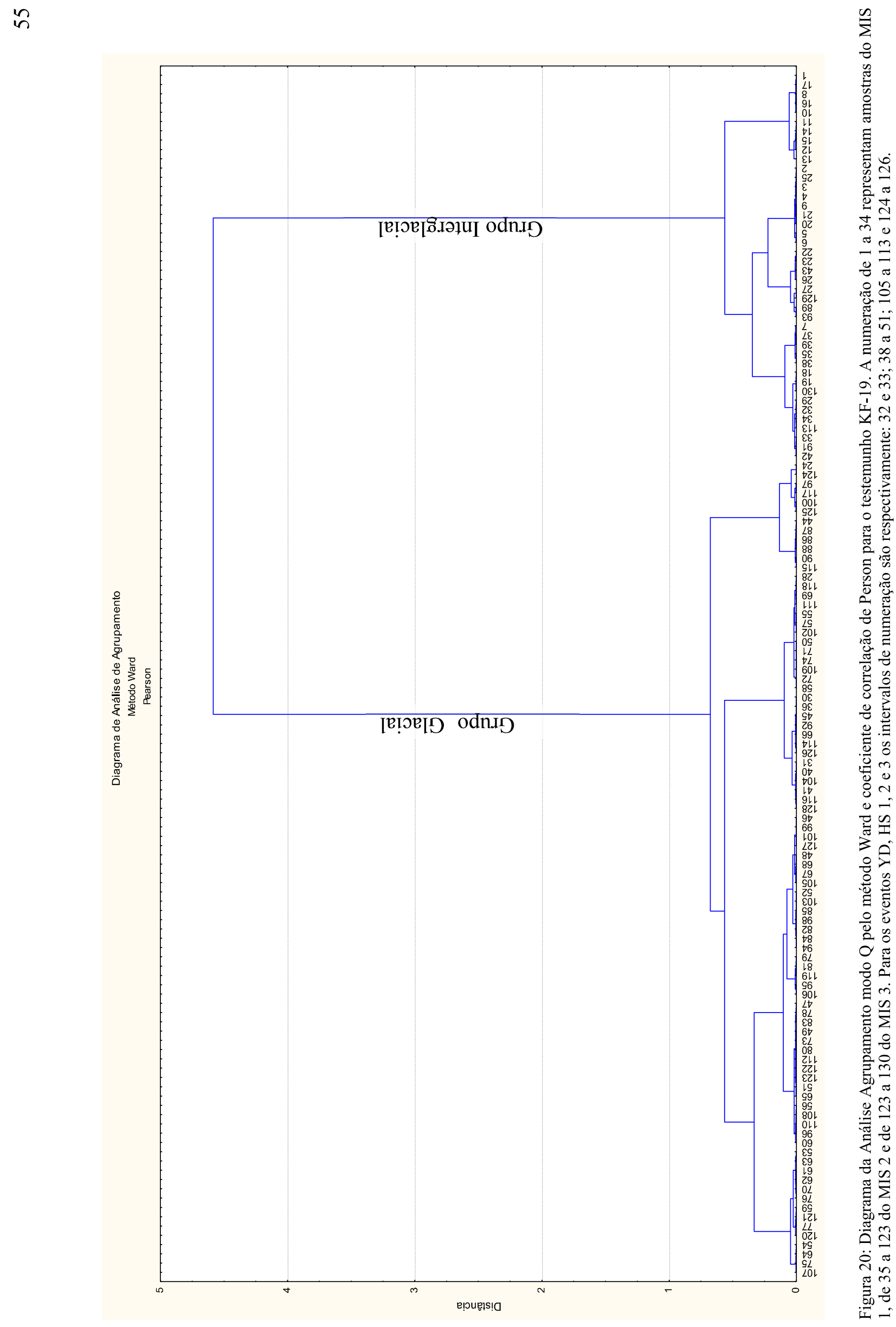




\section{Discussão}

\subsection{A Paleoprodutividade Primária}

Os resultados de paleoprodutividade primária de cocolitoforídeos, obtido através da equação de Beaufort et al. (1997), variaram entre o mínimo de 149,4 e o máximo de $303,7 \mathrm{gC} / \mathrm{m}^{2} /$ ano no intervalo estudado do testemunho KF-19. Esta variação é similar àquelas encontradas por Beaufort et al. (1997) e por Henriksson (2000) no intervalo temporal correspondente. Os valores encontrados no presente trabalho são comparáveis aquele encontrado por Brandini (1990) durante o inverno de 1982, cuja a produtividade primária do fitoplâncton foi de $164,23 \mathrm{gC} / \mathrm{m}^{2} /$ ano, próximo a região de amostragem do testemunho KF-19. Valores parecidos foram observados por Santos (2016) em estudo com imagem de satélite. A produtividade primária do fitoplâncton encontrada pelo autor foi de 150,75 gC/m²/ano, valor que corresponde à média de verão e inverno de 2002.

Os dados do presente estudo apresentaram, durante o último período glacial, uma menor variação nos valores máximos e mínimos de paleoprodutividade primária $(278,80$ e $165,93 \mathrm{gC} / \mathrm{m}^{2} /$ ano respectivamente) se comparados com os do Holoceno. No último período glacial a produtividade média foi de 224,48 $\mathrm{gC} / \mathrm{m}^{2} / \mathrm{ano}$, sendo a média do MIS 3 de $197,98 \mathrm{gC} / \mathrm{m}^{2} /$ ano e de $226,57 \mathrm{gC} / \mathrm{m}^{2} /$ ano no MIS 2 .

As amostras correspondentes ao MIS 1 apresentaram maior variação de paleoprodutividade, com mínima de $149,44 \mathrm{gC} / \mathrm{m}^{2} /$ ano e máxima de $303,71 \mathrm{gC} / \mathrm{m}^{2} /$ ano. O valor médio deste intervalo foi de $205,19 \mathrm{gC} / \mathrm{m}^{2} / \mathrm{ano}$.

Em estudo realizado por Lourenço et al. (2016) no talude superior (testemunho \#7485), em região próxima à área de coleta do testemunho KF-19, o indicador de paleoprodutividade marinha, hidrocarbonetos alifáticos de cadeia curta, apresentou comportamento muito próxima daquelas observados na curva de paleoprodutividade primária do testemunho KF-19. Algumas diferenças entre as curvas pode se dever à baixa resolução do testemunho \#7485, no intervalo correspondente ao MIS 1, e à calibração da cronologia dos testemunhos que apresentam datações de $\mathrm{C}^{14}$ em profundidades/idades diferentes com grandes intervalos sem quaisquer datação (figura 21). 


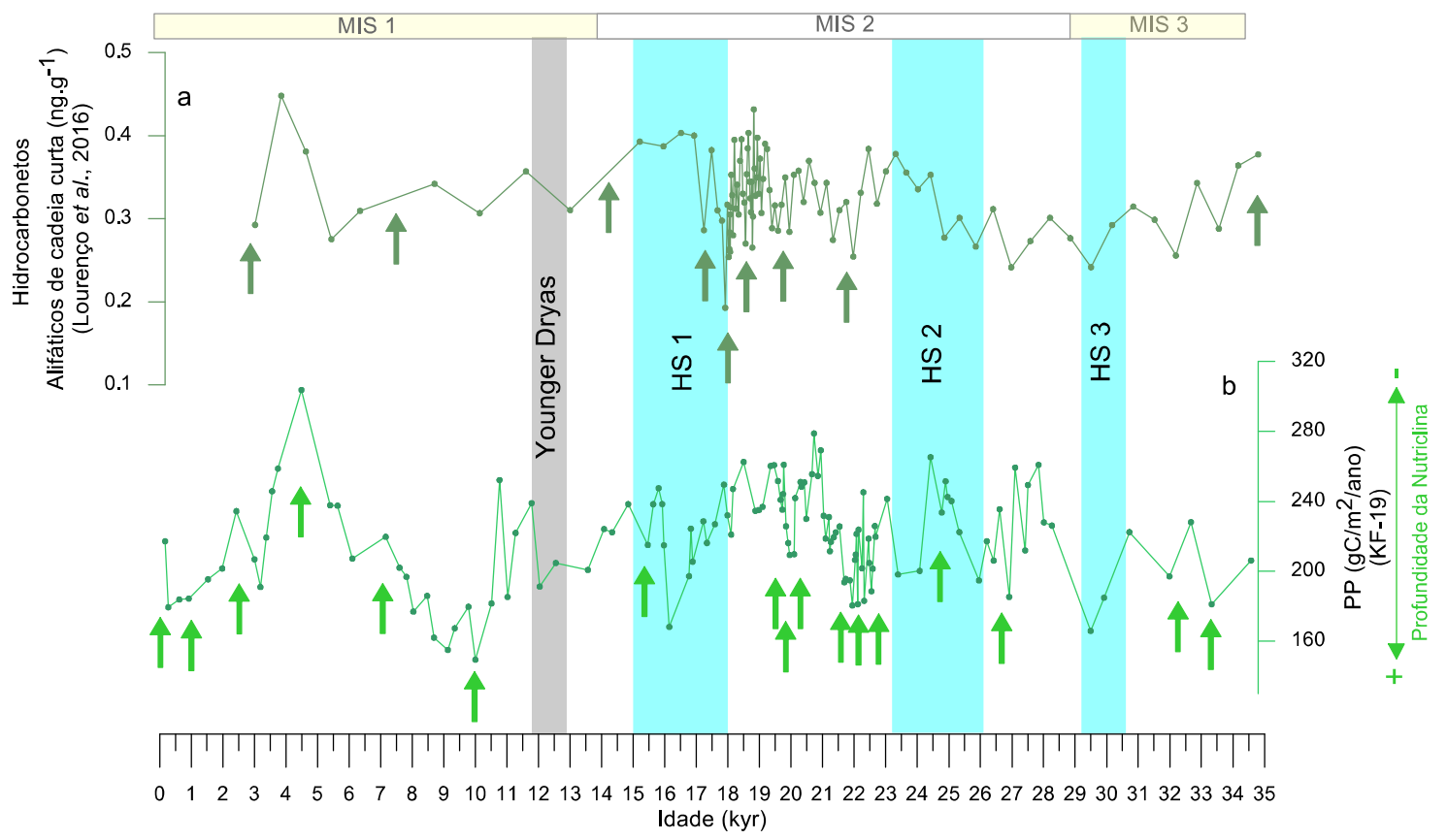

Figura 21: Gráfico com curva de Hidrocarbonetos Alifáticos de cadeia curta (a) de Lourenço et al. (2016) e Paleoprodutividade Primária (b) do testemunho KF-19. As setas sob as curvas indicam amostras datadas por $\mathrm{C}^{14}$. Estão representados os intervalos isotópicos marinhos 1, 2 e 3 e os eventos Younger Dryas (faixa cinza) e Heinrich 1, 2 e 3 (faixas azuis) (Salgueiro et al.,2014).

\subsection{A Análise Espectral}

Através da análise espectral foi possível constatar os sinais orbitais da obliquidade (41 mil anos) e da precessão (banda espectral de 19 a 23 mil anos) sobre os dados de paleoprodutividade primária do testemunho KF-19. A estes intervalos de frequência são atribuídas mudanças na insolação que, por sua vez, é responsável por uma fração da variação climática (Berger et al., 2006). Na figura 22 é possível observar a forte influência que a insolação e a precessão imprimem sobre a produtividade primária.

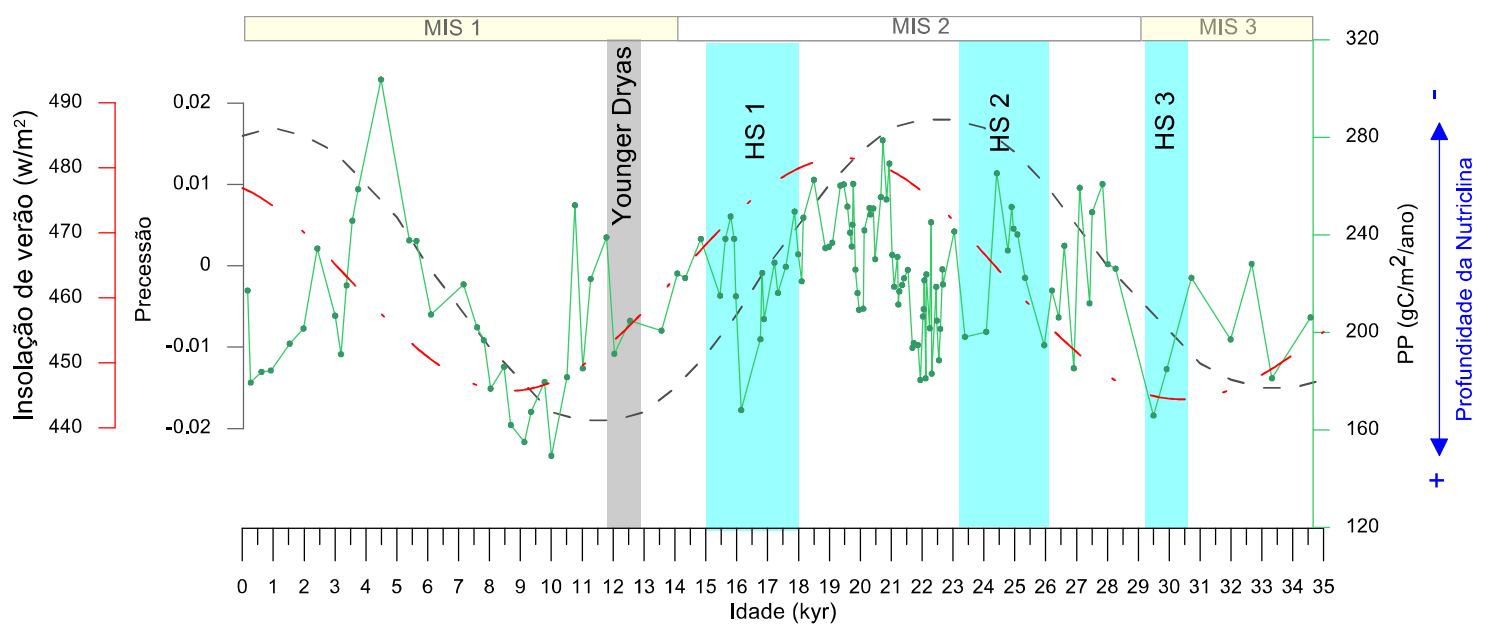

Figura 22: Gráfico com curva de paleoprodutividade primária de cocolitoforídeos (linha verde)(KF-19), de precessão (linha cinza) e insolação de verão em $25^{\circ} \mathrm{S}$ (linha vermelha). Estão representados os intervalos isotópicos marinhos 1 , 
2 e 3 e os eventos Younger Dryas (faixa cinza) e Heinrich 1, 2 e 3 (faixas azuis) (Salgueiro et al.,2014). As curvas de precessão e insolação de verão foram obtidas por Laskar et al. (2004).

A forçante precessional além de contribuir com a modulação da insolação (Berger et al., 2006; Stríkis e Novello, 2014) também exerce influência sobre a variação dos ventos alísios e, desta forma, da posição latitudinal média da Zona de Convergência Intertropical (Molfino \& McIntyre, 1990; Stríkis e Novello, 2014). Zhang e Delworth (2005) e Broccoli et al. (2006), por sua vez, propuseram que o enfraquecimento da CRMA e baixas temperaturas no Hemisfério Norte são capazes de mudar a posição latitudinal média da ZCIT em direção ao sul.

\subsection{A Pluviosidade sobre o Centro/ Sul do Brasil}

Wang et al. (2007), a partir de dados de isótopo de oxigênio (figura 23a) obtidos em espeleotemas no sul do Brasil, observou que os menores valores do isótopo, portanto ambiente mais úmido, ocorreu em fase com máxima de insolação em $30^{\circ} \mathrm{S}$ produzido pelo ciclo de precessão da Terra. Os autores concluíram que o padrão encontrado é consistente com a migração da ZCIT promovido pelo enfraquecimento da CRMA juntamente com temperaturas anômalas quentes da superfície do mar no Atlântico Sul subtropical, durante as partes mais frias do glacial (glacial stadials), que produzia uma intensificação da Monção de Verão da América do Sul (Monção de Verão da América do Sul ) e consequente alta na precipitação sobre o centro/sul do Brasil. Padrões com migração da ZCIT para o norte, de forma oposta, produzia períodos mais secos como os observados próximo ao final do MIS 3 e ao redor da primeira metade do Holoceno.

A variação da razão Ti/CA encontrada nas amostras do testemunho KF-19 (Figura 23b) está de acordo com os dados de isótopo de oxigênio de Wang et al. (2007). Períodos de maior umidade sobre o continente são acompanhados por maior aporte de sedimento terrígeno sobre a plataforma via fluvial. Fe e Ti são elementos comumente relacionados ao componente siliciclástico dos sedimentos continentais, variando com a fração terrígena dos sedimentos marinhos (Govin et al., 2012; Costa et al., 2016). O Ca, por sua vez, é componente da calcita e da aragonita que compõem a fração carbonática do sedimento de origem principalmente biogênica. Por este motivo, a razão Ti/Ca $(\mathrm{Fe} / \mathrm{Ca})$ é usada como traçadora da entrada de sedimento terrígeno, sendo os maiores valores desta razão relacionados ao maior aporte de sedimentos terrígenos (Costa et al., 2016).

O carbonato de cálcio $\left(\mathrm{CaCO}_{3}\right)$, fração do sedimento basicamente biogênica, no testemunho KF-19, apresentou, como esperado, variação antifásica àquelas observadas 
na razão $\mathrm{Ti} / \mathrm{Ca}$. Ou seja, as maiores percentagens de $\mathrm{CaCO}_{3}$ são encontradas em sedimentos de períodos menos úmidos e as menores em intervalos de maior aporte de sedimentos terrígenos (Figura 23c).

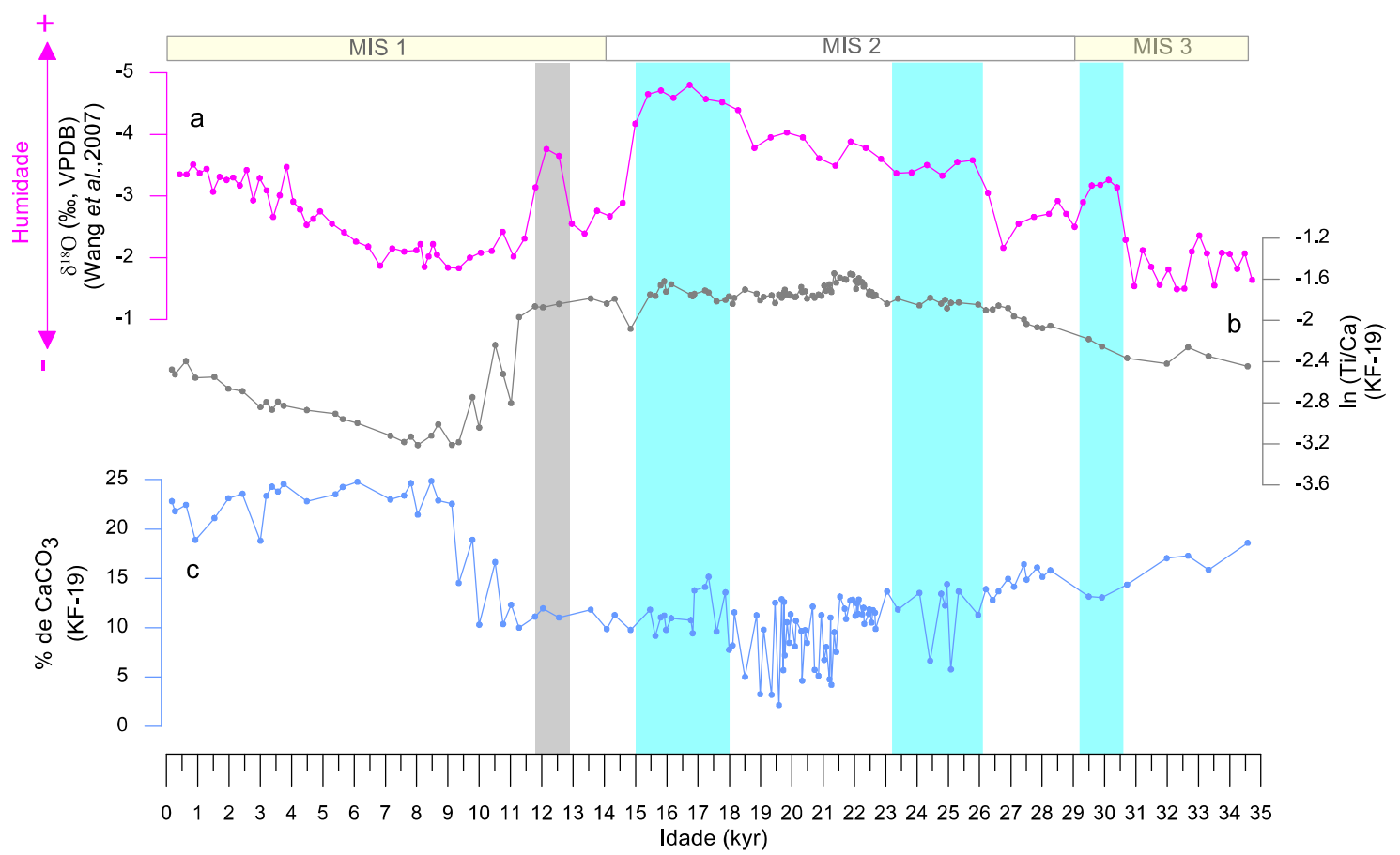

Figura 23: A curva lilás (a) representa o gráfico de $\delta^{18} \mathrm{O}(\%$, VPDB) de Wang et al. (2007), a curva cinza (b) representa a razão logarítmica de $\mathrm{Ti} / \mathrm{Ca}$ e a curva em azul claro (c) representa $\mathrm{CaCO}_{3}$. Estão representados os intervalos isotópicos marinhos 1, 2 e 3 e os eventos Younger Dryas (faixa cinza) e Heinrich 1, 2 e 3 (faixas azuis) (Salgueiro et al.,2014).

\subsection{O Nível Relativo do Mar}

É preciso considerar que no último período glacial, o nível da superfície do mar esteve, em alguns momentos, ao redor de $130 \mathrm{~m}$ abaixo do atual (Yokoyama et al.,2000; Uriarte, 2011; Furtado, 2013; Correa et al., 2014, Spratt e Lisiecki., 2016). Este cenário, onde parte da plataforma ficou exposta e por onde passavam vales de rios (Conti e Furtado 2009), favorecia a entrada de sedimento continental, uma vez que a fonte destes estavam mais próximas do talude. A figura 24 apresenta a curva de nível do mar do testemunho KF-19 juntamente com a curva de nível do mar global proposta por Spratt e Lisiecki. (2016), mostrando um bom acoplamento entre ambas. 


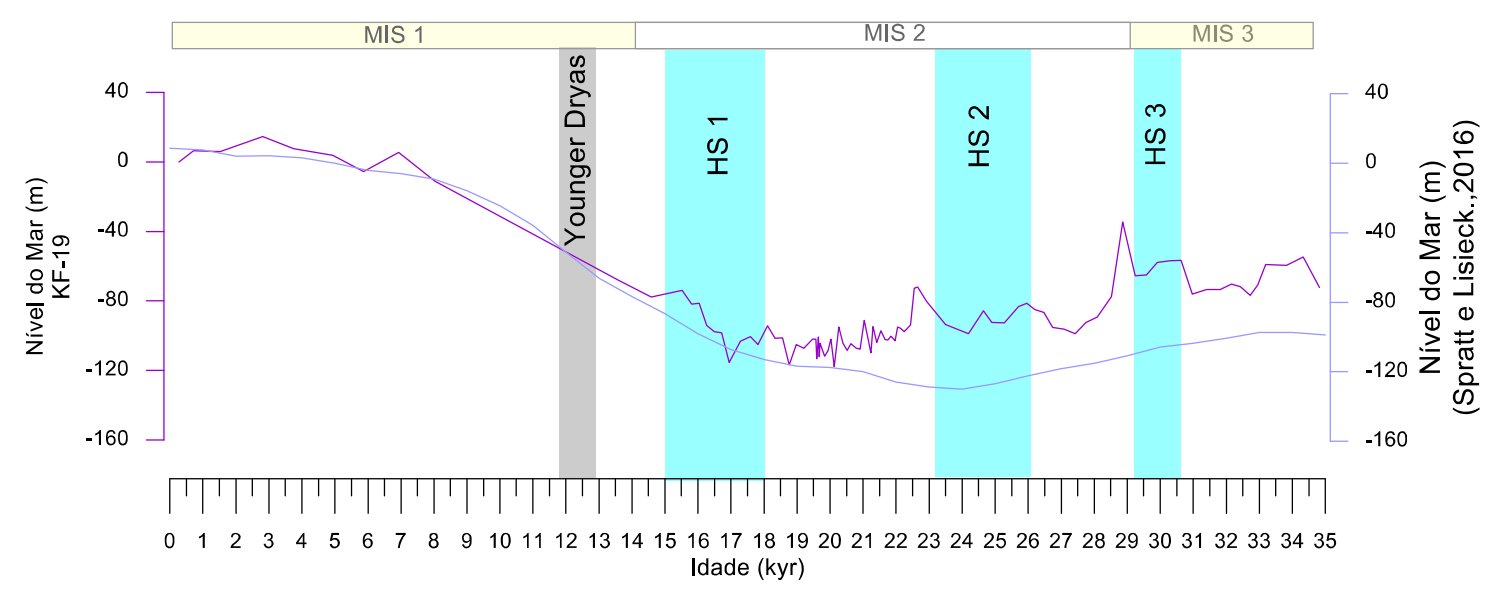

Figura 24: Gráfico de nível do mar (m) do testemunho KF-19 (em roxo) e a curva de nível do mar (m) proposta por Spratt e Lisiecki et al. (2016). Estão representados os intervalos isotópicos marinhos 1, 2 e 3 e os eventos Younger Dryas (faixa cinza) e Heinrich 1, 2 e 3 (faixas azuis) (Salgueiro et al.,2014).

\subsection{As razões logarítmicas Elementares, o $\mathrm{CaCO}_{3}$ e Paleoprodutividade Primária}

As razões de elementos maiores $\mathrm{Fe} / \mathrm{Ca}$ e $\mathrm{Ti} / \mathrm{Ca}$ apresentaram comportamentos muito similares e, por ambas indicarem variação no aporte de sedimento terrígenos, somente uma delas $(\mathrm{Ti} / \mathrm{Ca})$ será utilizada nesta discussão.

Em termos gerais, durante o intervalo do testemunho KF-19 correspondente ao MIS 3, o nível médio do mar encontrava-se ao redor de $-66 \mathrm{~m}$ e, de acordo com Wang e colaboradores (2007), foi um período mais árido. As razões $\mathrm{Ti} / \mathrm{Ca}, \mathrm{Fe} / \mathrm{K}$ e $\mathrm{Al} / \mathrm{Si}$ bem como a PP apresentaram tendência de uma leve subida até 232 mil anos AP (Figura 25 b, c, d, e). A partir deste ponto até o final do MIS 3 ( 29 mil anos AP), uma leve queda e um posterior aumento, dentro do evento Heinrich 3, foram observados nas razões elementares enquanto a PP sofreu uma tendência de queda até 29 mil anos AP. 


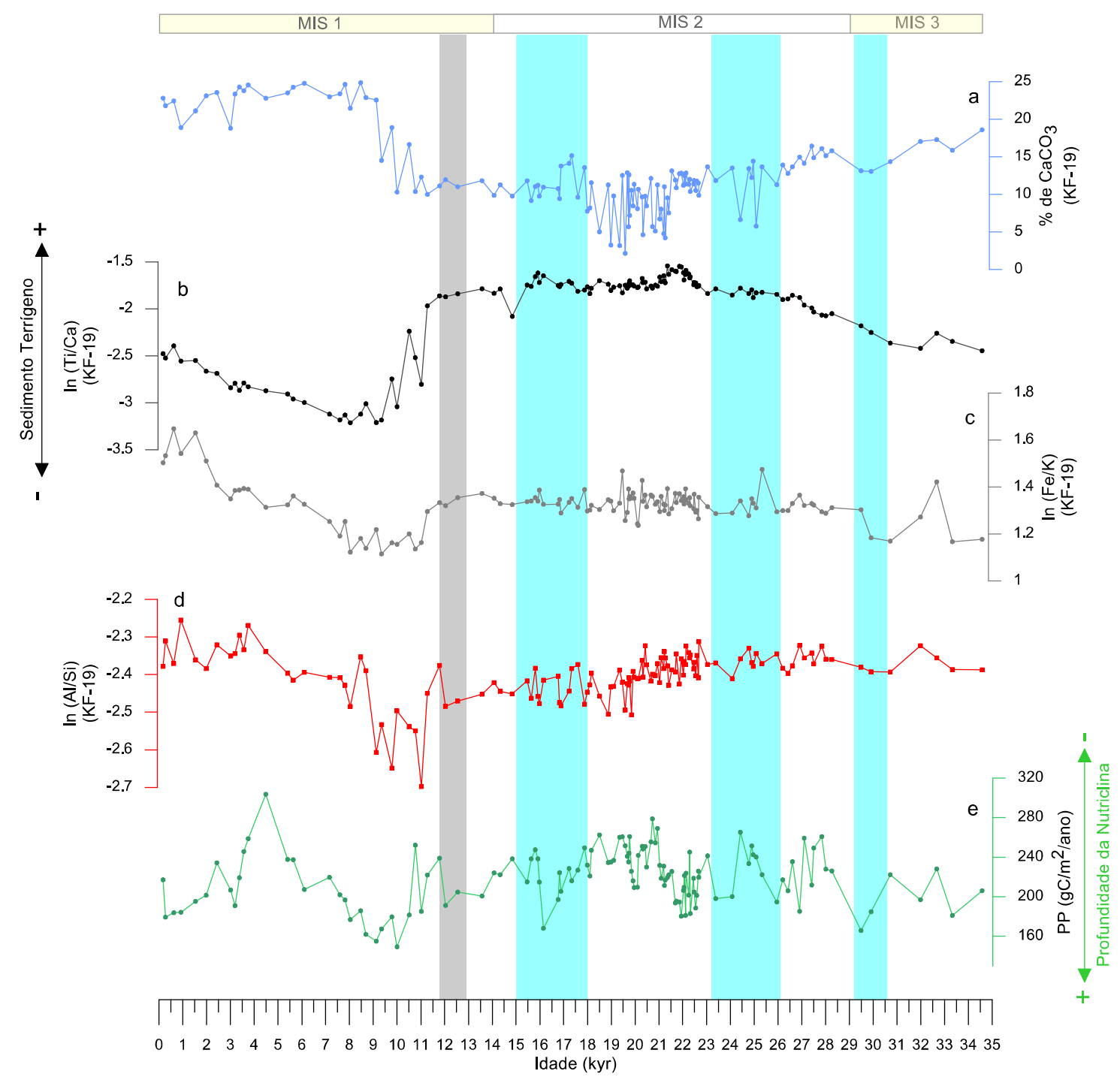

Figura 25: Gráficos de teor de carbonato de cálcio (\%) (a), das razões logarítmicas de Ti/Ca (b), $\mathrm{Fe} / \mathrm{K}$ (c), $\mathrm{Al} / \mathrm{Si}$ (d) e da paleoprodutividade primária $\left(\mathrm{gC} / \mathrm{m}^{2} / \mathrm{ano}\right)$ (e). Estão representados os intervalos isotópicos marinhos 1,2 e 3 e os eventos Younger Dryas (faixa cinza) e Heinrich 1, 2 e 3 (faixas azuis) (Salgueiro et al.,2014).

No estágio 3, o nível do mar estava baixo, trazendo a área fonte dos sedimentos terrígenos mais próximos da região de estudo, podendo ser a causa dos altos valores relativos da razão de Ti/Ca (figura 25b) e do baixo teor de $\mathrm{CaCO}_{3}$ (figura 25a).

O valor médio da razão elementar de $\mathrm{Fe} / \mathrm{K}$ (figura 25c) foi de 1,24, a mais baixa do período glacial, indicando um enriquecimento em K. Govin et al. (2012), em sedimentos atuais amostrados entre o Rio da Prata e $24^{\circ} \mathrm{S}$ na costa brasileira, relacionou os baixos valores da razão $\mathrm{Fe} / \mathrm{K}$ a um material rico em ilita, proveniente da drenagem de rios andinos trazidos pela pluma do Rio da Prata. Mahiques et al. (2017) verificou que, em sedimentos atuais do talude médio na costa sudeste do Brasil, a origem dos sedimentos está ligada a uma fonte remota, carregados pela Corrente Profunda de Contorno Oeste. Como a razão $\mathrm{Al} / \mathrm{Si}$ (figura 25d), entre a base do testemunho e 29 mil anos AP, exibiu 
altos valores, indicando condições úmidas na bacia de drenagem (Govin et al., 2012), para este intervalo, onde o centro/sul do Brasil apresentava condições mais secas (Wang et al., 2007), é possível que o sinal de $\mathrm{Fe} / \mathrm{K}, \mathrm{Al} / \mathrm{Si}$, Ti/Ca e Fe/Ca seja proveniente de uma origem remota (Mahiques et al., 2017), bem como em áreas emersas da costa sudeste brasileira devido à proximidade da fonte geradora.

Os valores menos negativos de isótopo de oxigênio observado na curva de Wang et al. (2007) (figura 23a) no MIS 3, está ligado a uma ZCIT mais ao norte, o que explica a menor umidade sobre o centro/sul do Brasil neste período e uma CRMA mais atuante com formação da correspondente glacial da atual APAN (Böhm et al., 2015). Este cenário apresentava provavelmente uma CB menos intensa e ao largo da plataforma. Menores disponibilidade de nutrientes, devido ao menor aporte provenientes de rios, aliados a uma mínima de insolação, podem ter atuado na diminuição da produtividade primária média neste intervalo (192 $\left.\mathrm{gC} / \mathrm{m}^{2} / \mathrm{ano}\right)$.

No estágio isotópico marinho 2, a CB permaneceu afastada da plataforma (Mahiques et al., 2007) e provavelmente mais intensa (Clauzet et al., 2007). O nível relativo do mar apresentou uma queda gradual (figura 24), com a menor profundidade em $\sim 19$ mil anos. A profundidade média deste estágio foi de $96 \mathrm{~m}$ abaixo do atual, apresentando um padrão de subida gradual do nível do mar nos últimos 5 mil anos do MIS 2.

Ao contrário do que ocorreu no MIS 3, no MIS 2 observou-se um aumento das chuvas no centro/sul do Brasil, devido ao deslocamento da ZCIT em direção ao hemisfério sul (Wang et al., 2007) (figura 23a). No MIS 2 o hemisfério norte experimenta menores temperaturas. Estas foram responsáveis pela diminuição da formação da correspondente glacial da APAN e do deslocamento da sua área de formação mais para sul. Nos eventos Heinrich 2 e 1 a formação desta massa de água diminuiu ainda mais ao ponto de cessar sua produção e por consequência houve o "desligamento" da CRMA nestes eventos (Rahmstorf, 2002; Böhm et al., 2015).

No MIS 2, a razão Ti/Ca (figura 25b) apresentou um aumento gradativo até $\sim 22$ mil anos AP e deste ponto até o fim do estágio 2 manteve-se relativamente constante. A razão neste trecho possuiu os maiores valores de todo o intervalo de estudo, com média de $-1,76$. O aumento da precipitação sobre o continente, aliado a uma plataforma 
continental exposta teria provocado uma maior entrada de sedimento terrígeno nas bacias do sul/sudeste do Brasil, motivo que pode ter causado o aumento da razão Ti/Ca.

Contrariamente a razão $\mathrm{Ti} / \mathrm{Ca}$, observou-se uma queda gradual na percentagem de $\mathrm{CaCO}_{3}$ (figura 25a), a qual está de acordo com o efeito de diluição, sobre este, causado pelo maior aporte de sedimento terrígeno observado durante este intervalo.

A razão $\mathrm{Fe} / \mathrm{K}$ (figura 25c) manteve-se relativamente constante durante todo o MIS 2 (média de 1,33) e com valor médio mais alto que no estágio marinho anterior, ao passo que a razão $\mathrm{Al} / \mathrm{Si}$ (figura 25d) apresentou uma tendência de queda gradual até $\sim 14$ mil anos AP possuindo valor médio de $-2,39$, pouco menor do que a média do MIS 3 , que foi de $-2,37$. Os valores mais altos da razão $\mathrm{Fe} / \mathrm{K}$, assim como os de $\mathrm{Al} / \mathrm{Si}$, que se mantiveram relativamente constantes, refletem a presença de material altamente intemperizado e bacia de drenagem úmida (Govin et al., 2012), comportamento esperado num período de alta pluviosidade sobre o continente.

A PP (figura 25e) esteve alta, em relação ao estágio anterior, por quase todo o estágio 2, apresentando valor médio de $226,5 \mathrm{gC} / \mathrm{m}^{2} /$ ano e incursões de baixos valores nos eventos Heinrich 2 e 1 e no intervalo entre 22,5 e 21,5 mil anos AP. Os altos valores da PP pode se dever a entrada de nutrientes através das paleobacias de drenagem que existiam sobre a plataforma exposta na costa sudeste do Brasil e que estavam mais próximas da área de estudo em período de nível relativo do mar baixo (Conti e Furtado, 2009), ao aumento de pluviosidade e a alta insolação de verão (figuras 23a e 22).

Nos primeiros 5 mil anos do MIS 1, as variáveis: Ti/Ca, Fe/K, Al/Si e PP (figura $25 \mathrm{~b}, \mathrm{c}, \mathrm{d}, \mathrm{e})$ apresentam tendência de queda, com um declínio mais abrupto a partir do início do Holoceno (11,7 mil anos AP) e atingem mínima em $\sim 9$ mil anos AP, dentro do intervalo mais seco desta época. $\mathrm{O}$ teor de $\mathrm{CaCO}_{3}$, por sua vez, mostrou comportamento inverso, aumentando desde o início do MIS 1 até 9 mil anos.

Nestes primeiros 5 mil anos do estágio 1, o comportamento observado nas variáveis pode dever-se, em parte, pela progressiva queda da pluviosidade, inferida a partir da curva de isótopos de oxigênio de Wang et al. (2007) (figura 23a) desde a transição entre os estágios 2 e 1. Este padrão é interrompido repentinamente no intervalo correspondente ao Younger Dryas com a volta a um breve período úmido. Ao termino do evento, condições cada vez mais secas, causada pelo novo deslocamento da ZCIT para o 
norte, se inserem no centro/sul do Brasil, atingindo o mínimo de umidade em $\sim 9$ mil anos AP.

Além do acima exposto, o nível médio do mar (figura 24), desde o final do MIS 2 apresenta um gradual e substancial aumento, passando de aproximadamente $-115 \mathrm{~m} \mathrm{em}$ $\sim 17$ mil anos AP para algo em torno a - $20 \mathrm{~m}$ em $\sim 9$ mil anos. A consistente transgressão do nível do mar afogou as paleodrenagens do período de plataforma exposta (Conti e Furtado, 2009) e permitiu a aproximação em direção a costa das águas quentes da CB (Mahiques et al., 2006 e Lourenço et al., 2017). O afastamento das áreas fontes de sedimentos terrígenos, ocasionado pelo progressivo aumento do nível do mar, juntamente com uma diminuição da pluviosidade e da drenagem das áreas emersas adjacentes, teriam causado a diminuição gradativa da entrada de sedimentos terrígenos sobre a área de estudo, sendo refletido na razão logarítmica de $\mathrm{Ti} / \mathrm{Ca}$ e na expressiva queda da taxa de sedimentação (figura 9).

Logo após o Younger Dryas, entre 11,7 a 10,7 mil anos AP, a paleoprodutividade primária apresentou um súbito aumento (figura 25e), atingindo valores próximos aos encontrados no MIS 2. A proximidade temporal entre o evento Younger Dryas e o aumento repentino da PP aventa a possibilidade de que ambos estejam relacionados, uma vez que este trecho do testemunho KF-19 não apresenta datações de $\mathrm{C}^{14}$ e assim ocasionando seu deslocamento como artefato do modelo de idade adotado. A análise de agrupamento modo Q identificou similaridades das amostras entre 10,7 e 11,7 mil anos AP com amostras do período glacial, corroborando com a hipótese acima citada.

No intervalo seguinte, que se estende de 9 mil anos AP até o presente, a taxa de aumento do nível do mar diminuiu progressivamente até que a superfície do mar atingiu uma estabilidade ao redor da cota observada atualmente (figura 24).

O centro/sul do Brasil, depois de passar por um período mais seco no início do MIS 1, começa a experimentar paulatinamente condições mais úmidas, como indica a queda nos valores de isótopos de oxigênio em espeleotema (Wang et al., 2007). Este aumento de umidade se deve, provavelmente, à uma posição média da ZCIT gradualmente mais ao sul, com a intensificação da Monção de Verão da América do Sul, em um período de aumento da insolação de verão (figura 22) no hemisfério sul (Wang et al.,2007). 
As razões $\mathrm{Ti} / \mathrm{Ca}, \mathrm{Fe} / \mathrm{K}$ e Al/Si (Figura 25 b,c, d) e a PP (figura 25e) apresentam tendência geral de elevação até aproximadamente 4,5 mil anos AP. Ti/Ca, $\mathrm{Fe} / \mathrm{K}$ e Al/Si seguem a tendência de aumento até o presente, porém a PP, a partir de $\sim 4,5$ mil anos AP, inicia queda abrupta, seguindo até o presente com esta tendência média. A elevação das razões Ti/Ca, Fe/K e Al/Si (figura 25 b, c, d), supõem o aumento da entrada de sedimento terrígeno altamente intemperizado, proveniente de uma bacia de drenagem úmida (Govin et al., 2012) e, provavelmente, de uma fonte remota, trazido pela Corrente Intermediária de Contorno Oeste (Mahiques et al., 2017).

A PP apresentou forte incremento no intervalo de aproximadamente 9 a 4,5 mil anos AP. Aparentemente a gradual subida do nível do mar, a gradativa aproximação da CB em direção a costa e sua progressiva intensificação, ligada ao enfraquecimento da CRMA (Arz et al., 1999; Chiessi et al., 2014 e Böhm et al., 2015), propiciou o aumento da PP de cocolitoforídeos, com especial contribuição da espécie E. huxleyi (figura 16b).

No trecho entre $\sim 4,5$ mil anos AP e o presente, a estabilização próxima do atual nível do mar e da posição média da $\mathrm{CB}$, juntamente com a sua desintensificação, por influência do fortalecimento da CRMA (Arz et al., 1999; Chiessi et al., 2014 e Böhm et al., 2015), provavelmente foi capaz de diminuir a PP.

\subsection{Análise Fatorial}

A análise fatorial foi aplicada com o propósito de reduzir a dimensão dos dados composicionais multivariados, sem que houvesse perda de informações mais relevantes a respeito da variabilidade e assim, explorar a influência dos principais parâmetros ambientais que atuaram sobre as amostras, elementos maiores, a assembleia de cocolitoforídeos e paleolprodutividade primária ao longo do período estudado.

A análise extraiu 29 fatores, tanto para o modo Q quanto para o R (Tabelas 2 e 3 respectivamente), cujas variâncias acumuladas atingiram $100 \%$, porém apenas os dois primeiros fatores, com os maiores percentuais de variância, conseguiram fornecer alguma interpretação ambiental. Portanto, o fator 1 seguido pelo fator 2 foram interpretados como as principais influências sobre as amostras (modo Q) e sobre as assembleias de cocolitoforídeos, razões elementares e PP (modo R).

A análise fatorial, no modo Q, extraiu dois fatores com percentual de variância mais significativas. O fator 1 (variância de 99,44\%) foi interpretado como Período Glacial. Neste fator, as cargas fatoriais (tabela 4) da maior parte das amostras do período 
glacial e adjacências apresentaram valores mais altos (maiores ou iguais a 0,7 ) indicando sua relação com aquele período. O fator 2 (variância de 0,38\%) foi considerado como Período Interglacial, pelo motivo inverso do fator 1.

Para a análise fatorial modo $\mathrm{R}$, o fator 1 (variância de 15,9\%) é dominado positivamente pelas cargas fatoriais mais altas de $\mathrm{Fe} / \mathrm{Ca}(0,884), \mathrm{Ti} / \mathrm{Ca}(0,868), \mathrm{PP}(0,67)$ e de Gephyrocapsa spp. $(0,774)$ e negativamente pela espécie $F$. profunda $(-0,700)$. Desta forma este fator foi identificado como Continentalidade (proximidade da costa ou das áreas fontes de sedimento terrígenos), uma vez que na área de estudo, em termos gerais, a entrada de sedimento terrígeno (indicados pelas razões $\mathrm{Ti} / \mathrm{Ca}$ e $\mathrm{Fe} / \mathrm{Ca}$ ) são acompanhados pelo aumento da abundância de Gephyrocapsa spp., uma espécie eutrófica (Brand, 1994), e PP, cujo o seu aumento é um indicativo de águas enriquecidas em nutrientes. A espécie $F$. profunda, por sua vez, está ligada negativamente ao fator 1, uma vez que prefere um ambiente oceânico, de águas claras e com termoclina/nutriclina profunda (Okada, 1983; Molfino e McIntyre, 1990).

O fator 2, cuja a variância alcançou 9,7\%, ligou-se negativamente com $\mathrm{Fe} / \mathrm{K}$ (0,6), E. huxleyi (-0,691), Umbellosphaera $(-0,656)$ e Umbilicosphaera (-0,702). Embora estas entidades taxinômicas sejam um indicativo de ambiente fortemente oligotróficos, devido especialmente à Umbellosphaera spp. e Umbilicosphera spp., a ligação das espécies de cocolitoforídeos com a razão logarítmica de $\mathrm{Fe} / \mathrm{K}$ não pôde ser explicada, impossibilitando a identificação da característica do fator 2 do modo R.

\subsection{As associações das espécies de cocolitoforídeos}

Para tentar identificar variações nas associações de cocolitoforídeos durante os estágios isotópicos marinhos 1, 2 e 3 e nos eventos climáticos Younger Dryas, Heinrich 1,2 e 3 foi realizada a análise de agrupamento modo Q.

A análise de agrupamento modo Q, realizadas sobre a planilha de abundância relativa de cocolitoforídeos por amostra, conseguiu separar as amostras do MIS 1 daquelas do MIS 2 e 3, porém não foi eficiente em separar estes dois últimos estágios. Da mesma forma, os eventos climáticos listados anteriormente, também não foram identificados pela análise.

A área de estudo foi classificada por McIntyre e Bé (1967) como uma região de domínio de espécies subtropicais de cocolitoforídeos, em estudo realizado com amostras de água do Atlântico Norte e Sul. No entanto, apesar da maioria das espécies encontradas 
no sedimento do testemunho KF-19 sejam espécies subtropicais, não foi observado o padrão de abundâncias propostas pelos autores.

Apesar do caráter subtropical das espécies observada neste estudo, a espécie Coccolithus spp., que na atualidade é encontrada em regiões subárticas do Atlântico e em regiões de ressurgência da costa sul africana (McIntyre e Bé, 1967, Ziveri et al., 2004), foi observada em muitas amostras do MIS 2 e 3 e durante a primeira metade do MIS 1 (figura 27a). Comportamento que pode indicar eventos de intrusão de águas mais frias ou uma gradual mudança de preferência ambiental da espécie (McIntyre e Bé, 1967).

Os táxons dominantes (aqueles que atingiram abundância relativa maior que $3 \%$ ), com exceção de espícula de ascídia, foram encontrados ao decorrer de todo o testemunho (figuras 16 e 17) com o domínio de algumas destas espécies durante o glacial e de outras delas no percurso do interglacial.

As espécies que apresentaram as maiores abundâncias relativas e ocorrência preferencial durante o período glacial foram: Gephyrocapas spp., Syracosphaera spp., espículas de Ascídias, Rhabdosphaera spp., Pontosphaera spp., Coronosphaera spp., Coccolithus spp., Discosphaer tubifera, Oolithotus spp., Scyphosphaera apsteinii, Ceratolithus spp., Braarudosphaera. bigelowii, Thoracosphaera spp., Reticulofenestra spp., Acanthoica spp. e Tetralithoides quadrilaminata (figuras 26 e 27). Estas espécies parecem se beneficiar do período de nível de mar baixo, de alta pluviosidade e de maior insolação de verão observadas durante o MIS 2. 


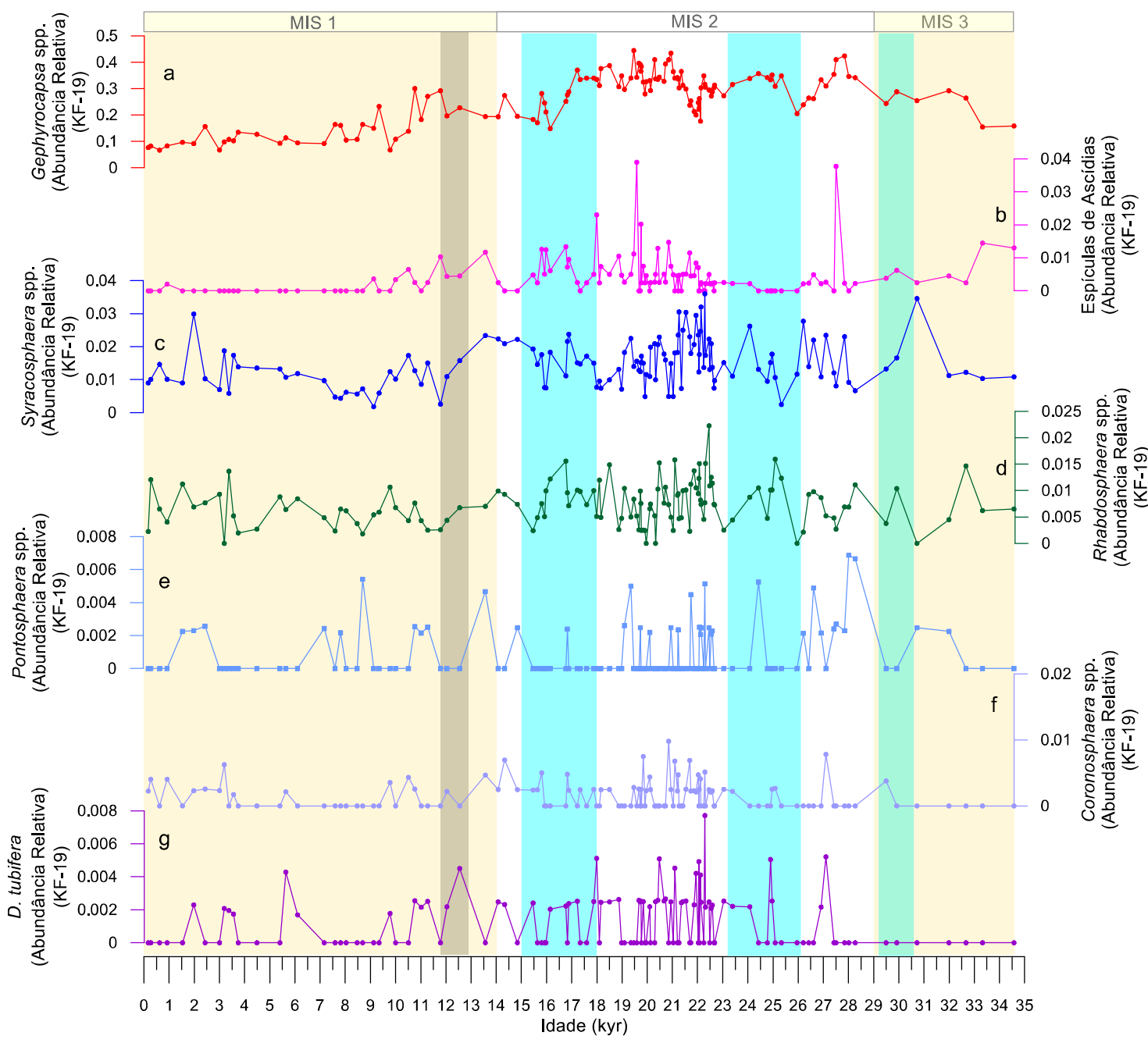

Figura 26: Gráficos das espécies de cocolitoforídeos que apresentaram maior abundância e ocorrência durante o período glacial. Ao topo da figura estão representados por barras os intervalos do MIS 1, 2 e 3 que são acompanhados pelas faixas amarelas e brancas. A faixa cinza representa o evento Younger Dryas e as azuis os eventos Heinrich 1, 2 e 3 (da esquerda para a direita) (Salgueiro et al.,2014). 


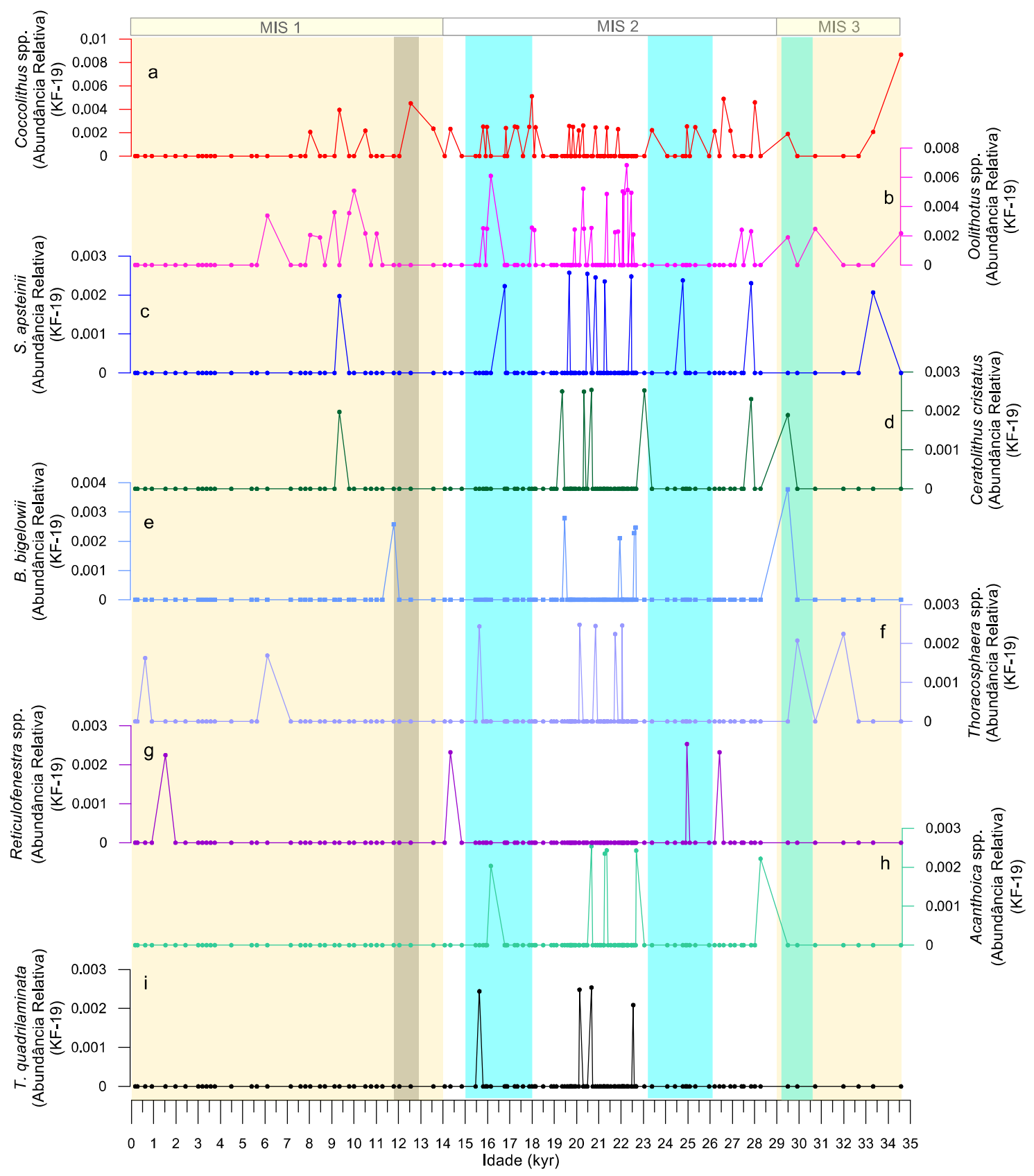

Figura 27: Gráficos das espécies de cocolitoforídeos que apresentaram maior abundância e ocorrência durante o período glacial. Ao topo da figura estão representados por barras os intervalos do MIS 1, 2 e 3 que são acompanhados pelas faixas amarelas e brancas. A faixa cinza representa o evento Younger Dryas e as azuis os eventos Heinrich 1, 2 e 3 (da esquerda para a direita) (Salgueiro et al.,2014).

As espécies Emiliania huxleyi, Umbilicosphaera spp., Umbellosphaera spp., Florisphaera profunda, Calcidiscus spp., Helicosphaera spp. e Calciosolenia spp. manifestaram maiores abundâncias relativas durante o MIS 1 (figura 28).

A maior frequência relativa das espécies Umbelosphaera spp., Umbilicosphaera spp., Calcidiscus spp., Helicosphaera spp. e até mesmo de E. huxleyi pode estar associada a um ambiente mais oligotrófico, pois as mesmas se beneficiam nestas condições (Brand, 1994), e pelo aumento do nível do mar durante o MIS 1. 
Apesar de aumentar sua abundância durante o MIS 1, a espécie $F$. profunda se beneficia de uma termoclina/nutriclina profunda e da transparência da água, apresentando frequência espelhada àquela observada em E. huxleyi (Brand, 1994).

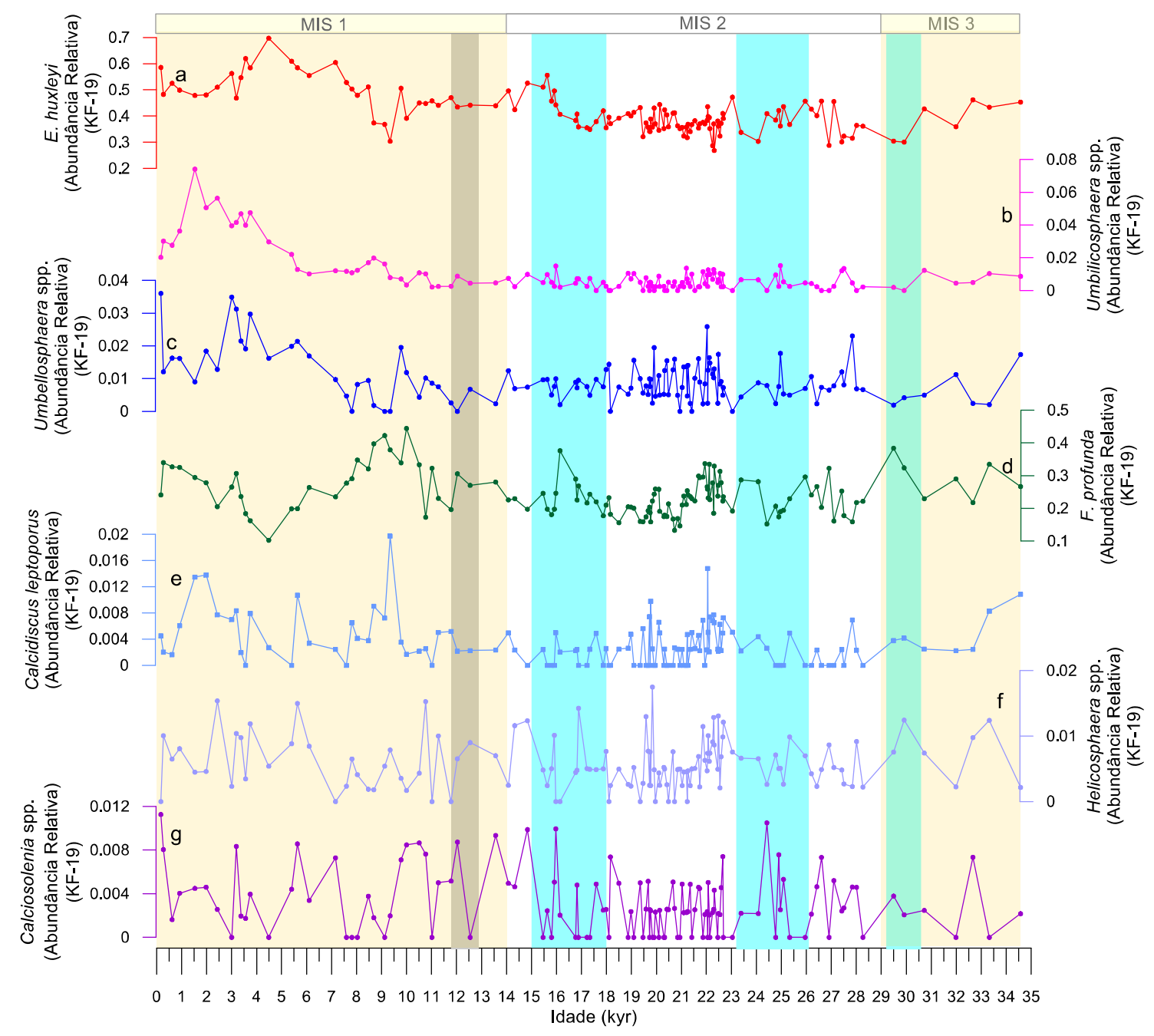

Figura 28: Gráficos das espécies de cocolitoforídeos que apresentaram maior abundância durante o MIS 1. Ao topo da figura estão representados por barras os intervalos do MIS 1, 2 e 3 que são acompanhados pelas faixas amarelas e brancas. A faixa cinza representa o evento Younger Dryas e as azuis os eventos Heinrich 1, 2 e 3 (da esquerda para a direita) (Salgueiro et al.,2014). 


\section{Conclusão}

\subsection{A Paleoprodutividade Primária (PP) e os elementos maiores}

A variação da PP durante os últimos $\sim 35$ mil anos parece estar ligada aos elementos maiores conforme a proveniência dos mesmos. Em períodos de nível relativo do mar baixo, onde parte da plataforma estava exposta, e de alta pluviosidade é provável que a maior parte do sedimento terrígeno que chegava sobre a área de estudo era proveniente de áreas fontes próximas, embora houvesse a contribuição de sedimentos de origem remota. Neste cenário, onde CB estava mais ao largo da plataforma, a PP foi alta, indicando uma relação positiva desta com a entrada de sedimento terrígeno, como observado através dos maiores valores das razões Ti/Ca $(\mathrm{Fe} / \mathrm{Ca}), \mathrm{Fe} / \mathrm{K}$ e $\mathrm{Al} / \mathrm{Si}$ (figura 25 $b, c, d)$.

A PP, em momentos de plataforma exposta e condições mais úmidas, foi fortemente influenciada pelas espécies de cocolitoforídeos E. huxleyi e Gephyrocapsa spp. (figura 16), as quais apresentaram altas abundâncias relativas no período. Gephyrocapsa spp., que se beneficia em ambientes mais eutróficos e próximos da costa, apresentou suas maiores abundâncias durante o estágio 2, indicando que neste intervalo as águas superficiais estavam enriquecidas em nutrientes, os quais podem ter origem na entrada dos sedimentos de fontes próximas.

Em períodos mais secos e de nível relativo do mar baixo, como os observados no MIS 3 e na primeira metade do MIS 1, a queda nas razões elementares também significou queda na PP. A queda na abundância de Gephyrocapsa spp., com consequente diminuição em sua contribuição na PP, deveu-se ao empobrecimento em nutrientes das águas superficiais, ocasionadas provavelmente pela diminuição do aporte de sedimentos terrígenos de fontes próximas trazidos pelas paleodrenagens.

Na segunda metade do estágio isotópico marinho 1, quando as paleodrenagens já estavam totalmente afogadas, devido ao aumento do nível do mar até a cota atual, os sedimentos terrígenos provenientes das áreas mais próximas deixaram de contribuir significativamente na área estudada. $\mathrm{O}$ aumento das razões elementares observada neste período, não significou um enriquecimento em nutrientes, como no MIS 2, corroborado pela queda na abundância relativa de Gephyrocapsa spp. e o aumento das abundâncias de Umbellosphaera spp. e Umbilicosphaera spp., Calcidiscus spp., espécies oligotróficas. Este aumento das razões elementares deve-se, provavelmente, à entrada de sedimento terrígeno de proveniência remota trazidos pela Corrente Profunda de Contorno Oeste 
como proposto por Mahiques et al. (2017), e, aparentemente, não se relacionam com o aumento de PP observado até 4,5 mil anos AP, e com sua queda em idades mais recentes.

\subsection{As associações de cocolitoforídeos}

As associações de cocolitoforídeos do testemunho KF-19 variaram durante os estágios MIS 1, 2 e 3. Durante este período foi observado uma associação mais típica do glacial e outra do interglacial. A diferença nas associações deveu-se à maior ou menor abundância das espécies e não necessariamente à presença ou ausência de determinado táxon em um dos períodos.

A associação típica do glacial apresentou maior abundância das espécies: Gephyrocapa spp., Syracosphaera spp., espículas de Ascídias, Rhabdosphaera spp., Pontosphaera spp., Coronosphaera spp., Coccolithus spp., Discosphaera tubifera, Oolithotus spp., Scyphosphaera apsteinii, Ceratolithus spp., Braarudosphaera. bigelowii, Thoracosphaera spp., Reticulofenestra spp., Acanthoica spp. e Tetralithoides quadrilaminata (figuras 27 e 28). A espécie Tetralithoides quadrilaminata apresentou ocorrência apenas no glacial.

As espécies da associação típica do interglacial foram: Emiliania huxleyi, Umbilicosphaera spp., Umbellosphaera spp., Florisphaera profunda, Calcidiscus spp., Helicosphaera spp. e Calciosolenia spp. (figura 28).

\subsection{As associações de cocolitoforídeos e os eventos Younger Dryas e Heinrich 1,} 2 e 3

Os eventos climáticos do hemisfério norte, Younger Dryas e Heinrich 1, 2 e 3, parecem não influenciar diretamente sobre ocorrência ou a frequência das espécies de cocolitoforídeos nos sedimentos do testemunho KF-19. Nenhuma espécie apresentou um padrão claro de subida, nem mesmo queda, nas suas abundâncias durantes estes eventos. 


\section{Referências Bibliográficas}

ANTUNES, R. L. 1997. Introdução ao estudo dos nanofósseis calcários. Rio de Janeiro: UFRJ. $115 p$.

ARBUSZEWSKI, J.A., de MENOCAL, P.B., CLÉROUX, C., BRADTMILLER, L., MIX, A., 2013. Meridional shifts of the Atlantic intertropical convergence zone since the Last Glacial Maximum. Nature Geoscience, v. 6, p. 959-962.

ARZ, H.W., PÄTZOLD, J., WEFER, G., 1999, Climatic changes during the last deglaciation recorded in sediment cores from the northeastern Brazilian Continental Margin: Geo- Marine Letters, v. 19, n. 3, p. 209-218.

BAKER, P., FRITZ, S., 2015. Nature and causes of Quaternary climate variation of tropical South America. Quatern. Sci. Rev., v. 124, p. 31-47.

BAUMANN, K. -H. 2005. The significance of extant coccolithophores as indicators of ocean water masses, surface water temperature, and paleoproductivity: a review. Paläontologische Zeitschrift, v. 79/1, p. 93-112.

BEHLING, H. 2002. South and southeast Brazilian grassland during Late Quaternary times: a synthesis. Palaegeography, Palaeclimatology, Palaeoecology, v. 177, p. 19-27.

BEHRENFELD, M.J., O'MALLEY, R.T., SIEGEL, D.A., MCCLAIN, C.R., SARMIENTO, J.L., FELDMAN, G.C., MILLIGAN, A.J., FALKOWSKI, P.G., LETELIER, R.M., BOSS, E.S. 2006. Climate-driven trends in contemporary ocean productivity. Nature, v. 444, p. 752-755.

BEAUFORT, L., BASSINOT, F., VINCENT, E. 1999. Primary production response to orbitally induced variations of the southern oscillation in the equatorial Indian Ocean, In: ABRANTES, F., MIX, A.C., (ed). Reconstructing Ocean History: A Window into the Future, Plenum, New York, p. 245-271.

BEAUFORT, L., LANCELOT, Y., CAMBERLIN, P., CAYRE, O., VINCENT, E., BASSINOT, F., LABEYRIE, L. 1997. Insolation Cycles as a Major Control of Equatorial Indian Ocean Primary Production. Science, v. 278, p.1451- 1454.

BERGER, A., LOUTRE, M.F., MÉLICE, J.L. 2006. Equatorial insolation: From precession harmonics to eccentricity frequencies. Clim. Past, v. 2, p. 131-136. 
BOECKEL, B., BAUMANN, K.-H., RÜDIGER, H., KINKEL, H. 2006. Coccolith distribution patterns in South Atlantic and Southern Ocean surface sediments in relation to environmental gradients. Deep-Sea Research I, v. 53, p. 1073-1099.

BÖHM, E., LIPPOLD, J., GUTJAHR, M., FRANK, M., BLASER, P., ANTZ, B., FOHLMEISTER, J., FRANK, N., ANDERSEN, M.B., DEININGER, M. 2015, Strong and deep Atlantic meridional overturning circulation during the last glacial cycle. Nature, 517, p. 73-76.

BOWN, P.R. e YOUNG, J.R. 1998 Introduction. In: BOWN, P.R. (ed). Calcareous Nannofossil Biostratigraphy. Kluwer Academic Publishers. p. 1-15.

BRAGA, E. S.; NIENCHESKI. L. F. H. 2006 Composição das massas de água e seus potenciais produtivos na área entre o Cabo de São Tomé (RJ) e o Chuí (RS). In: ROSSI-WONGTSCHOWSKI, C. L. D. B., MADUREIRA, L. S. P. (ed). O ambiente oceanográfico da Plataforma Continental e do Talude na Região Sudeste-Sul do Brasil. São Paulo: Edusp, p. 161-218.

BRAND, L. E., 1994. Physiological ecology of marine coccolithophores. In: WINTER, A., SIESSER, W. (ed). Coccolithophores. Cambrige University Press, Cambrige, p. 39-49.

BRANDINI, F.P. 1990. Hydrography and characteristics of the phytoplankton in shelf and oceanic waters of southeastern Brazil during winter (july/august 1982) and summer (february/march 1984). Hydrobiologia, v. 196, p. 111-148.

BROCCOLI, A.J., DAHL, K.A., STOUFFER, R.J. 2006. Response of the ITCZ to northern hemisphere cooling. Geophys. Res. Lett., v. 33, L01702, p. 1-4.

BROWN, C. E. 1998. Applied Multivariate Statistics in Geohydrology and Related Sciences. Berlin: Springer-Verlag. 248p.

Buccianti, A. \& ESPOSITO, P. 2004. Insights into Late Quaternary calcareous nannoplankton assemblages under the theory of statistical analysis for compositional data. Palaeogeography, Palaeoclimatology, Palaeoecology, v. 202, p. 209-227.

CABARCOS, E. Evolución de la productividad en el Pacífico y mar de Arabia durante la última deglaciación y el Holoceno. Tese de doutorado. Universidade de Salamanca. Departamento de Geologia da Faculdade de Ciências. 249p. 2013. 
CACHÃO, M., MOITA, M. T. 2000 Coccolithus pelagicus, a productivity proxy related to moderate fronts off Western Iberia. Marine Micropaleontology, v. 39, p. 131155.

CASTRO, B. M., LORENZZETTI, J. A., SILVEIRA. I. C. A., MIRANDA, L. B. 2006. Estrutura termohalina e circulação na região entre Cabo de São Tomé (RJ) e o Chuí (RS). In: O ambiente oceanográfico da plataforma continental e do talude na região sudeste-sul do Brasil. EDUSP, Universidade de São Paulo, São Paulo, $472 \mathrm{p}$.

CHARLSON, R. J.; LOVELOCK, J. E.; ANDREAE, M. O. e WARREN, S. G. 1987. Oceanic phytoplankton, atmospheric sulphur, cloud albedo and climate. Nature, v. 326, p. $655-661$.

CHIANG, J. C. H., BIASUTTI, M., BATTISTI, D.S. 2003. Sensitivity of the Atlantic intertropical convergence zone to last glacial maximum boundary conditions, Paleoceanography, v. 18, n. 4, 1094, p. 1-18.

CHIESSI, C. M., MULITZA, S. G., JEROEN, S. J. B., CAMPOS, M. C., GURGEL, M. H. C. 2014. Variability of the Brazil Current during the late Holocene, Palaeogeogr. Palaeocl., v. 415, p. 28-36.

CHOU, S., NOBRE, P. 2014 Avaliação de Modelos Globais e Regionais Climáticos. In: AMBRIZZI, T.; ARAUJO, M. (ed). PBMC - Painel Brasileiro de Mudanças Climáticas. Base científica das mudanças climáticas. Contribuição do Grupo de Trabalho 1 do Painel Brasileiro de Mudanças Climáticas ao Primeiro Relatório da Avaliação Nacional sobre Mudanças Climáticas. COPPE. Universidade Federal do Rio de Janeiro, Rio de Janeiro, RJ, Brasil, p. 278-319.

CLARK, P.U., DYKE, A.S., SHAKUN, J.D., CARLSON, A.E., CLARK, J., WOHLFARTH, B., MITROVICA, J.X., HOSTETLER, S.W., MCCABE, A.M. 2009. The Last Glacial Maximum. Science, v. 325, p. 710-714.

CLARK, P.U., PISIAS, N.G., STOCKER, T.F.; WEAVER, A.J. 2002. The role of the thermohaline circulation in abrupt climate change. Nature, v. 415, p. 863-869.

CLAUZET, G., WAINER, I., LAZAR, A., BRADY, E., OTTO-BLIESNER, B. 2007. A numerical study of the South Atlantic circulation at the Last Glacial Maximum. Palaeogeogr. Palaeoclimatol. Palaeoecol., v. 253, p. 509-528. 
CONTI, L. A., FURTADO, V. V. 2009. Topographic registers of paleo-valleys on the Southeastern Brazilian Continental shelf. Brazilian Journal of Oceanography, v. 57, n. 2, p. 113-121.

CORRÊA, I.C.S., MEDEANIC, S., WESCHENFELDER, J., TOLDO JÚNIOR, E.E., NUNES, J.C., BAITELLI, R. 2014. The palaeo-drainage of the La Plata river in southern Brazil continental shelf. Revista Brasileira de Geofísica. v. 32, n. 2, p. 259-271.

COSTA, K.B., CABARCOS, E., SANTAROSA, A.C.A., BATTAGLI, B.B.F., TOLEDO, F.A.L. 2016. A multiproxy approach to the climate and marine productivity variations along MIS 5 in SE Brazil: A comparison between major components of calcareous nannofossil assemblages and geochemical records. Palaeogeography Palaeoclimatology Palaeoecology. v. 449, p. 275-288.

CRUZ, F.W., BURNS, S.J., KARMANN, I., SHARP, W.D., VUILLE, M., CARDOSO, A.O., FERRARI, J.A., DIAS, P.L.S., VIANA, O., Jr., 2005. Insolation-driven changes in atmospheric circulation over the past 116,000 years in subtropical Brazil. Nature, v. 434, p. 63-66.

FLORES, J.A., BÁRCENA, M.A., SIERRO, F.J. 2000. Ocean-surface and wind dynamics in the Atlantic Ocean off Northwest Africa during the last 140,000 years. Palaeogeography, Palaeoclimatology, Palaeoecology, v. 161, p. 459-478.

FLORES, J.A., MARINO, M. 2002. Pleistocene calcareous nannofossil stratigraphy for ODP Leg 177 (Atlantic sector of the Southern Ocean). Mar. Micropaleontol., v. 45(3-4), p. 191-224.

FLORES, J.A., SIERRO, F.J. 1997. Revised techniques for calculation of calcareous nannofossil accumulation rates. Micropaleontology, v. 43, p. 321-324.

FURTADO, V.V. 2003. Upper quaternary sea level fluctuations and stillstands on the continental shelf of São Paulo State, Brazil: a summary. Revista Brasileira de Geofísica., v. 31, n. 1, p. 43-48.

GAETA, S.A., BRANDINI, F.P., 2006. Produção primária do fitoplâncton na região entre Cabo de São Tomé (RJ) e o Chuí (RS). In: WONGSCHOSWSKI, C.L.D.R., MADUREIRA, L.S.D. (ed). O ambiente da plataforma continental e do talude na região Sudeste-Sul do Brasil. São Paulo: Editora USP. p. 219-264. 
GARREAUD, R. D., VUILLE, M., COMPAGNUCCI, R., MARENGO, J. 2008. Present day South American climate, Palaeogeogr. Palaeocl., v. 281, p. 180-195.

GIRAUDEAU, J. 1992. Coccolith paleotemperature and paleosalinity estimates in the Caribbean Sea for the Middle-Late Pleistocene (DSDP Leg 68-Hole 502B). Memorie Scienze Geologiche, Padova, v. 43, p. 375-387.

GOVIN, A., HOLZWARTH, U., HESLOP, D., KEELING, L.F., ZABEL, M., MULITZA, S., COLLINS, J.A. 2012. Distribution of major elements in Atlantic surface sediments $\left(36^{\circ} \mathrm{N}-49^{\circ} \mathrm{S}\right)$ : Imprint of terrigenous input and continental weathering. Geochemistry, Geophysics, Geosystems, v. 13, p. 1-23.

GRODSKY, A., CARTON, J., 2003. The Intertropical Convergence Zone in the south Atlantic and the equatorial cold tongue. Journal of Climate, v. 16, p. $723-733$.

HENRIKSON, A.S. 2000. Coccolithophore response to oceanographic changes in the equatorial Atlantic during the last 200,000 years. Palaeogeography, Palaeoclimatology, Palaeoecology, v. 156, p. 161-173.

HERRLE, J.O. 2003. Reconstructing nutricline dynamics of mid-Cretaceous oceans: evidence from calcareous nannofossils from the Niveau Paquier black shale (SE France). Marine Micropaleontology, v. 47, p. 307-321.

HERRLE, J.O., PROSS, J., FRIEDRICH, O., KÖBLER, P. e HEMLEBEN, C. 2003. Forcing mechanisms for mid-Cretaceous black shale formation: evidence from the Upper Aptian and Lower Albian of the Vocontian Basin (SE France). Palaeogeography, Palaeoclimatology, Palaeoecology, v. 190, p. 399-426.

Hirama, M.V., Toledo, F.A.L., Camillo Jr., E., Costa, K.B., Quadros, J.P. 2010. Q Mode and R-Mode factor analysis in quantitative studies of microfossils of the late Quaternary in sediments from the Brazilian continental margin. Terrae, v. 7, p. 41-49.

IBGE, Instituto Brasileiro de Geografia e Estatística - Boletins. Disponível em:

$<$ https://agenciadenoticias.ibge.gov.br> Acesso em: 25 de abril de 2018.

KAMPEL, M., LORENZZETTI, J. A., SILVA JR., C. L. 1997. Observação por satélite de ressurgências na costa S-SE brasileira. In: VII Congresso Latino Americano de Ciências do Mar - COLACMAR, Santos. Anais. São Paulo: IOUSP. p. 3840. 
KARWATH, B., JANOFSKE, D., TIETJEN, F., WILLEMS, H. 2000. Temperature effects on growth and cell size in the marine calcareous dinoflagellate Thoracospaera heimii, Mar. Micropaleontol., v. 39, p. 43-51.

KODAMA, Y.-M., 1992: Large-scale common features of sub-tropical precipitation zones (the Baiu Frontal Zone, the SPCZ, and the SACZ). Part I: characteristics of subtropical frontal zones. J. Meteor. Soc. Japan, v. 70, p. 813-835.

KOUSKY, V. E., MOLION, L. C. B. Climatologia dinâmica da troposfera sobre uma tropical da Amazônia. INPE-3560-RPE/480, São José dos Campos, São Paulo, Brazil, 1985.

KUCERA, M., MALMGREN, B.A. 1998. Logratio transformation of compositional data - a resolution of the constant sum constraint. Mar Micropaleontol, v. 34, p. 117120

KUHLBRODT, T., GRIESEL, A., MONTOYA, M., LEVERMANN, A., HOFMANN, M., RAHMSTORF, S. 2007. On the driving processes of the Atlantic meridional overturning circulation. Rev. Geophys., v. 45, RG2001, P. 1-32.

LABEYRIE, L., SKINNER, L., CORTIJO, E. 2007. Paleoclimate reconstructions. SubMilankovitch (DO/Heinrich) events. In: Elias S (ed) Encyclopedia of quaternary sciences, Elsevier, Amsterdam, p. 1964-1974.

LASKAR, J., GASTINEAU, M., JOUTEL, F., ROBUTEL, P., LEVRARD, B., CORREIA, A. 2004. A long term numerical solution for the insolation quantities of Earth: Astron. Astrophys., v. 428, p. 261-285.

LOURENÇO, R.A., MAGALHÃES, C.A., MAHIQUES, M.M., TANIGUCHI, S., BÍCEGO, M.C. 2017. Distribution of terrigenous and marine material along the Southeastern Brazilian continental margin. Regional Studies in Marine Science. v. 14 , p. $118-125$.

LOURENÇO, R.A., MAHIQUES M.M., WAINER I.E.K.C., ROSELL-MELÉ A., BÍCEGO M.C. 2016. Organic biomarker records spanning the last 34,800 years from the southeastern Brazilian upper slope: links between sea surface temperature, displacement of the Brazil Current, and marine productivity. GeoMarine Letters. v. 36, n. 5, p. 361-369. 
LOURENÇO, S.O. ; MARQUES JR, A.N. 2002 . Produção primária marinha. In: PEREIRA, R.C.; SOARES-GOMES, A.. (Org.). Biologia Marinha. Rio de Janeiro: Interciência, p. 195-227.

MAHIQUES, M.M., FUKUMOTO, M.M., SILVEIRA, I.C.A., FIGUEIRA, R.C.L., BÍCEGO, M.C., LOURENÇO, R.A., MELLO-E-SOUSA, S.H., 2007. Sedimentary changes on the Southeastern Brazilian upper slope during the last 35,000 years. Annals of the Brazilian Academy of Sciences, v. 79, p. 171-181.

MAHIQUES, M.M., HANEBUTH, T.J.J., NAGAI, R.H., BÍCEGO, M.C., FIGUEIRA, R.C.L., SOUSA, S.H.M., BURONE, L., FRANCO-FRAGUAS, P., TANIGUCHI, S., SALAROLI, A.B., DIAS, G.P., PRATES, D.M., FREITAS, M.E.F. 2017. Inorganic and organic geochemical fingerprinting of sediment sources and ocean circulation on a complex continental margin (São Paulo Bight, Brazil). Ocean Science, v. 13, p. 209-222.

MAHIQUES, M. M., TASSINARI, C. C. G., MARCOLINI, S., VIOLANTE, R. A., FIGUEIRA, R. C. L., SILVEIRA, I. C. A., BURONE, L., SOUSA, S. H. M. 2008. $\mathrm{Nd}$ and $\mathrm{Pb}$ isotope signatures on the southeastern South American upper margin, implications for sediment transport and source rocks. Marine Geology, v. 250 , p. 51-63.

MATSUOKA, H., OKADA, H., 1989. Quantitative analysis of Quaternary nannoplankton in subtropical northwestern Pacific Ocean. Mar. Micropaleontol, v.14, p. 97-118.

MATSUURA, Y. 1986. Contribuição ao estudo da estrutura oceanográfica da região sudeste entre Cabo Frio (RJ) e Cabo de Santa Marta Grande (SC). Ciência e Cultura, v.38, n.8, p.1439-1450.

MARENGO, J.A., SOARES, W.R., SAULO, C., NICOLONIBO, M. 2004. Climatology of the low-level jet east of the Andes as derived from NCEP-NCAR reanalysis: characteristics and temporal variability. Journal of Climate, v. 17, p. 2261-2280.

MCINTYRE, K. \& BÉ, A. W. H. 1967. Modern Coccolithophoridae in the Atlantic ocean. Placoliths and crytholiths. Deep-Sea Research, v. 14, p. 561-597.

MIRANDA, L. B., CASTRO FILHO, B. M. 1982. Geostrophic flow conditions of the Brazil current at $19^{\circ}$ S. Ciencia interamer., v. 22, n.112, p. 44-48. 
MIX, A.C., BARD, E., SCHNEIDER, R. 2001. Environmental processes of the ice age: land, oceans, glaciers (EPILOG). Quaternary Science Reviews, v. 20, p. 627657.

MOLFINO, B., MCINTYRE, A. 1990. Precessional Forcing of nutricline dynamics in the Equatorial Atlantic. Science, v. 249, p. 766-769.

MOSTAJO, E. L. 1986. Estudio de dos testigos submarinos del oceano Pacífico Sudecuatorial. Revista Española de Micropaleontologia, v. 18, n. 3, p. 433-442.

NAGAI, R.H., FERREIRA, P.A.L., MULKHEREE, S., MARTINS, M.V., FIGUEIRA, R.C.L., SOUSA, S.H.M., MAHIQUES, M.M. 2014. Hydrodynamic controls on the distribution of surfasse sediment from the southeast South American shelf between $23^{\circ} \mathrm{S}$ and $38^{\circ} \mathrm{S}$. Continental Shelf Research, v. 89, p. 51-60.

NIMER, E. 1989. Climatologia do Brasil. 1BGE, Rio de Janeiro. 421 p.

NOBRE, P.; SHUKLA, J. Variations of Sea Surface Temperature, Wind Stress and Rainfall over the Tropical Atlantic and South America. Journal of Climate, v. 9, p. 2464-2479, 1996.

NOVELlO, V.F., CRUZ, F.W., VUILLE, M., STRÍKIS, N.M., EDWARDS, R.L., CHENG, H., EMERICK, S., PAUlA, M.S., LI, X., BARRETO, E.S., KARMANN, I., SANTOS, R.V. 2017. A high-resolution history of the South American Monsoon from Last Glacial Maximum to the Holocene. Sci. Rep., v. 7, 44267.

OKADA, H. 1983. Modern nannofossil assemblages in sediments on coastal and marginal seas along the western Pacific ocean. Utrecht Micropaleontology Bulletin, v. 30, p. 171-187.

OKADA, H. 1992. Biogeographic control of modern nannofossil assemblages in surface sediments of Ise Bay, Mikawa Bay e Kumano-Nada, off coast of central Japan. Memorie di Scienze Geologiche, v. 43, p. 431-449.

OKADA, H. e HONJO, S. 1973. The distribution of oceanic coccolithophorids in the Pacific. Deep-Sea Research, v. 20, p. 355-374.

OKADA, H e MCINTYRE, A. 1979. Seasonal distribution of modern coccolithophores in the western North Atlantic. Marine Biology, v. 54, p. 319-328. 
PARKER, W.C., AND ARNOLD, A.J. 1999. Quantitative methods of data analysis in foraminiferal ecology, In: SEN GUPTA, B.K., (ed)., Modern Foraminifera: Dordrecht, The Netherlands, Kluwer Academic Publishers, p. 71-89.

PEREIRA, M.J., FEIJÓ, F.J. 1994. Bacia de Santos. Boletim de Geociências da PETROBRAS, v. 8, n. 1, p. 219-234.

PETERSON, R.G., STRAMMA, L. 1991. Upper-level circulation in the South Atlantic Ocean. Progress in Oceanography, v. 26, p. 1-73.

PIOLA, A.R., CAMPOS, E., DONNERS, J., GORDON, A,L., NOF, D. 2003. The South Atlantic contribution to the global thermohaline circulation. In: The South Atlantic Climate Observing System Workshop, Angra dos Reis. Report of the SACOS Workshop, p. 30-37.

RAHMSTORF, S. 2002. Ocean circulation and climate during the past 120,000 years. Nature, v. 419, p. 207-214.

REICHLER, T. 2009. Changes in the atmospheric circulation as indicator of climate change. In: LETCHER, T.M. (ed). Climate change: Observed impacts on planet Earth, Elsevier BV, The Netherlands, ISBN: 978-0-444-53301-2, p. 145-164.

REIMER, P.J., BARD, E., BAYLISS, A., BECK, J.W., BLACKWELL, P.G., BRONK, RAMSEY, C., BUCK, C.E., CHENG, H., EDWARDS, R.L., FRIEDRICH, M., GROOTES, P.M., GUILDERSON, T.P., HAFLIDASON, H., HAJDAS, I., HATtÉ, C., HEATON, T.J., HOFFMANN, D.L., HOGG, A.G., HUGHEN, K.A., KAISER, K.F., KROMER, B., MANNING, S.W., NIU, M., REIMER, R.W., RICHARDS, D.A., SCOTT, E.M., SOUTHON, J.R., STAFF, R.A., TURNEY, C.S.M., VAN DER PLICHT, J. 2013. IntCal13 and Marine13 radiocarbon age calibration curves $0-50,000$ years cal BP. Radiocarbon, v. 55, n. 4, p.1869-1887.

RODRIGUES, R. R., LORENZZETTI, J. A., 2001. A numerical study of the effects of bottom topography and coastline geometry on the Southeast Brazilian coastal upwelling. Continental shelf research, v. 21, p. 371-394.

RODRIGUES, S. A., LOTUFO, T., ROCHA, M. 1999. Ascidiacea. In: JOLY, C. A., BICUDO, C. E. M. (ed) Biodiversidade do Estado de São Paulo. Síntese do conhecimento ao final do século XX. São Paulo, FAPESP, 331p. 
ROTH, P. 1994. Distribution of coccoliths in oceanic sediments. In: Winter, A. e Siesser, W. (ed). Coccolithophores. Cambrige University Press, Cambrige, p. 199-218.

ROTH P.H., THIERSTEIN H.R. 1972. Calcareous nannoplankton: Leg 14 of the Deep Sea Drilling Project. In: HAYS D.E., PIMM A.C., et al. (ed), Initial Reports of the Deep Sea Drilling Project, 14, U.S. Government Printing Office, Washington, D.C., p. 421-485.

SAlGUEIRO, E., NAUGHTON, F., VOELKER, A.H.L., de ABREU, L., ALBERTO, A., ROSSIGNOL, L., DUPRAT, J., MAGAlHÃES, V.H., VAQUEIRO, S., TURON, J.-L., ABRANTES, F. 2014. Past circulation along the western Iberian margin: a time slice vision from the Last Glacial to the Holocene. Quaternary Science Reviews, v. 106, p. 316-329.

SANT'ANNA NETO, J. L. S., NERY, J. T. 2005. Variabilidade e mudanças climáticas no Brasil e seus impactos regionais. In: SOUZA, C. R. G.; SUGUIO, K.; OLIVEIRA, A. M. S.; OLIVEIRA, P. E. (ed). Quaternário do Brasil. Ribeirão Preto: Holos. p. 28-51.

SANTOS, J.F.C. 2016. Contribuição ao estudo da estimativa da produtividade primária por satélite na margem continental sudeste brasileira. Dissertação de Mestrado. Instituto Nacional de Pesquisa Espaciais, 131 p.

SANTOS, T.P., LESSA, D., VENANCIO, I.M., CHIESSI, C.M., MULITZA, S., KUHNERT, H., GOVIN, A., MACHADO, T., COSTA, K.B., TOLEDO, F.A., DIAS, B.B., ALBUQUERQUE, A.L.S. 2017. Prolonged warming of the Brazil Current precedes deglaciations. Earth and Planetary Science Letters, v. 463, p. $1-12$.

SCHULZ, M., MUDELSEE, M., 2002. REDFIT: estimating red-noise spectra directly from unevenly spaced paleoclimatic time series. Comput. Geosci., v. 28, p. 421426.

SEYVE, C. 1990. Introdução à Micropaleontologia. Universidade A. Neto. Elf Aquitaine editor, Bousseens. 232p.

SHACKLETON, N.J. 1977. $\delta 13 \mathrm{C}$ in Uvigerina: Tropical rainforest history and the Equatorial Pacific carbonate dissolution cycles. In: ANDERSEN, N. R., 
MALAHOFF, A. (ed). The Fate of Fossil Fuel $\mathrm{CO}_{2}$ in the Oceans. New York: Plenum, p. 401-427.

SILVEIRA, I. C. A. DA., SCHIMIDT, A. C. K., CAMPOS, E. J. D., de GODOI, S. S., IKEDA, Y. 2000. A Corrente do Brasil ao Largo da Costa Leste Brasileira, Rev. bras. Oceanogr., v. 48, n. 2, p. 171-183(C11).

SPRATT, R. M.; LISIECKI, L.E. 2016. A Late Pleistocene sea level stack, Climate of the Past, v. 12, p. 1079-1092.

STRAMMA, L., ENGLAND, M.H., 1999. On the water masses and mean circulation of the South Atlantic Ocean. Journal of Geophysical Research: Oceans (19782012) 104, p. 20863- 20883.

STRÍKIS, N.M., CHIESSI, C.M., CRUZ, F.W., VUILLE, M., CHENG, H., BARRETO, E.A. de S., MOLLENHAUER, G., KARSTEN, S., KARMANN, I., BERNAL, J.P., SALES, H.D.R. 2015. Timing and structure of Mega-SACZ events during Heinrich Stadial 1. Geophys. Res. Lett., v. 42, p. 1-8.

STRÍKIS, N. M., NOVELLO, V. F. 2014. Evolução Hidrológica do Brasil durante o Pleistoceno Superior e Holoceno. In: CARVALHO, I.S., GARCIA, M.J., Lana, C.C., STROHSCHOEN JR. O., (Org.). ALEONTOLOGIA: Cenários de vida Paleoclimas. 1ed.Rio de Janeiro: Interciência, v. 5, p. 343-351.

STUIVER, M., REIMER, P.J. 1993. Extended 14C data base and revised CALIB 3.0 14C age calibration program. Radiocarbon, v. 35, n. 1, p. 215-230.

THIERSTEIN, H.R., CORTES, M.Y., HAIDAR, A.T., 2004. Plankton community behaviour on ecological and evolutionary timescales: when models confront evidence. In: THIERSTEIN, H.R., YOUNG, J.R. (ed). Coccolithophores: From Molecular Processes to Global Impact. Springer-Verlag, p. 455-479.

TOGGWEILER, J., KEY, R. M. 2001. Ocean circulation: Thermohaline circulation. Encyclopedia of Atmospheric Sciences, v. 4, p. 1549-1555.

TOKUTAKE, L. R. 2005. Bioestratigrafia de Nanofósseis Calcários e Estratigrafia de Isótopos $(\mathrm{C}$ e $\mathrm{O})$ do talude médio, Quaternário, porção $\mathrm{N}$ da Bacia de Campos. Dissertação de mestrado. Instituto de Geociências, Universidade Federal do Rio Grande do Sul, 96 p.

TOLEDO, F. A. L. 2000. Variações Paleoceanográficas nos últimos 30.000 anos no oeste do Atlântico Sul: Isótopos de oxigênio, assembléias de foraminíferos planctônicos e nanofósseis calcários. Tese de Doutorado. Universidade Federal do Rio Grande do Sul, Instituto de Geociências, 245 p. 
TOLEDO, F.A.L.; AYUP-ZOUAIN, R.N.; COSTA, K.C. 1999. Análise fatorial (modoQ) em estudos quantitativos de nanofósseis calcários do Quaternário superior em um testemunho da Bacia de Campos, RJ-Brasil. Pesquisas, v. 26, p. 62-72.

URIARTE, A. 2000. Historia del clima de La Tierra. Servicio Central de Publicaciones del Gobierno Vasco. $2^{\mathrm{a}}$ edição. 403 p.

VALENTIN, J.L. 2000. Ecologia numérica: Uma introdução à análise multivariada de dados ecológicos. Editora Interciência, Rio de Janeiro, 117 p.

VALENTIN, J.L. 2001. The Cabo Frio upwelling system, Brazil. In: SEELIGER, U., KJERFVE, B. (ed). Coastal marine ecosystems of Latin America. Berlin: Springer, p. 97-105.

VERA, C., HIGGINS, W., AMADOR, J., AMBRIZZI, T. 2006. Toward a unified view of the 715 American monsoon systems. Journal of Sedimentary Petrology, v. 19, p. $4977-5000$.

WAELBROECK, C., LABEYRIE, L., MICHEL, E., DUPLESSY J.C., MCMANUS J. 2002. Sea-level and deep water temperature changes derived from benthic foraminifera isotopic records, Quaternary Sci. Rev., v. 21, p. 295-305.

WALISER, E.W.C., GAUTIER, C. 1993. A Satellite-derived Climatology of the ITCZ. Journal of Climate, v. 6. p.2162-2174.

WALKER, M.J.C., BERKELHAMMER, M., BJÖRCK, S., CWYNAR, L.C., FISHER, D.A., LONG, A.J., LOWE, J.J., NEWNHAM, R.M., RASMUSSEN, S.O., WEISS, H. 2012. Formal subdivision of the Holocene Series/ Epoch: a Discussion Paper by a Working Group of INTIMATE (Integration of ice-core marine and terrestrial records) and the Subcommission on Quaternary Stratigraphy (International Commission on Stratigraphy). J. Quaternary Sci., v. 27, p. 649-659.

WANG, X., AULER, A.S., EDWARDS, R.L., CHENG, H., ITO, E., WANG, Y., KONG, X., SOLHEID, M., 2007. Millennial-scale precipitation changes in southern Brazil over the past 90,000 years. Geophys. Res. Lett., v. 34, L23701.

WELTJE, G.J., TJALLINGII, R. 2008. Calibration of XRF core scanners for quantitative geochemical logging of sediment cores: theory and application. Earth and Planetary Science Letters, v. 274, p. 423-438. 
WESTBROEK, P., BROWN, C.W., BLEIJSWIJK, J.V., BROWNLEE, C., BRUMMER, G.J., CONTE, M., EGGE, J., FERNÁNDEZ, E., JORDAN, R., KNAPPERTSBUSCH, M., STEFELS, J., VELDHUIS, M., WAL, P.V.D., YOUNG, J. 1993. A model system approach to biological climate forcing. The example of Emiliania huxleyi. Global and Planetary change, v. 8, p. 27-46.

WINTER, A., JORDAN, R.W., ROTH, P.H. 1994. Biogeography of living coccolithophores in the ocean waters. In: WINTER, A., SIESSER, W. (ed). 75 Coccolithophores. Cambrige University Press, Cambrige, p. 161-177.

YOKOYAMA, Y., LAMBECK, K., DE DEKKAR, P., JOHNSTON, P., FIFIELD, L.K., 2000. Timing of the last glacial maximum from observed sealevel minima. Nature, v. 406, p. 713-716.

ZEMBRUSCKI, S. G. 1979. Geomorfologia da margem continental sul brasileira e das bacias oceânicas adjacentes. In: Hernani A. F. Chaves (ed), Relatório Final, Série Projeto REMAC N.7, PETROBRAS/CENPES/DINTEP, Rio de Janeiro, $177 \mathrm{p}$.

ZHANG, R.; DELWORTH, T. L. 2005. Simulated tropical response to a substantial weakening of the Atlantic thermohaline circulation. Journal of Climate, v. 18, n. 12, p. 1853-1860.

ZIVERI, P., BAUMANN, K.-H., BÖCKEL, B., BOLLMANN, J., YOUNG, J.R. 2004. Biogeography of selected Holocene coccoliths in the Atlantic Ocean. In: THIERSTEIN, H.R., YOUNG, J.R. (ed). Coccolithophores: From Molecular Processes to Global Impact. Springer-Verlag, p. 403-428. 
11. Anexos 
Anexo 1: Fotomicrografia de entidades taxonômicas observadas no testemunho KF-19
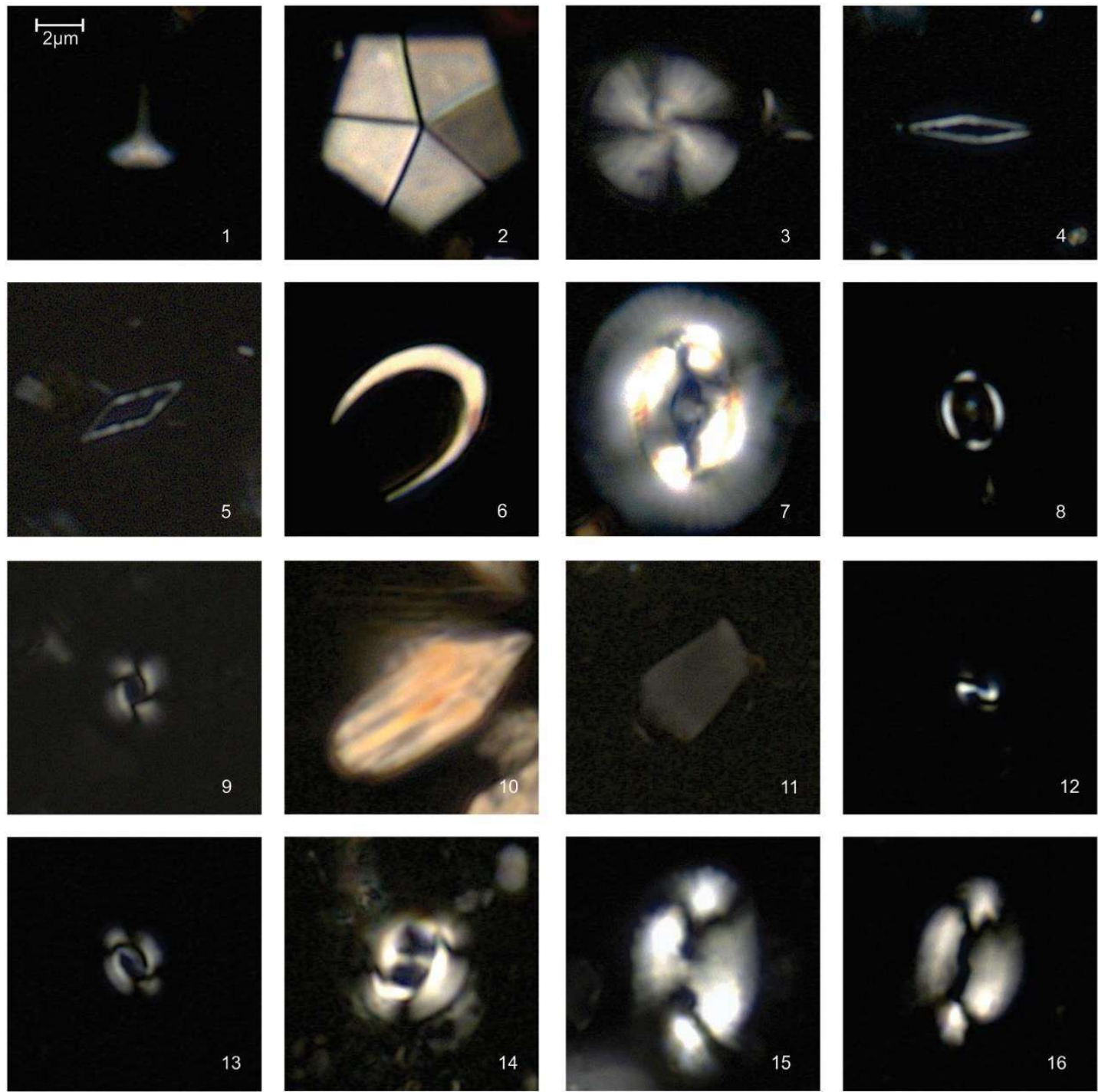

Foto: 1 Acanthoica sp.; 2 Braarudosphaera bigelowii; 3 Calcidiscus leptoporus e Discosphaera tubifera, amostra; 4 Calciosolenia brasiliensis; 5 Calciosolenia murrayi; 6 Ceratolithus cristatus; 7 Coccolithus pelagicus (braarudii); 8 Coronosphaera mediteranea; 9 Emiliania huxleyi; 10 Espicula de Ascídia; 11Florisphaera profunda; 12 Gephyrocapsa ericsonii; 13 Gephyrocapsa muelerae; 14 Gephyrocapsa oceanica; 15 Helicosphaera carteri; 16 Helicosphaera wallichii.

Fotos com nicóis cruzados

\begin{tabular}{l|l} 
Direções de \\
polarização
\end{tabular} 
Anexo 2: Fotomicrografia de entidades taxonômicas observadas no testemunho KF-19
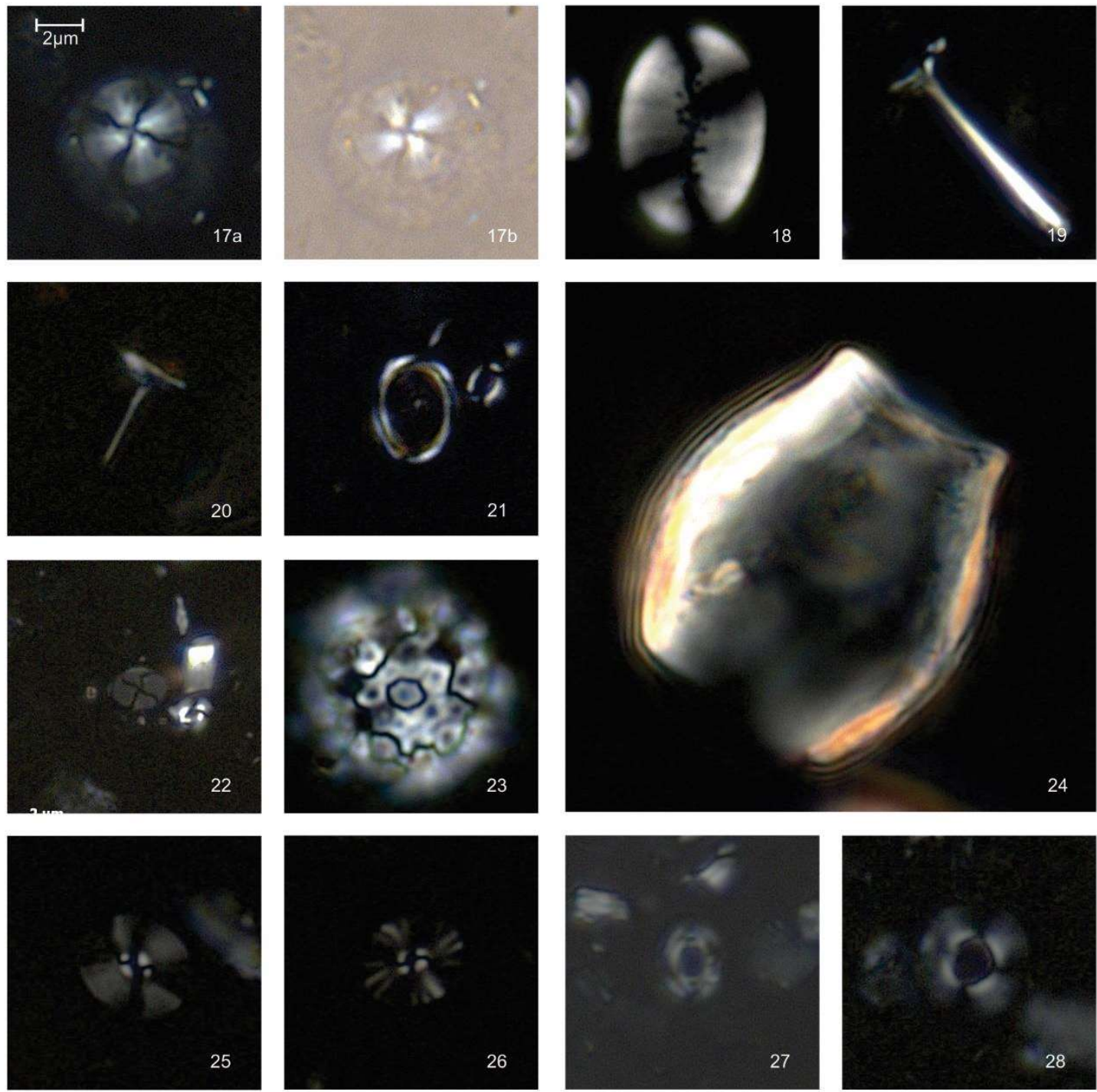

Foto:17a e 17b Oolithotus fragilis; 18 Pontosphaera messine; 19 Rhabdosphaera clavigera; 20 Rhabdosphaera stylifera; 21 Syracosphaera pulchra; 22 Tetralithoides quadrilaminata; 23 Thoracosphaera sp.; 24 Scyphosphaera apsteinii; 25 Umbellosphaera irregularis; 26 Umbellosphaera tenuis; 27 Umbilicosphaera huburtiana; 28 Umbilicosphaera sibogae.

Fotos com fundo escuro: nicóis cruzados Foto com fundo claro: nicóis paralelos

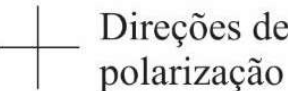




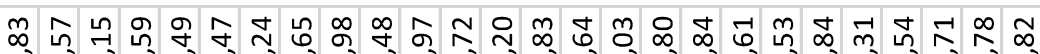

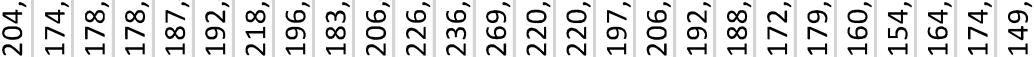
m

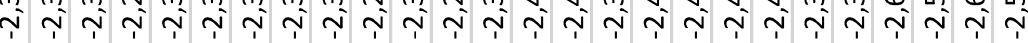

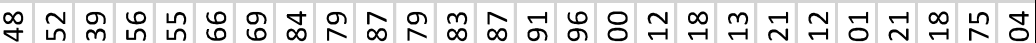

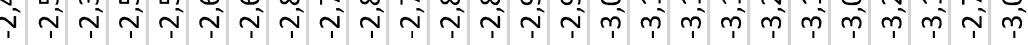

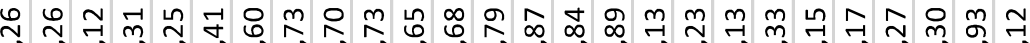

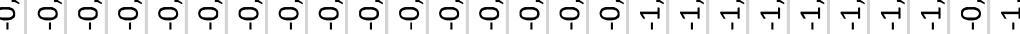
윴

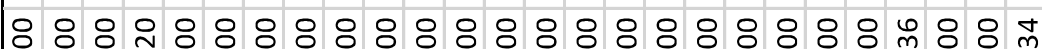

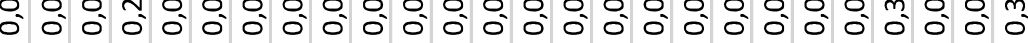
৪ o. 0 o. o.

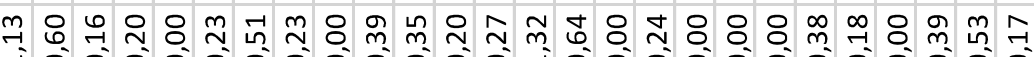

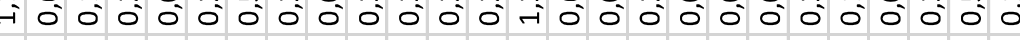

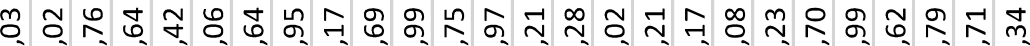
人́ñ

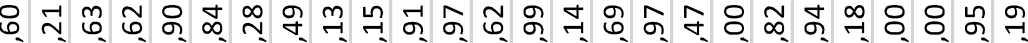
m ti tio ti mm

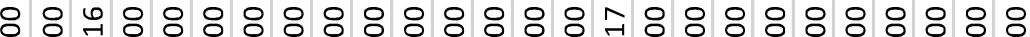

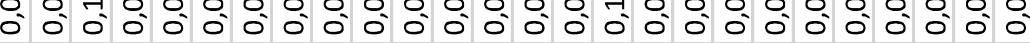

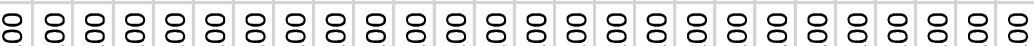

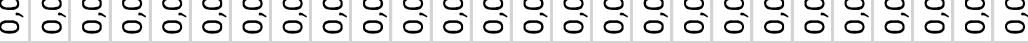

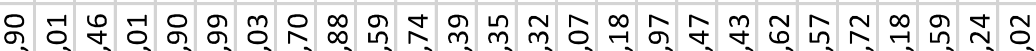

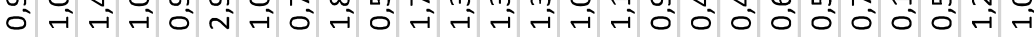

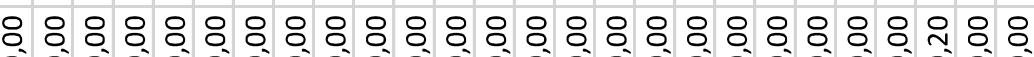
00000000000000000000000000

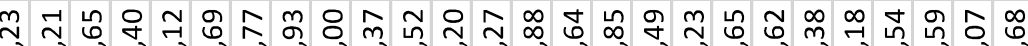

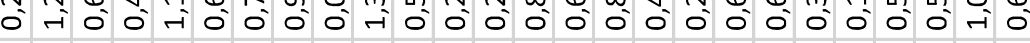
৪৪৪৪ ৪৪৪৪৪৪৪৪৪৪৪৪৪৪৪৪৪৪৪৪৪

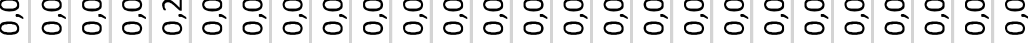
৪৪৪৪ N N

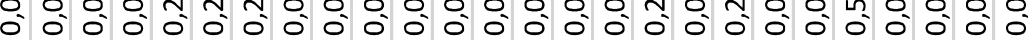
৪৪৪৪৪৪৪৪৪৪৪৪৪৪৪

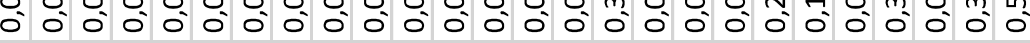

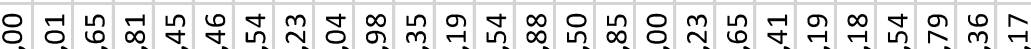

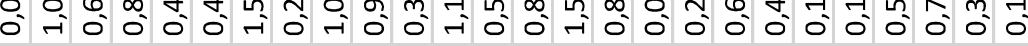
는

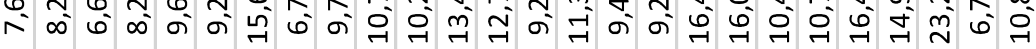

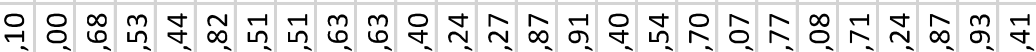

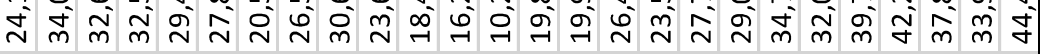

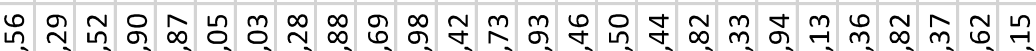

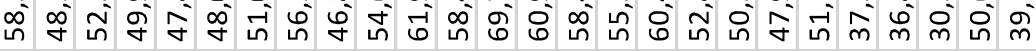

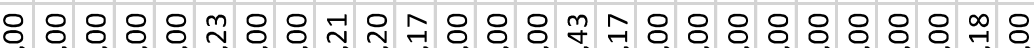

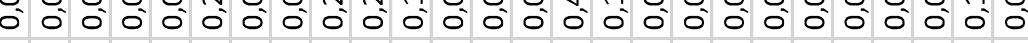

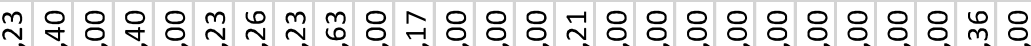

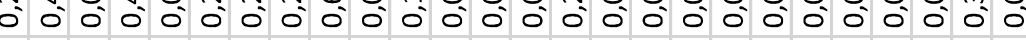

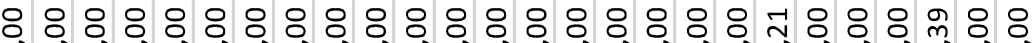

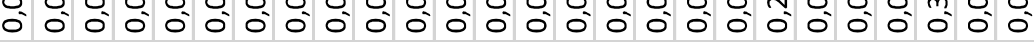

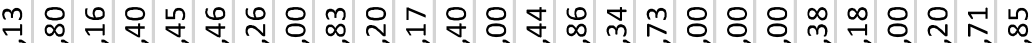

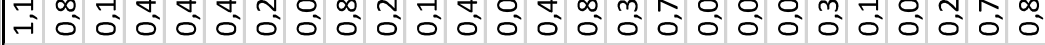
ケㅇำ

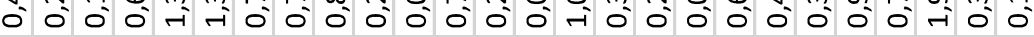

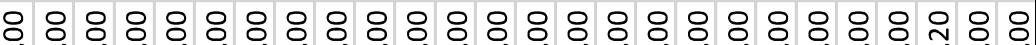

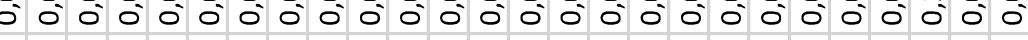

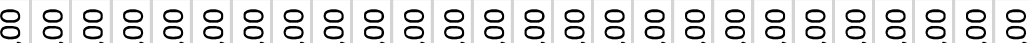

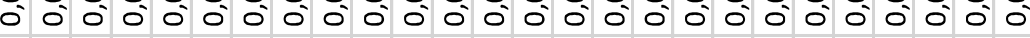

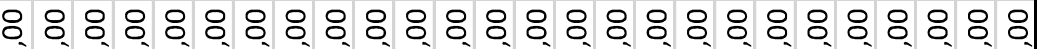

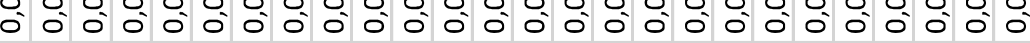

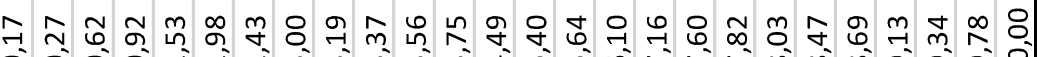




\begin{tabular}{|c|c|}
\hline (oue/Zvw/ว§) dd & 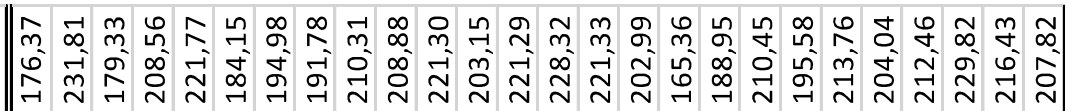 \\
\hline$(! S / \mid \forall)$ uा & 萑 \\
\hline (eכ/!1)u| & 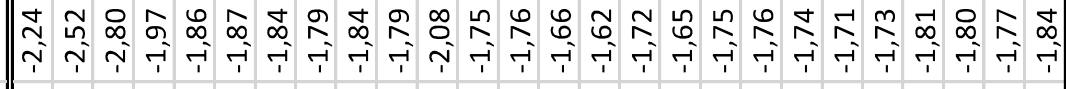 \\
\hline 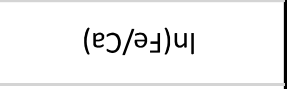 & 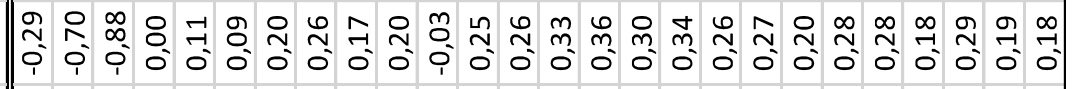 \\
\hline$\left(x_{/} / \partial^{\prime}\right)$ uा & 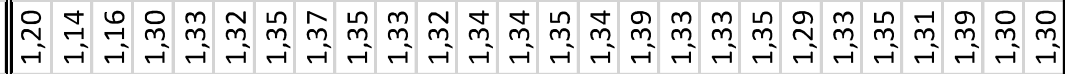 \\
\hline se|nગ̣ds] & 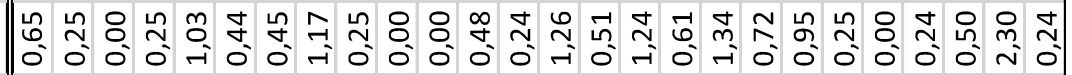 \\
\hline INJ & 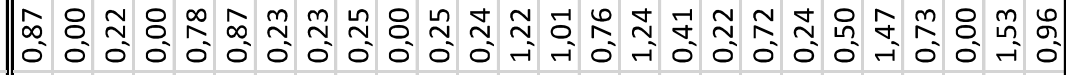 \\
\hline dWd & 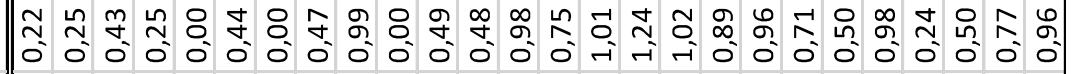 \\
\hline 'dds bגəbydsoכ!!!qun & 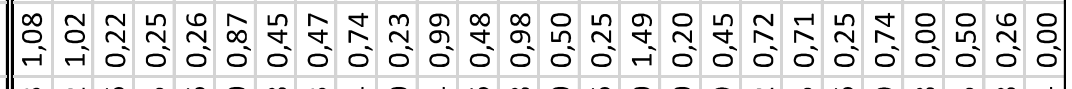 \\
\hline ·dds pגabydsol|zqun & 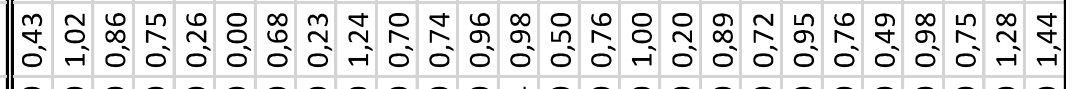 \\
\hline 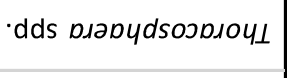 & 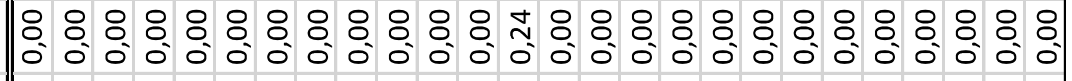 \\
\hline 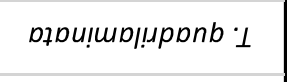 & 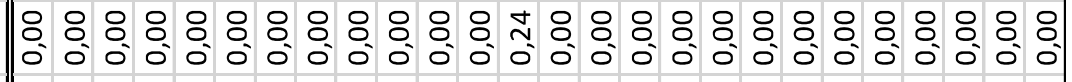 \\
\hline -dds bגəoydsoכDגKS & 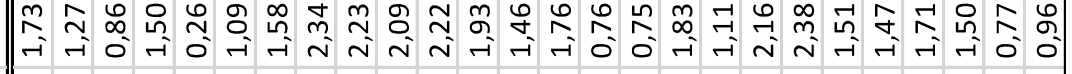 \\
\hline !!u!วłsdo $S$ & 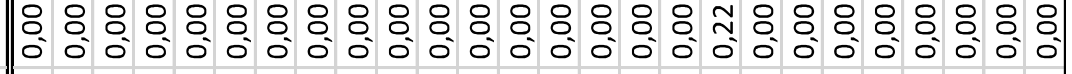 \\
\hline dds pגapydsopqpyy & 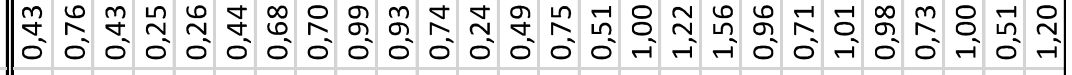 \\
\hline 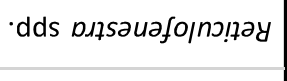 & 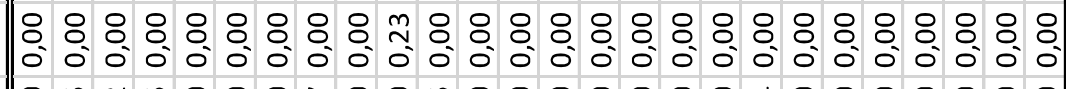 \\
\hline 'dds bגabydsozuod & 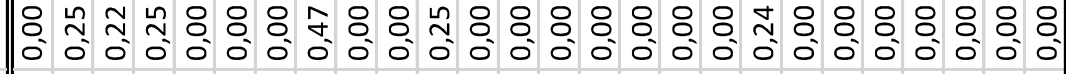 \\
\hline -dds sn¥oy?!!OO & 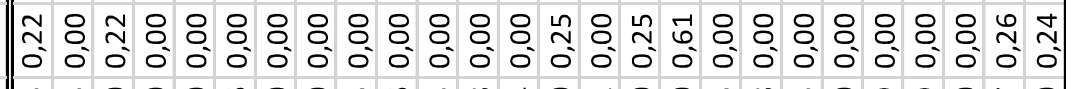 \\
\hline 'dds рגәруdsoכ!|әH & 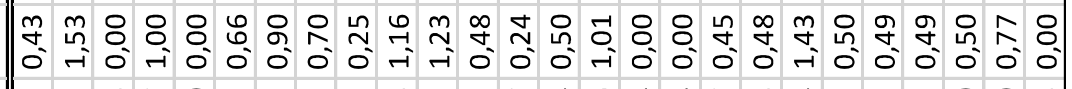 \\
\hline 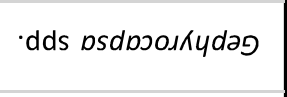 & 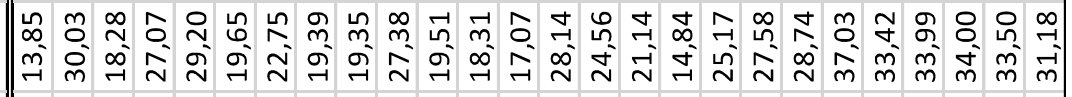 \\
\hline opunford' $y$ & 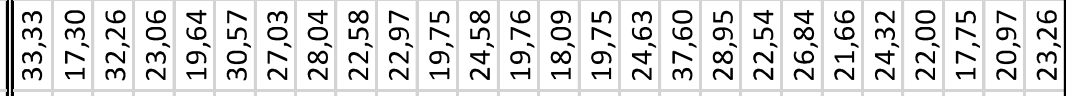 \\
\hline$!$ ! & 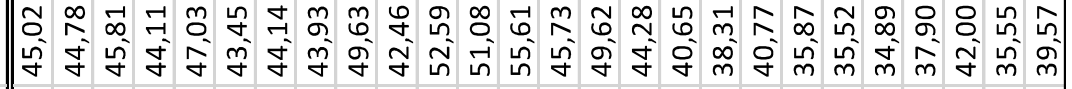 \\
\hline Dגaf!qnz $ם$ & : \\
\hline -dds DגәрудdsouoxoJ & 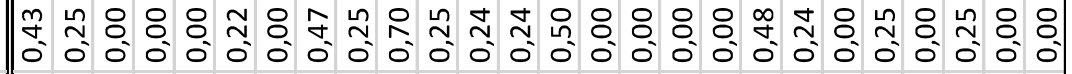 \\
\hline -dds sny?!!0ככ0כ & 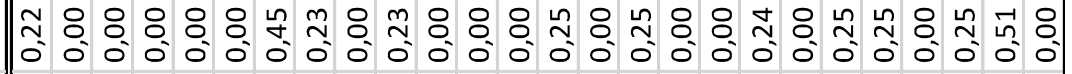 \\
\hline 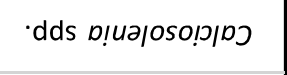 & ת̆ \\
\hline 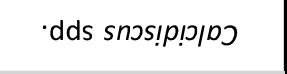 & 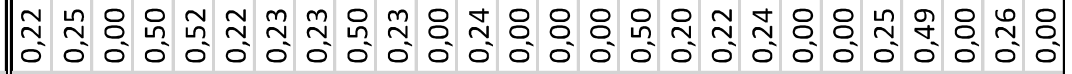 \\
\hline ·dds sny?!!|07DגaJ & 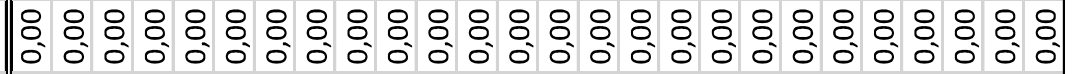 \\
\hline !!мораб!q 'я & 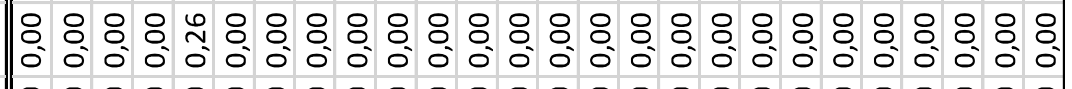 \\
\hline 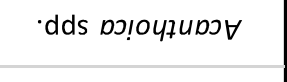 & 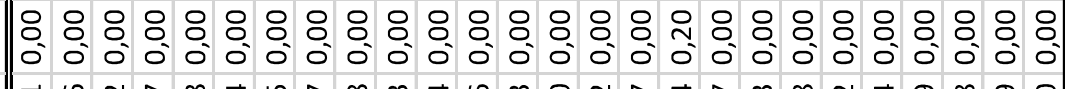 \\
\hline (оuеy) әрерI & 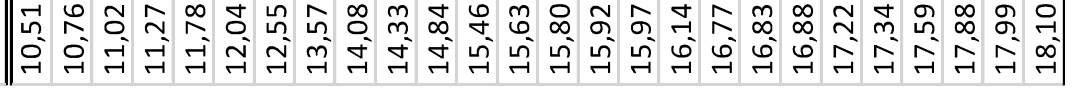 \\
\hline
\end{tabular}




\begin{tabular}{|c|c|}
\hline (oue/Zvm/כ8) dd & 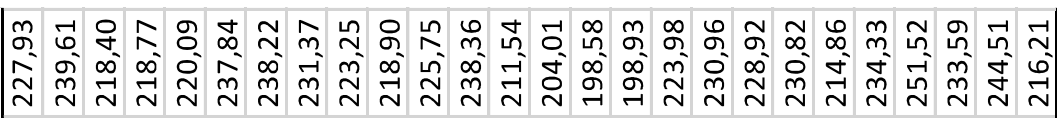 \\
\hline$(! S / \mid \forall)$ uा & 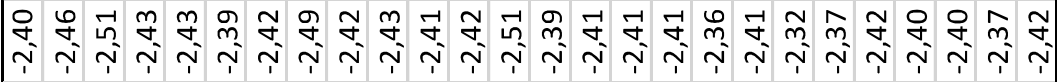 \\
\hline (eכ/!1)u| & 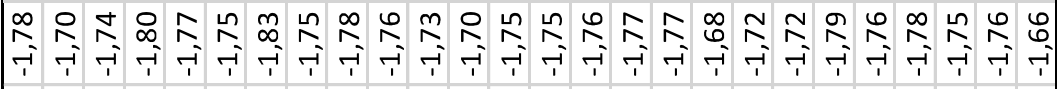 \\
\hline (eכ/ə寸)ul & 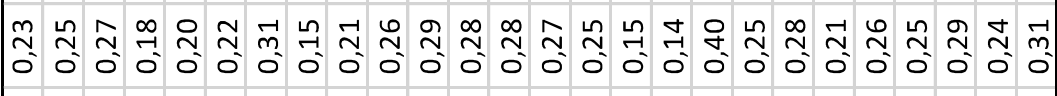 \\
\hline$\left(x / \partial_{-1}\right) \mathrm{ul}$ & 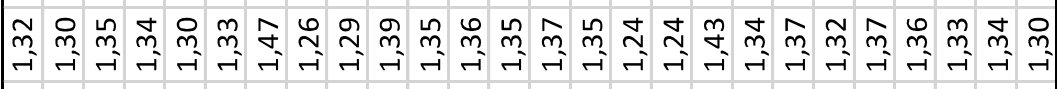 \\
\hline se|nọds] & 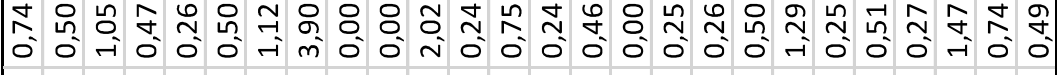 \\
\hline INJ & 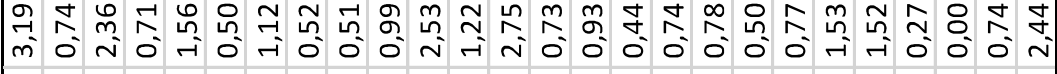 \\
\hline dWd & 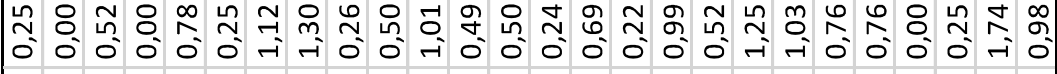 \\
\hline dds pגapydsoכ!!!qun & 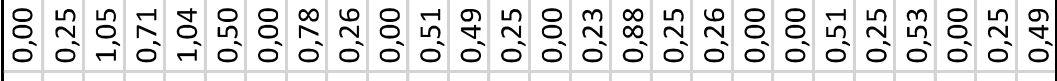 \\
\hline dds pגabydsol|zqun & 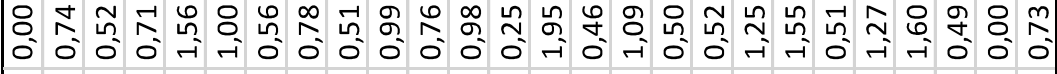 \\
\hline dds DגabydsoכDגOYL & 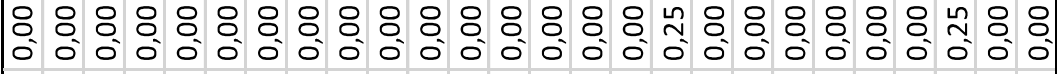 \\
\hline pұрu!ui!uponb $\perp$ & 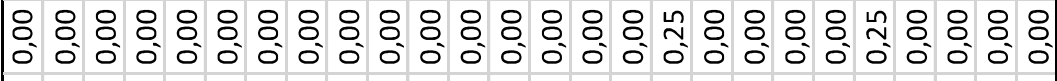 \\
\hline 'dds DגaDydsoכDגKS & 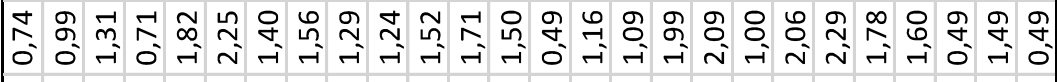 \\
\hline !lu!zวsdo S S & : : \\
\hline dds pגapydsopqbyy & స̂. \\
\hline 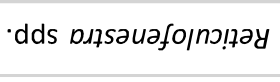 & 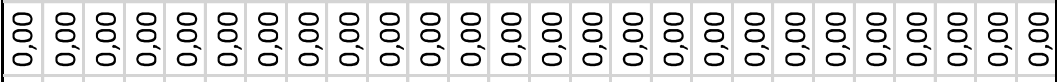 \\
\hline 'dds pдabydsozuod & 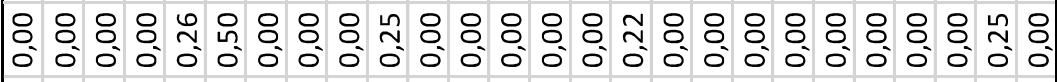 \\
\hline ·dds snłoy?!!OO & 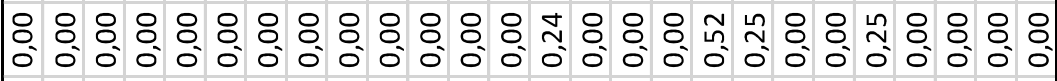 \\
\hline ·dds מגəDydsoכ!|כH & 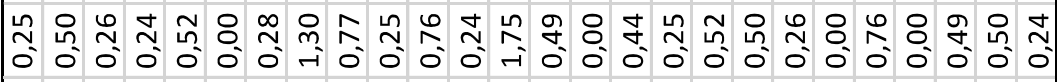 \\
\hline 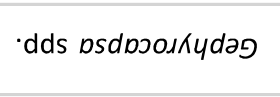 & 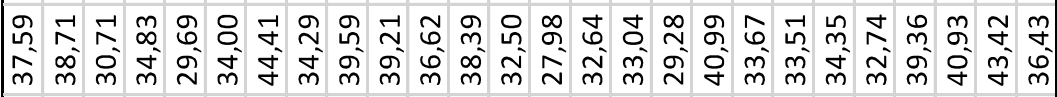 \\
\hline opunfosd' $y$ & 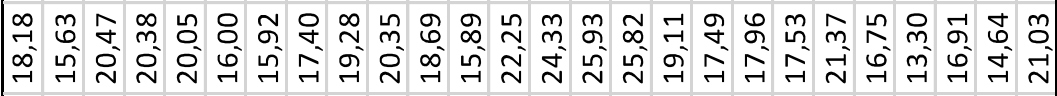 \\
\hline !Кархпу ’ $\exists$ & 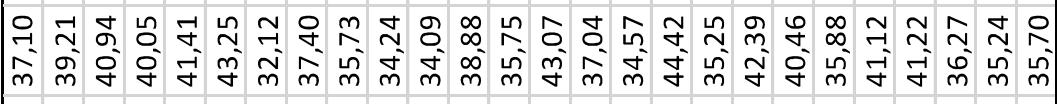 \\
\hline Dגaf!qnt 0 & 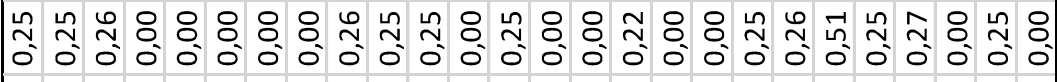 \\
\hline 'dds pגapydsouosoJ & 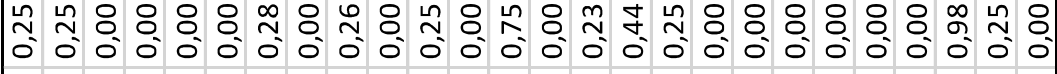 \\
\hline 'dds sny?!|0ככoכ & 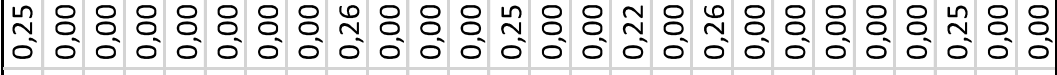 \\
\hline 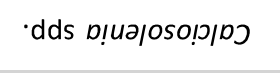 & 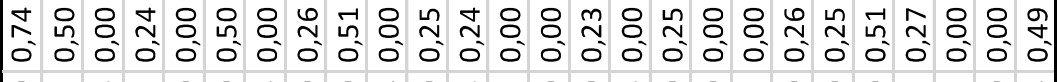 \\
\hline ·dds snכs!p!כ|כ) & 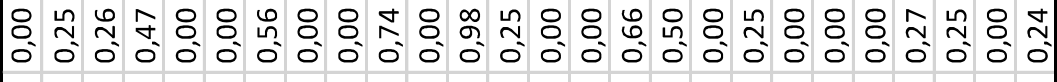 \\
\hline ·dds sny?!||07Dגaว & 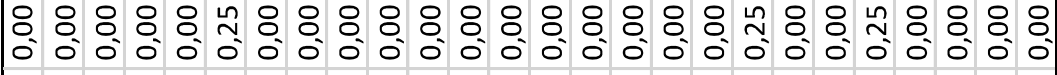 \\
\hline !!мораб!q ' & : $:$ : $:$ : $:$ : \\
\hline 'dds вэ!очдирэ & 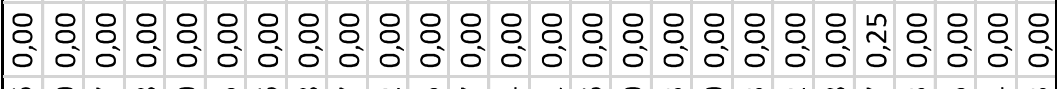 \\
\hline (оиеу) әрерІ & 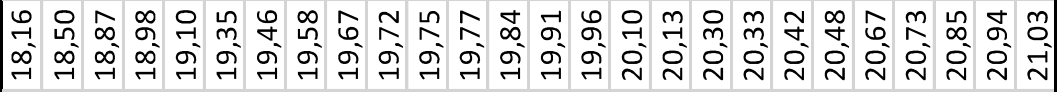 \\
\hline
\end{tabular}




\begin{tabular}{|c|c|}
\hline (oue/Zvm/د৪) dd & 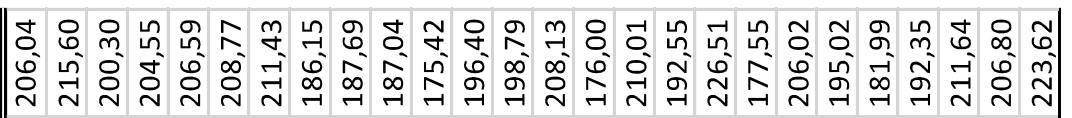 \\
\hline$(! S / \mid \forall)$ uा & 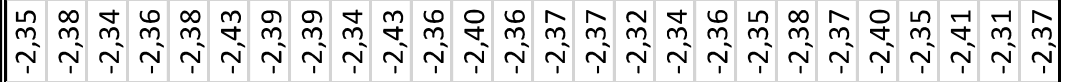 \\
\hline$(\mathrm{e} / ! \perp)$ uा & 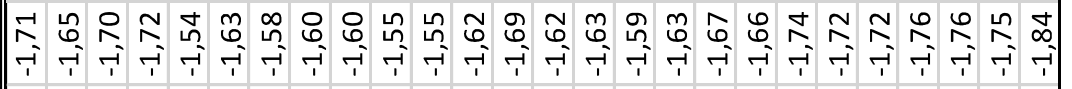 \\
\hline (eכ/Of)ul & 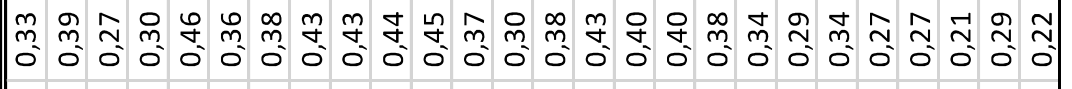 \\
\hline$\left(x / \partial_{-1}\right) \mathrm{ul}$ & 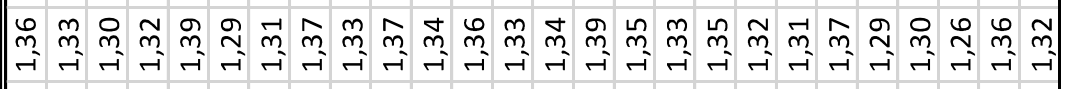 \\
\hline sejnગ̣ds $\exists$ & 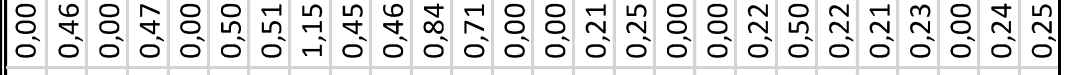 \\
\hline INJ & 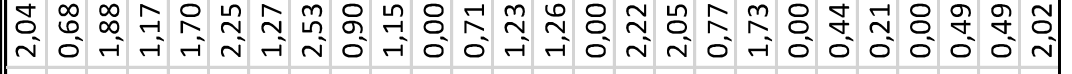 \\
\hline dWd & 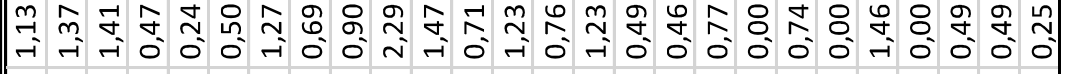 \\
\hline dds pגapydsoכ!!!qun & 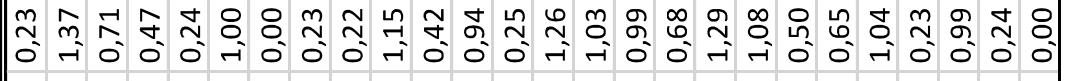 \\
\hline dds pגabydsol|aqun & S: \\
\hline dds DגabydsoכDגoYI & : : : : $: 0$ : \\
\hline pұрu!up! uppnb $\perp$ & 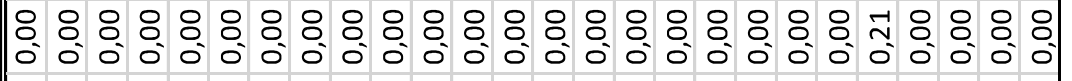 \\
\hline 'dds DגaDydsoכמאמא & 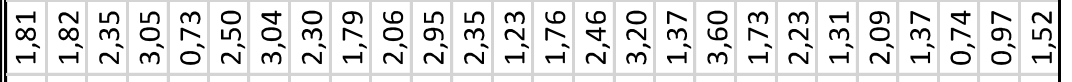 \\
\hline !!u!äsdo 's & 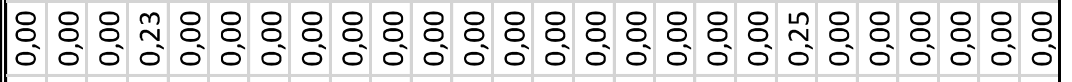 \\
\hline dds pגapydsopqpyy & 守守 \\
\hline 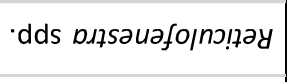 & : : : : : : : : $: 0: 0: 0$ \\
\hline 'dds bxabydsozuod & 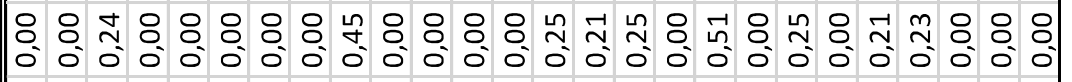 \\
\hline -dds snzou?!!100 & 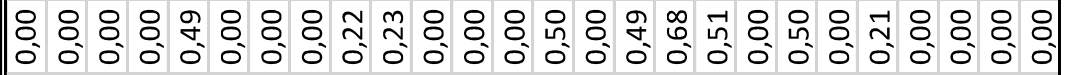 \\
\hline 'dds מגəסydsoכ!|כH & 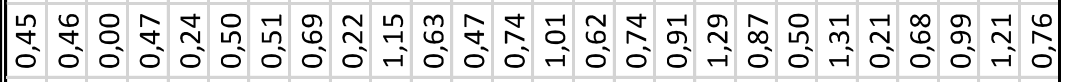 \\
\hline ·dds $b s d b \supset 01 K y d \partial g$ & 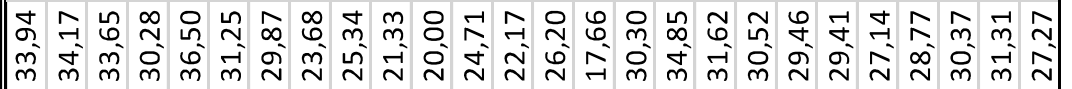 \\
\hline opunford' $y$ & 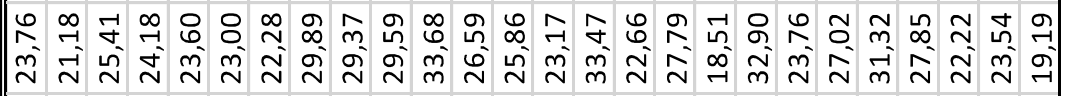 \\
\hline$!$ ! & 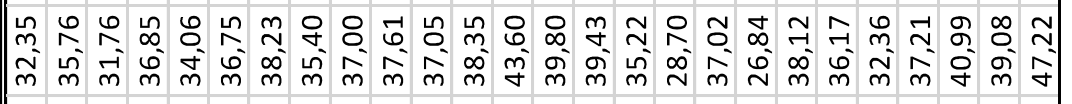 \\
\hline Dגəf!qnt 0 & 等 $8: 8$ \\
\hline 'dds pגabydsououoJ & 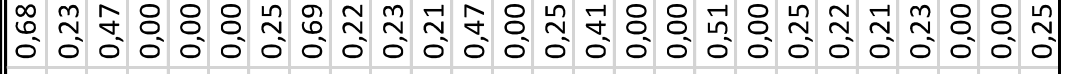 \\
\hline 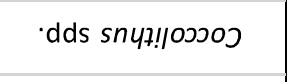 & : : : : : \\
\hline ·dds p!uəןosolगן & 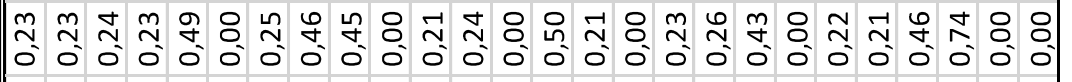 \\
\hline ·dds snכs!p!כוסכ & 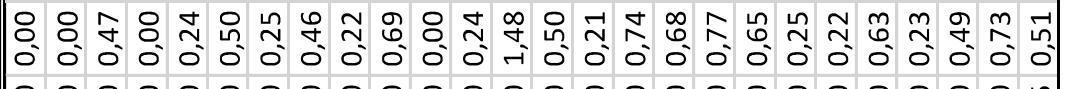 \\
\hline 'dds sny?!!070גəว & 영: $:$ \\
\hline !!мораб!q в & 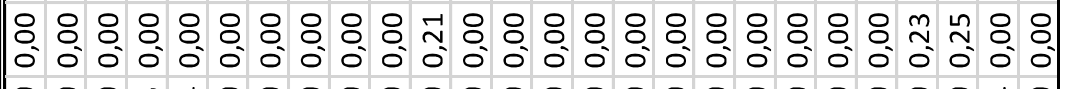 \\
\hline 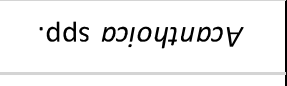 & 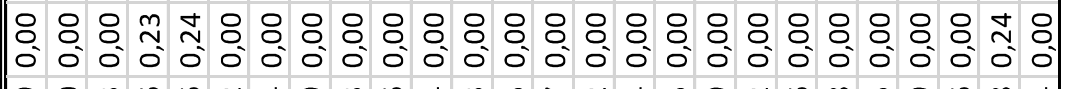 \\
\hline (ouey) әрері & 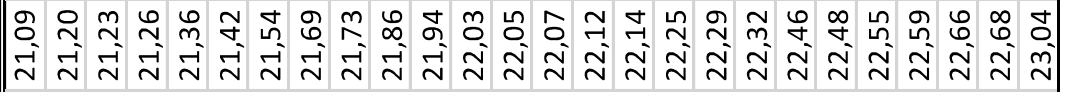 \\
\hline
\end{tabular}




\begin{tabular}{|c|c|}
\hline (oue/Zvw/J8) $d d$ & 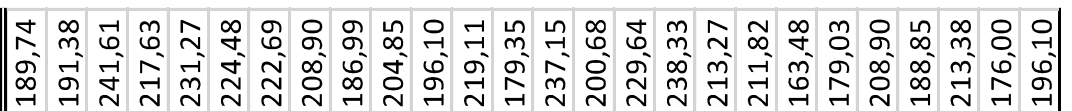 \\
\hline$(! S / \mid \forall)$ uा & 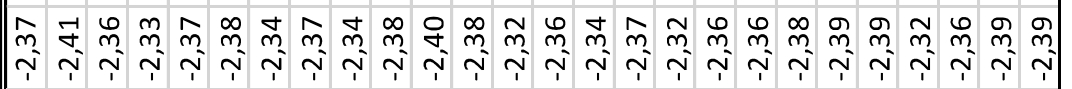 \\
\hline$(\mathrm{eJ} / ! \perp)$ uा & 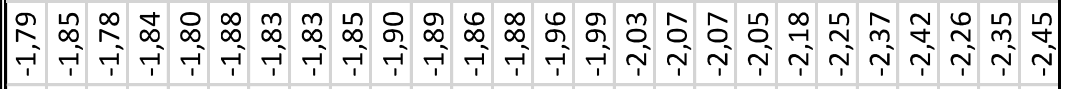 \\
\hline$\left(\mathrm{eJ} / \mathrm{Ag}_{\mathrm{A}}\right) \mathrm{ul}$ & 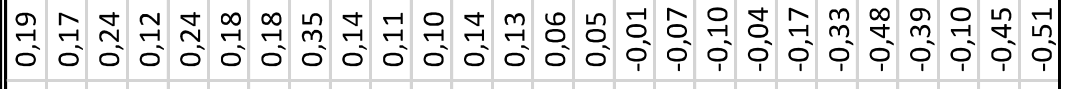 \\
\hline$\left(x / \partial_{-1}\right) \mathrm{ul}$ & 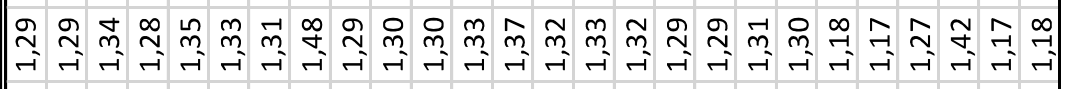 \\
\hline se|nગְds & 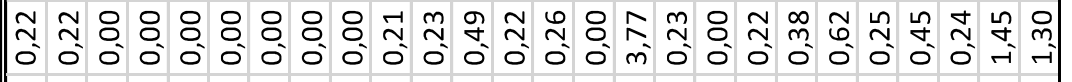 \\
\hline INJ & 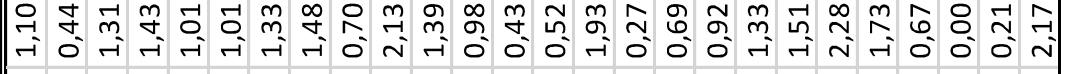 \\
\hline dWd & 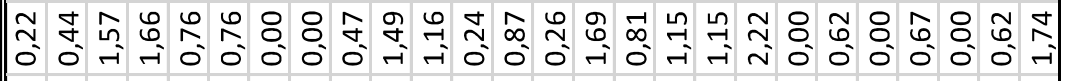 \\
\hline dds pגapydsoכ!!!qun & 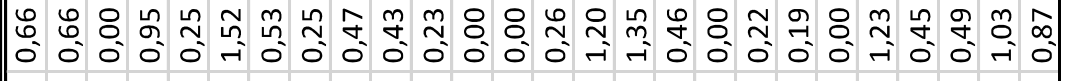 \\
\hline dds pגabydso|laqun & 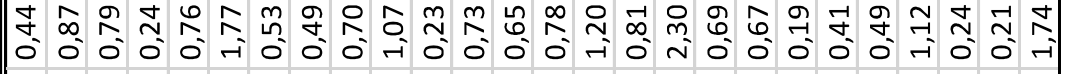 \\
\hline dds DגabydsoכDגOYL & 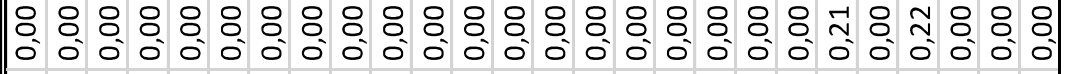 \\
\hline рұрu!шр|! & 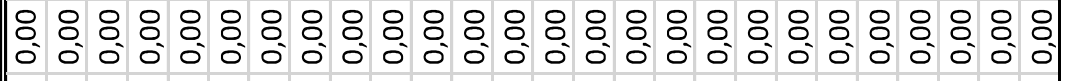 \\
\hline 'dds DגaDydsoכמאואS & 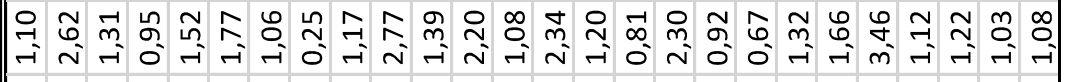 \\
\hline$! ! u \mid a z s d D$ 'S & : : : \\
\hline dds pגapydsopqpyy & 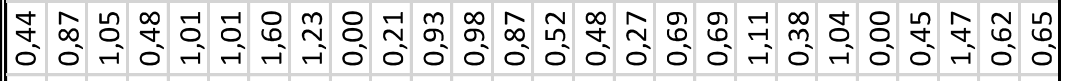 \\
\hline 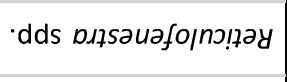 & 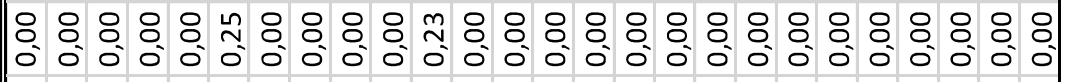 \\
\hline dds prabydsozuod & 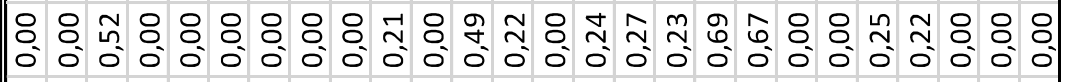 \\
\hline -dds snzo4?!!100 & 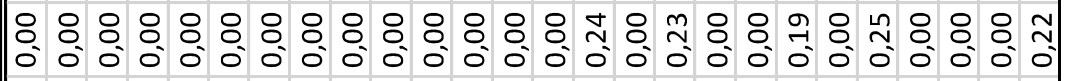 \\
\hline -dds Dגəסydsoכ!|כH & 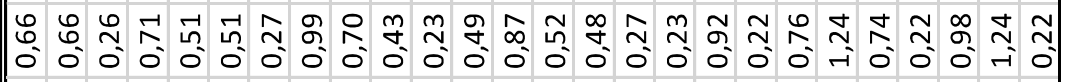 \\
\hline$\cdot d d s$ psdbכoגरydag & 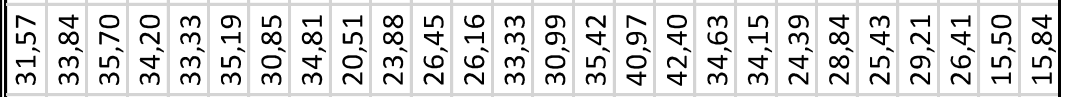 \\
\hline opunford' $y$ & 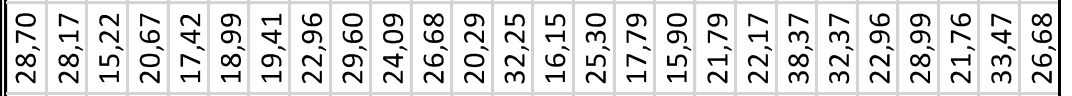 \\
\hline$!$ ! & 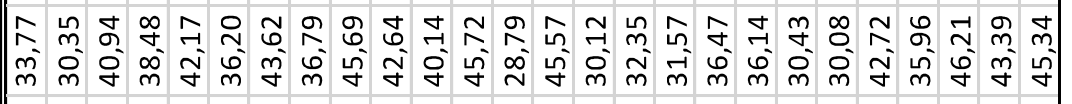 \\
\hline Dגaf!qn? & S: \\
\hline 'dds pגabydsououoJ & 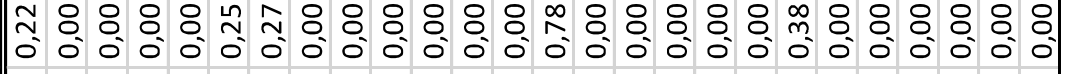 \\
\hline ·dds sny?!!0כ00כ & 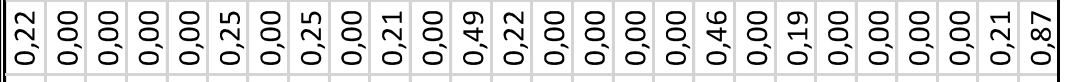 \\
\hline 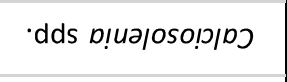 & ผูก \& \& \\
\hline 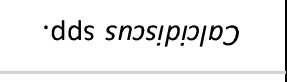 & 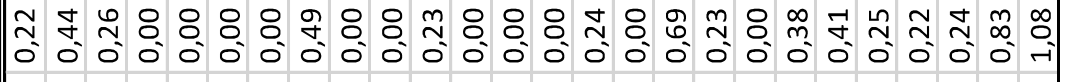 \\
\hline 'dds sny?!!|07Dגaว & : $:$ : $: \circ:$ \\
\hline !!мораб!q 'я & 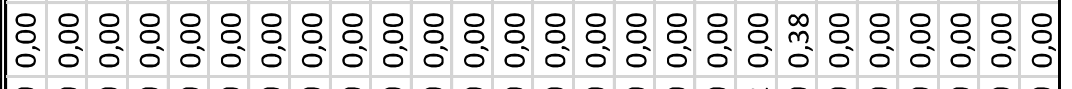 \\
\hline 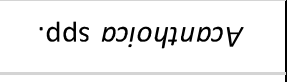 & 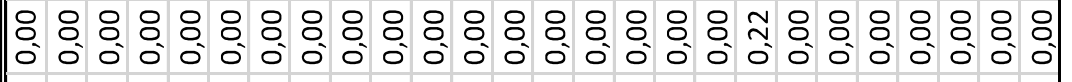 \\
\hline (оuеy) әрерІ & $\approx$. \\
\hline
\end{tabular}




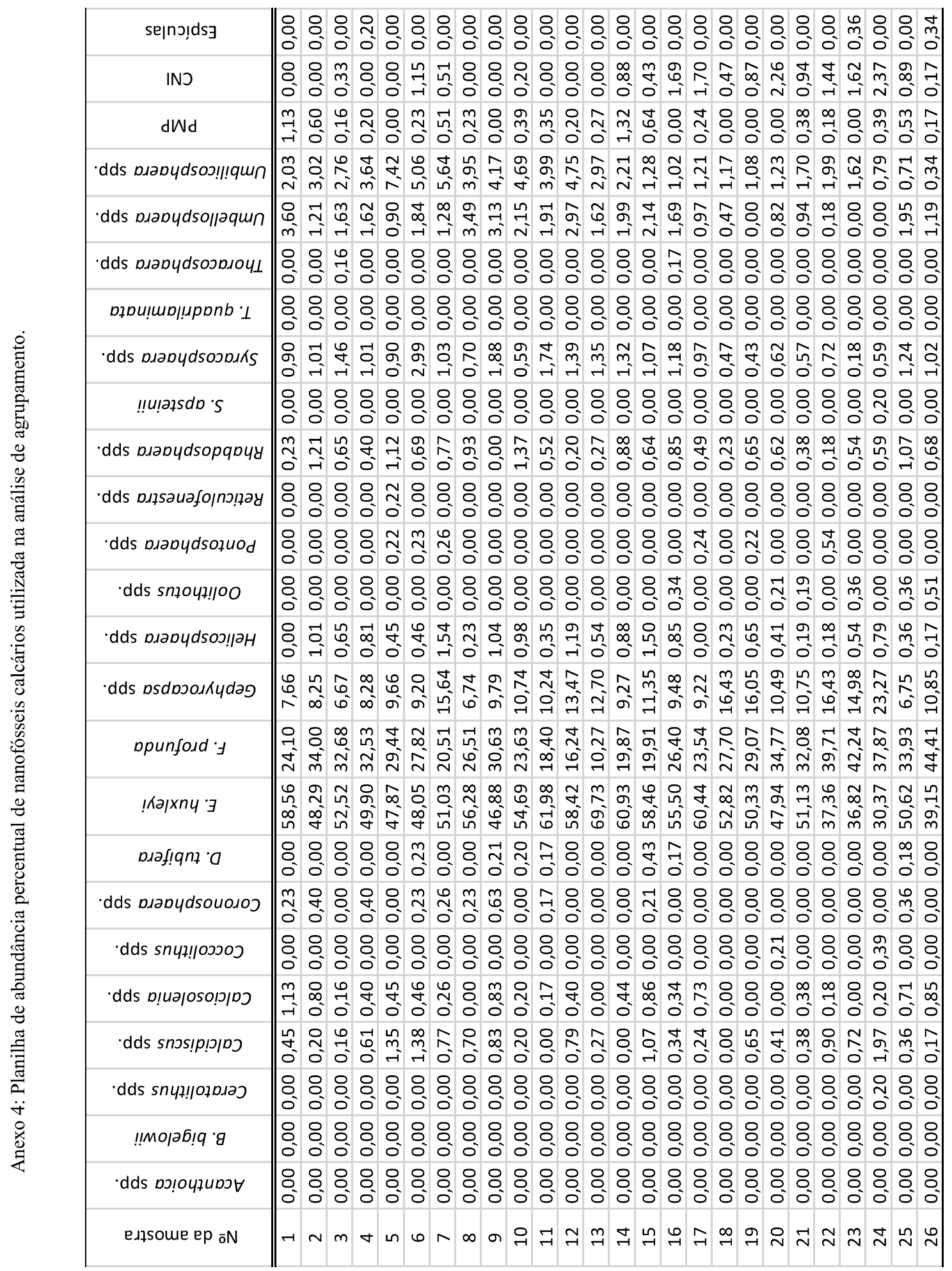




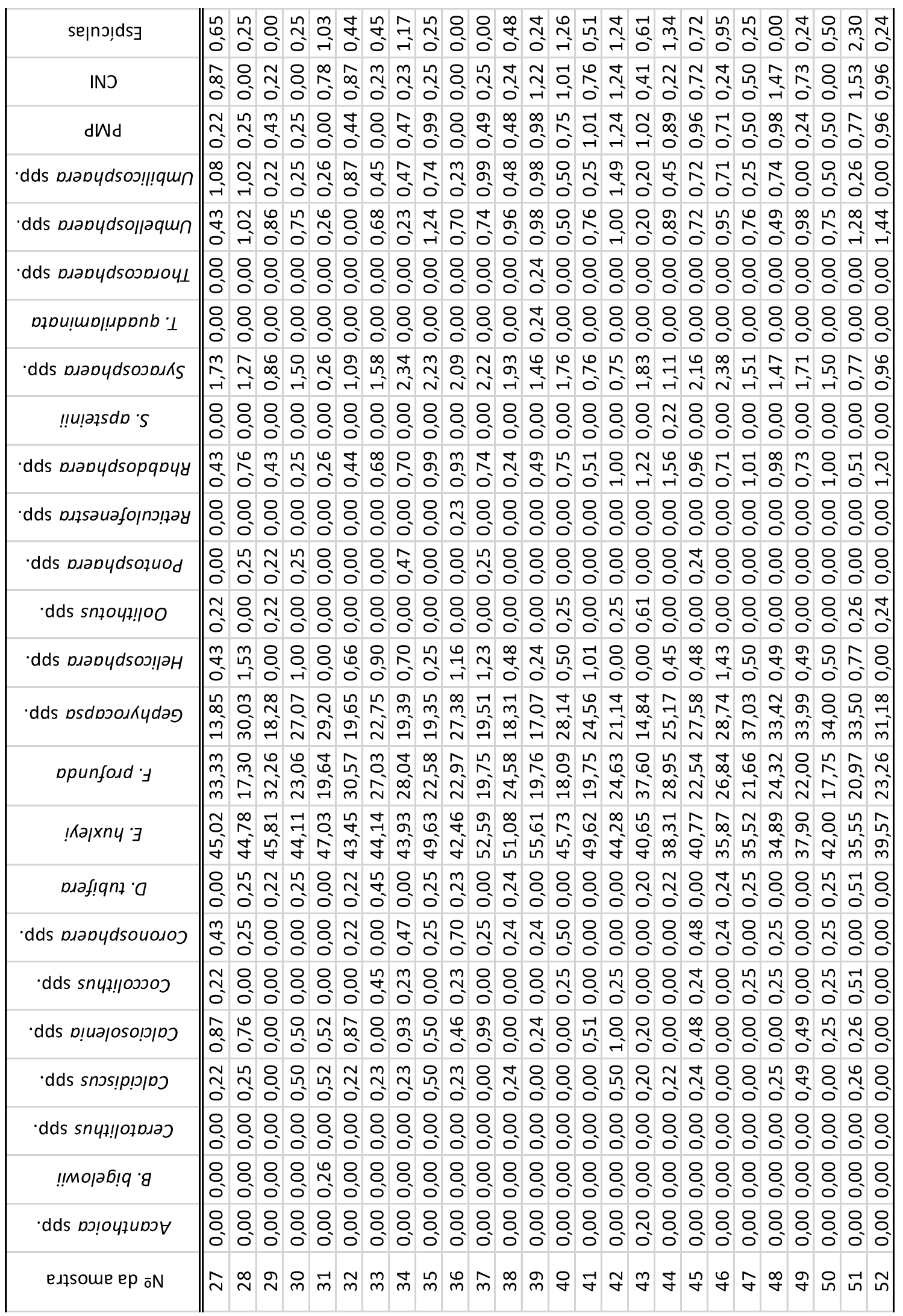




\begin{tabular}{|c|c|}
\hline seןnગ,ds & 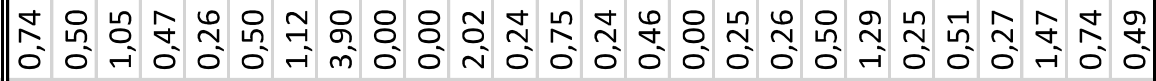 \\
\hline INJ & 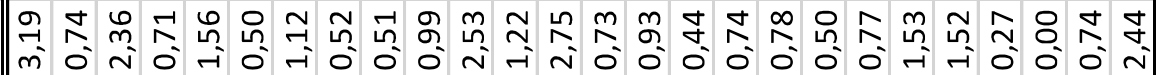 \\
\hline dWd & 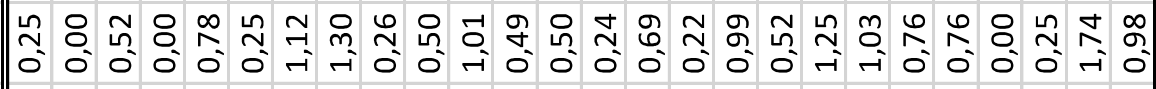 \\
\hline dds pıарydsoJ!!!qun || & 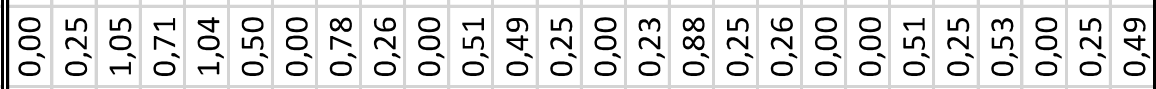 \\
\hline 'dds prapydsollaqun || & 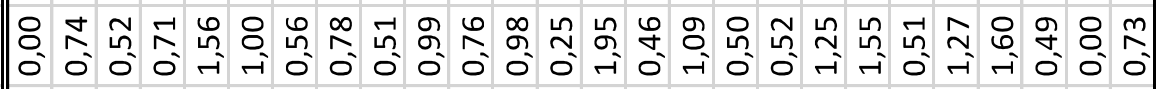 \\
\hline 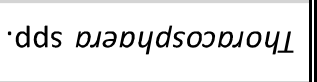 & 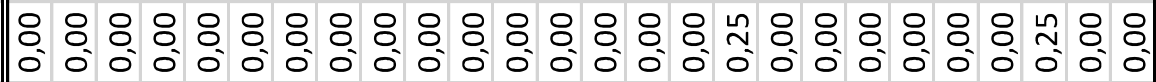 \\
\hline 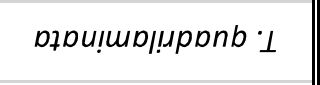 & 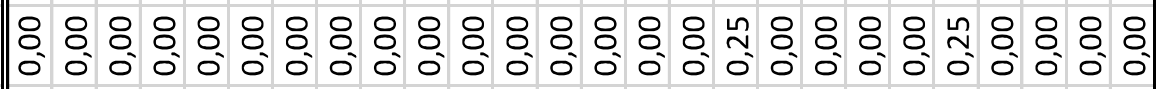 \\
\hline dds DגəoydsoכDגKs & 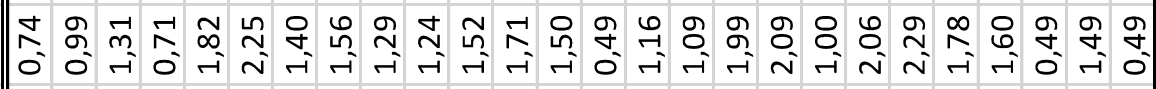 \\
\hline !!u!złs do 'S & 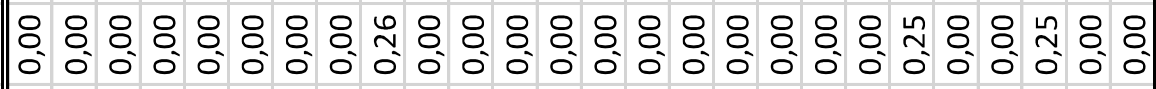 \\
\hline -dds pגabydsopqpyy & 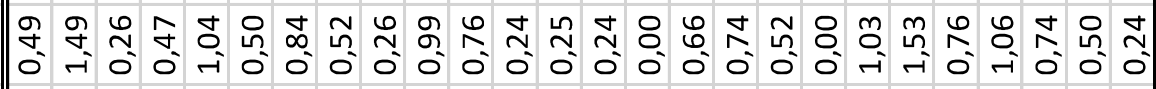 \\
\hline 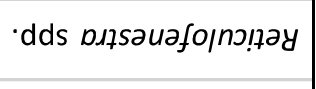 & 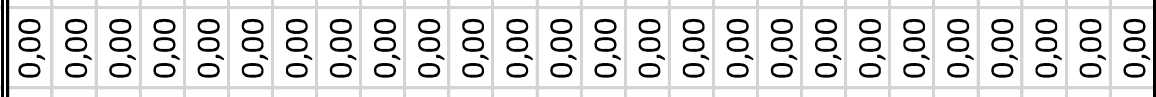 \\
\hline dds pגabydsozuod & 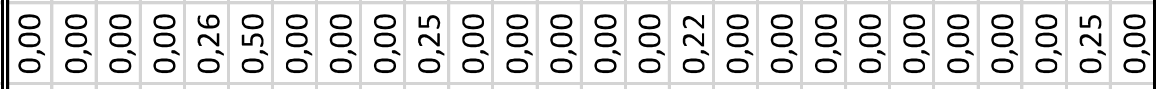 \\
\hline 'dds snłou¥!/0O & 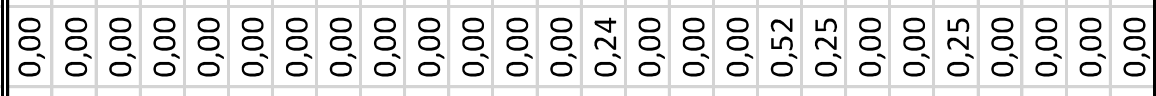 \\
\hline 'dds Dגəמydsoכ!|วH & 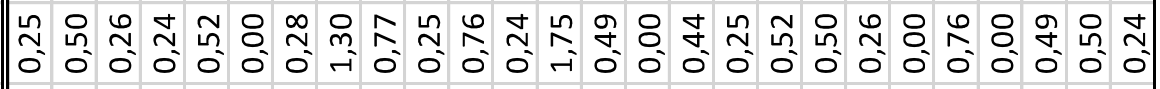 \\
\hline 'dds osdboukydag & 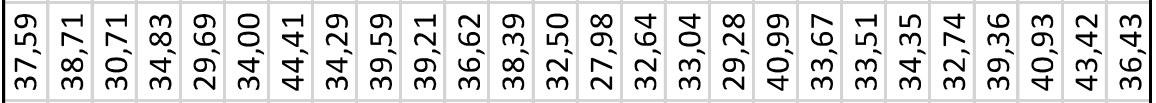 \\
\hline ppunford 'y & 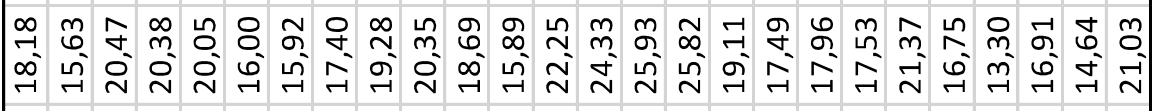 \\
\hline$!$ ! & 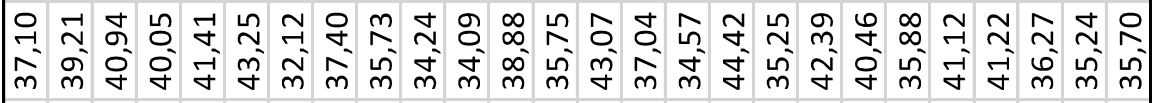 \\
\hline Dגaf!qnz • C & 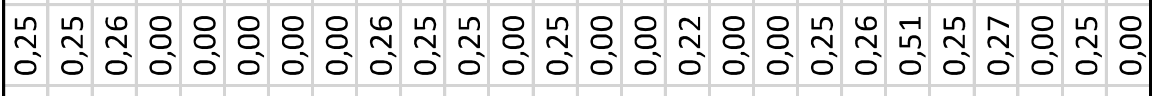 \\
\hline ·ds pגəoydsouosoJ & 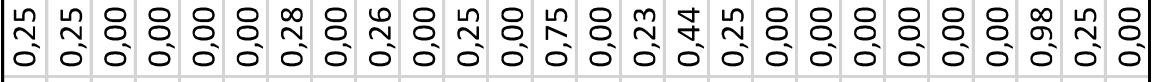 \\
\hline 'dds sny?!|0כว०כ & 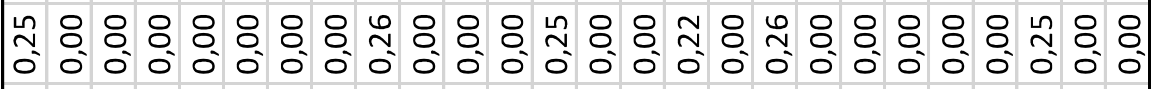 \\
\hline ·dds p! & 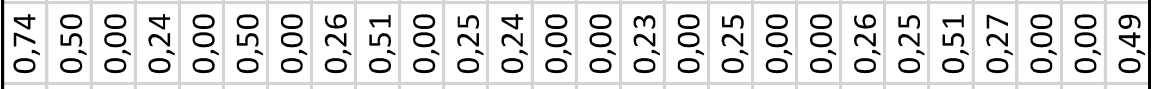 \\
\hline ·dds snכs!p!כ|כ) & 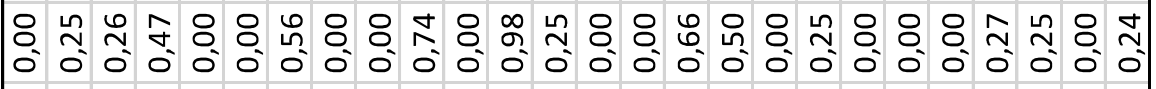 \\
\hline ·dds sny?!!07Dגaว & 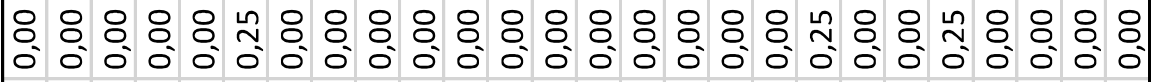 \\
\hline$! ! м 0 / 26 ! q \cdot g$ & 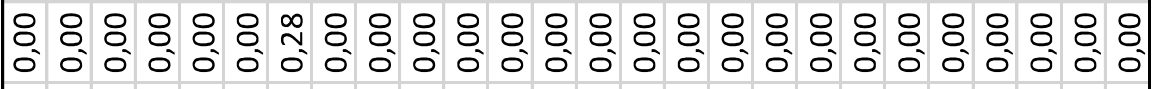 \\
\hline -dds מכ!OपдuDכ $\forall$ & 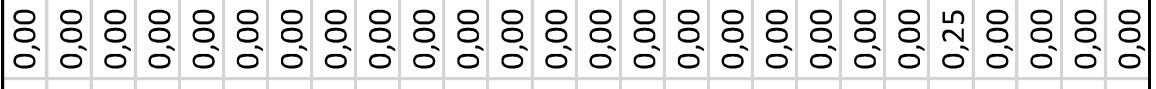 \\
\hline expsome ep on & 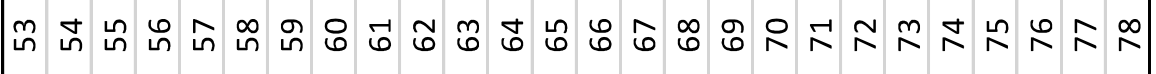 \\
\hline
\end{tabular}




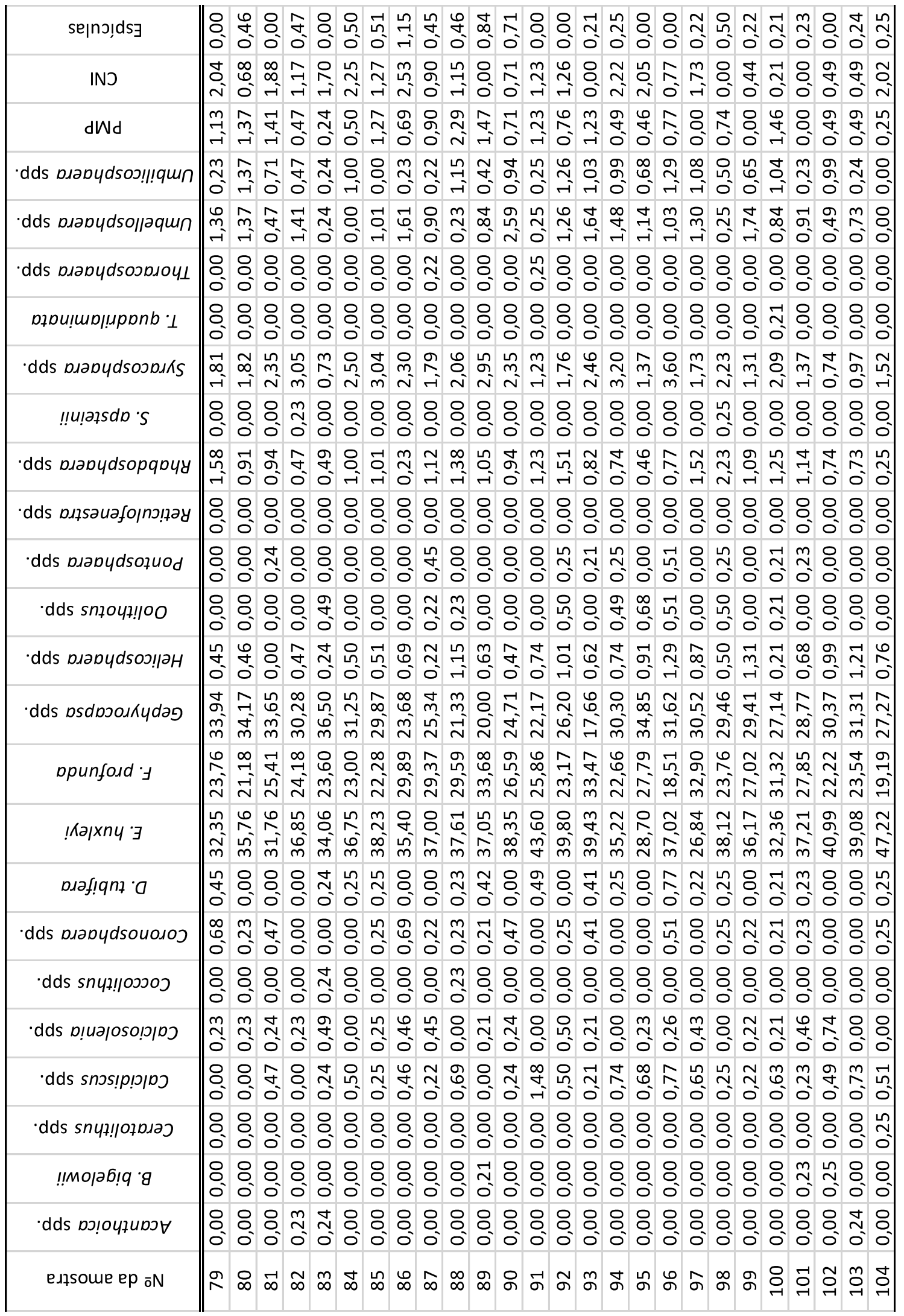




\begin{tabular}{|c|c|}
\hline !nग!ds & 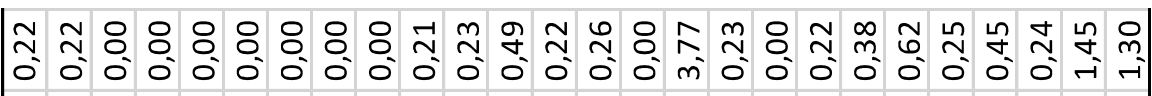 \\
\hline INJ & 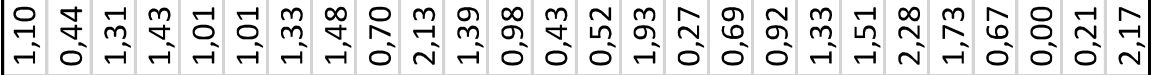 \\
\hline dWd & 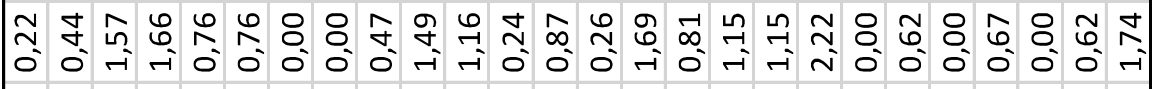 \\
\hline dds pגabydsoכ!!!qun & 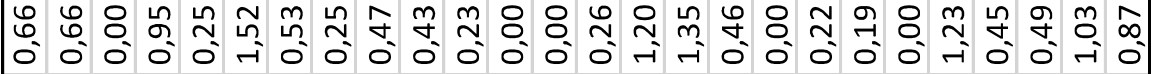 \\
\hline dds pגəDydso||วqun & 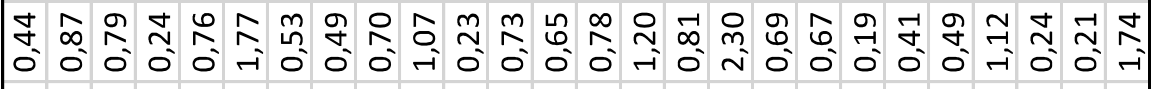 \\
\hline dds DגabydsoวDגOYI & 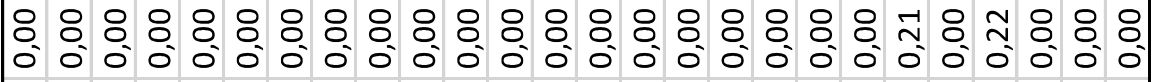 \\
\hline 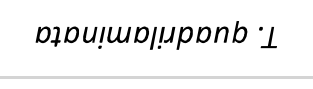 & \& \\
\hline 'dds סגәрчdsOכDגאS & 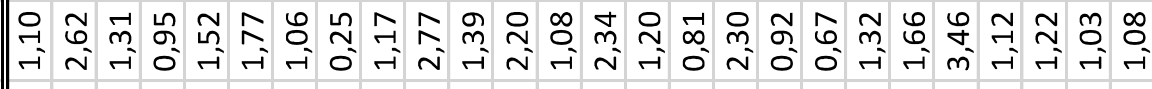 \\
\hline 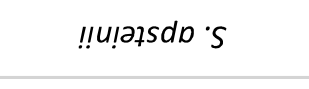 & : 8 : \\
\hline dds bxabydsopqbyy & 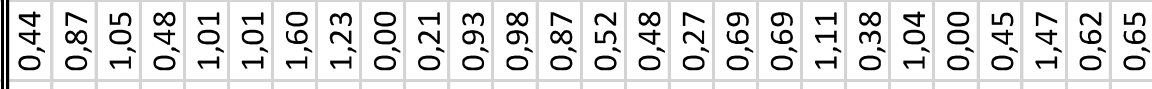 \\
\hline 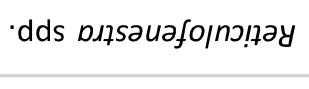 & 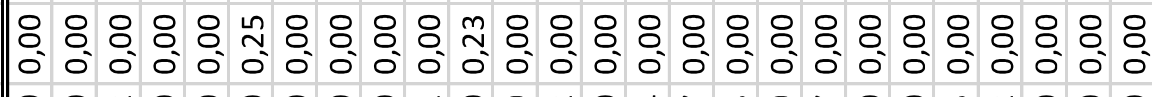 \\
\hline 'dds pגabydsozuod & 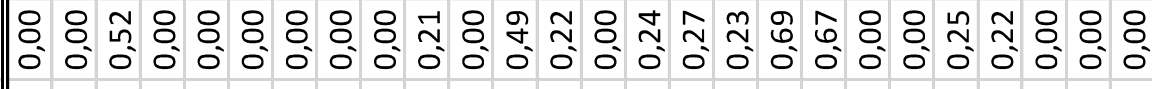 \\
\hline dds sn704?!100 & 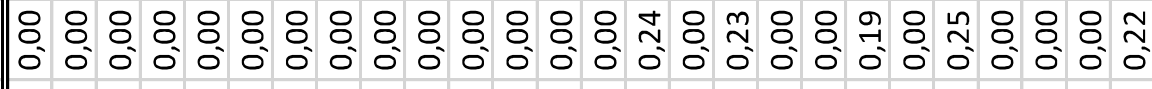 \\
\hline ·dds pגapydsoJ!|aH & 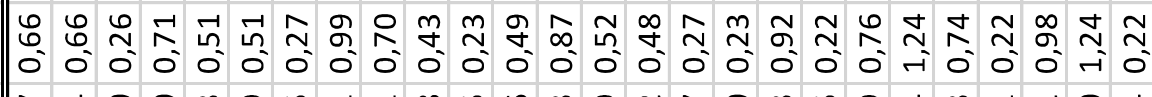 \\
\hline 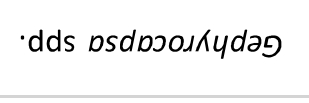 & 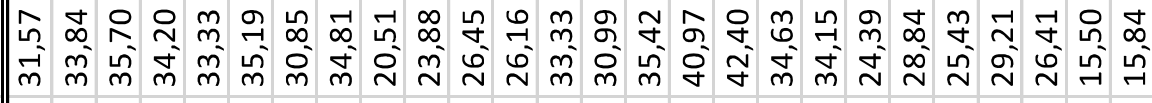 \\
\hline opunford' $y$ & 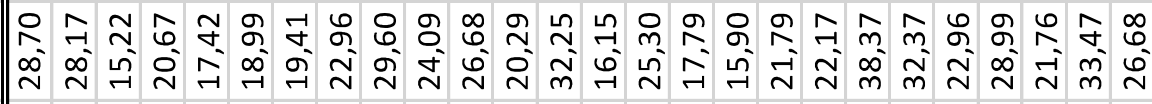 \\
\hline 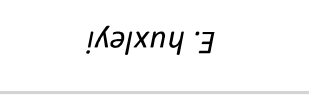 & 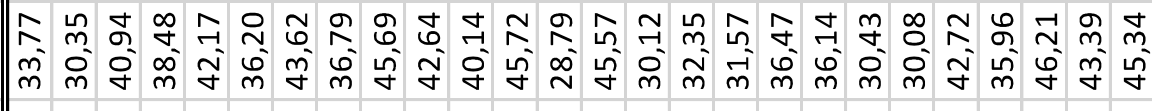 \\
\hline ם'व & 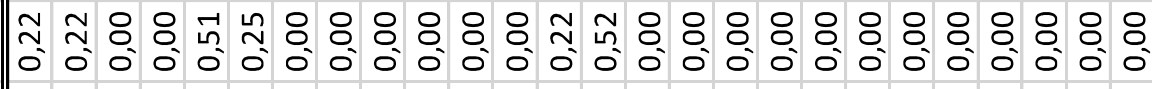 \\
\hline 'dds pגapydsouosoJ & 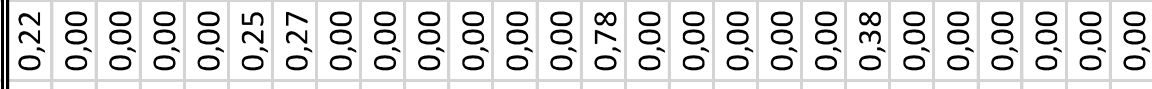 \\
\hline ·dds sny?!!0כ00J & 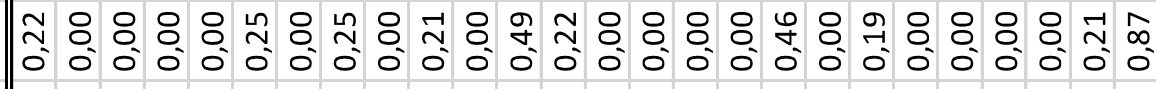 \\
\hline 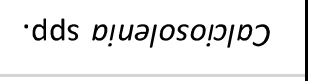 & 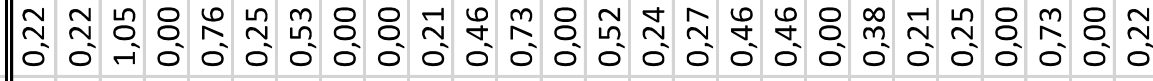 \\
\hline 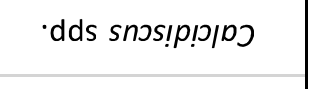 & 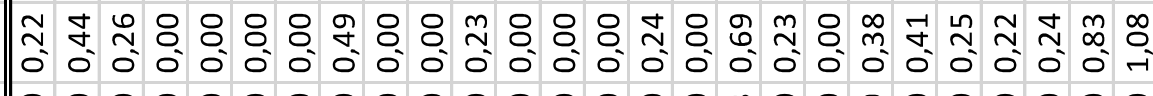 \\
\hline ·dds sn47!!07DגaJ & 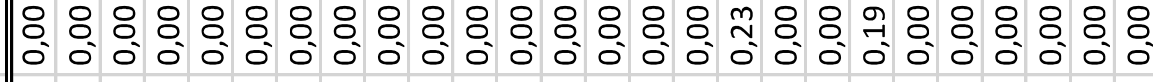 \\
\hline !!мораб!q 'в & 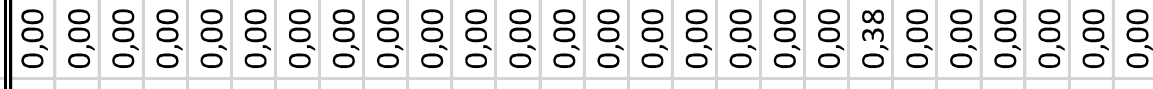 \\
\hline 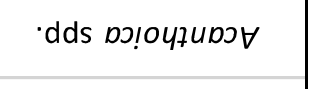 & 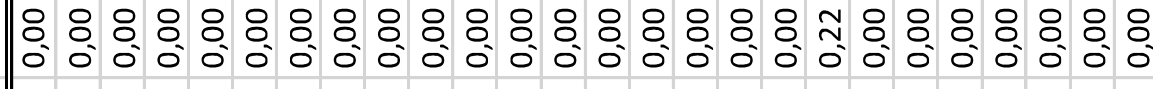 \\
\hline extsome ep o oN & 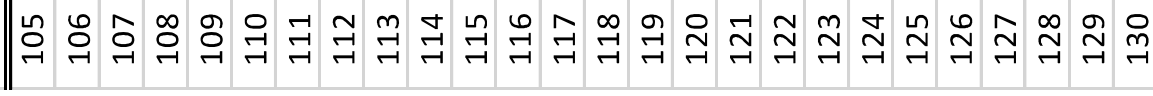 \\
\hline
\end{tabular}

